\title{
Asthma in children : towards improved monitoring strategies
}

Citation for published version (APA):

van Vliet, D. (2015). Asthma in children : towards improved monitoring strategies. [Doctoral Thesis, Maastricht University]. Maastricht University. https://doi.org/10.26481/dis.20150708dv

Document status and date:

Published: 01/01/2015

DOI:

$10.26481 /$ dis.20150708dv

Document Version:

Publisher's PDF, also known as Version of record

\section{Please check the document version of this publication:}

- A submitted manuscript is the version of the article upon submission and before peer-review. There can be important differences between the submitted version and the official published version of record.

People interested in the research are advised to contact the author for the final version of the publication, or visit the DOI to the publisher's website.

- The final author version and the galley proof are versions of the publication after peer review.

- The final published version features the final layout of the paper including the volume, issue and page numbers.

Link to publication

\footnotetext{
General rights rights.

- You may freely distribute the URL identifying the publication in the public portal. please follow below link for the End User Agreement:

www.umlib.nl/taverne-license

Take down policy

If you believe that this document breaches copyright please contact us at:

repository@maastrichtuniversity.nl

providing details and we will investigate your claim.
}

Copyright and moral rights for the publications made accessible in the public portal are retained by the authors and/or other copyright owners and it is a condition of accessing publications that users recognise and abide by the legal requirements associated with these

- Users may download and print one copy of any publication from the public portal for the purpose of private study or research.

- You may not further distribute the material or use it for any profit-making activity or commercial gain

If the publication is distributed under the terms of Article $25 \mathrm{fa}$ of the Dutch Copyright Act, indicated by the "Taverne" license above, 


\section{Asthma in Children}

Towards Improved Monitoring Strategies 
(c) Copyright D. van Vliet, Maastricht 2015

Cover design

Brainstorm cover

Layout

Printed by

ISBN/EAN
George Nietsch

Blue is the color of the sky: associated with health, stability, breath of fresh air.

Silhouette of children: age range of study population 6 to 18 years, children without activity limitations due to asthma.

Compass: an instrument that is used for navigation and orientation. The studies that are presented in this theses help to determine the direction of future research in children with asthma.

Dillys van Vliet

Gildeprint

978-94-6233-006-1

The research presented in this thesis was conducted at the School for Public Health and Primary Care: CAPHRI, Department Paediatrics, of Maastricht University.

This PhD research was funded by the Netherlands Organisation for Health Research and Development (ZonMW) and the board of the Maastricht University Medical Centre (MUMC ${ }^{+}$. Financial support for printing of this thesis was kindly provided by: Stichting ter bevordering Kindergeneeskunde, Stichting Astma Bestrijding, Longfonds, Maastricht Instruments BV/ IDEE, and Clinical Trial Center Maastricht (CTCM). 


\section{Asthma in Children \\ Towards Improved Monitoring Strategies}

\section{PROEFSCHRIFT}

ter verkrijging van de graad van doctor aan de Universiteit Maastricht,

op gezag van de Rector Magnificus, prof. dr. L.L.G. Soete

volgens het besluit van het College van Decanen,

in het openbaar te verdedigen

op woensdag 8 juli 2015 om 12:00 uur

door

Dillys van Vliet 


\section{Promotores}

prof. dr. E. Dompeling

prof. dr. J.W.M. Muris

\section{Copromotor}

dr. Q. Jöbsis

\section{Beoordelingscommissie}

prof. dr. G. Wesseling (voorzitter)

prof. dr. P.J.E. Bindels (Universiteit van Rotterdam)

dr. P.J.F.M. Merkus (Universiteit van Nijmegen)

prof. dr. C.P. van Schayck

prof. dr. L.J.I. Zimmermann 


\section{Contents}

$\begin{array}{lll}\text { Chapter } 1 \quad \text { General introduction } & 7\end{array}$

Chapter $2 \quad$ Electronic monitoring of symptoms and lung function to 21 assess asthma control in children

Annals of Allergy, Asthma \& Immunology 2014; 113: 257-62

Chapter $3 \quad$ Longitudinal relationships between asthma-specific QoL and

asthma control in children

Submitted for publication

Chapter $4 \quad$ Exhaled inflammatory markers discriminate between children with persistently controlled and uncontrolled asthma

Submitted for publication

Chapter $5 \quad$ Can exhaled volatile organic compounds predict asthma

exacerbations in children?

Submitted for publication

Chapter 6 Prediction of asthma exacerbations in children by innovative

exhaled inflammatory markers: results of a longitudinal study

PloS One 2015; 10(3): e0119434

Chapter $7 \quad$ General discussion

Appendix A Summary

Samenvatting

Valorisation

Appendix B Curriculum Vitae

List of publications

Dankwoord 



\section{Chapter 1}

General introduction

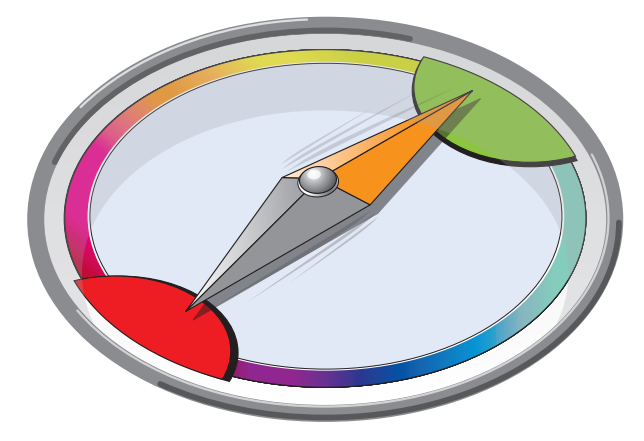


Asthma is the most common chronic disease in children worldwide. ${ }^{1}$ There is a wide variation in asthma prevalence globally. ${ }^{2}$ In the Netherlands there has been a five-fold increase in incidence of childhood asthma from 1984 to 1997, followed by a decreasing trend from 1998 to 2006 , with a stabilisation in the past few years..$^{3-5}$ In 8 to 11 years old children the prevalence of wheezing in 2001,2005 and 2010 was $7.2 \%, 8.2 \%$ and $6.0 \%$ respectively.

\section{Aetiology and pathogenesis}

Asthma is characterised by chronic airway inflammation. ${ }^{7-9}$ The exact causes of asthma remain uncertain. It is generally assumed that genetic factors, environmental influences and their interactions are involved in the pathogenesis. ${ }^{9}$ Genetic factors (history of asthma in the family, atopy) and environmental factors (viruses, allergens, occupational exposures) are associated with the inception and evolution of asthma. ${ }^{9}$

Airway inflammation in patients with asthma leads to (reversible) airway obstruction, bronchial hyperresponsiveness to (non-)specific triggers and asthma symptoms. ${ }^{7,8}$ These asthma characteristics are traditionally used to diagnose and to monitor asthma control. ${ }^{8,10}$ Different studies identified several asthma phenotypes. Phenotypes can be discriminated on the basis of different variables: 1) symptoms, 2) physiological measurements, 3) triggers, 4) response to treatment, 5) markers of airway inflammation, and 6) genetic polymorphisms. ${ }^{11,12}$

The most prevalent phenotype of asthma in children is atopic asthma. ${ }^{8}$ Atopic asthma is characterised by an environmental antigen-triggered IgE response. ${ }^{13}$ Many different cell types are important in atopic asthma: the eosinophil, the mast cell, the T-lymfocyte and the T-helper (Th) cell. ${ }^{14}$

After induction of allergic airway inflammation, each of these cells release different inflammatory mediators such as cytokines and chemokines. This causes an inflammatory cascade which results in an early phase reaction and a late phase reaction. ${ }^{15}$ First the allergen is captured by dendritic cells in the airways, after which it migrates to the lymph nodes, where the antigen is presented to Th-cells. ${ }^{15}$ This induces switching of Th-cells to the Th2 pathway. ${ }^{14}$ Th2 cells release interleukines IL-13 and IL-4, which stimulate B cells to produce IgE and finally stimulate mast cells. ${ }^{13,16}$ Mast cells produce histamine, which results in smooth muscle contraction in the early phase reaction of the inflammation process. ${ }^{15}$ Once $\operatorname{lgE}$ is present in tissue, eosinophils and neutrophils are stimulated. ${ }^{17}$ Eosinophils have a key role in the late phase reaction, causing bronchial epithelial lesions, bronchial hyperresponsiveness, airway obstruction, and airway remodelling. ${ }^{14,17}$ An important eosinophilic mediator is IL-5, but also IL-1 and TNF- $\alpha$ are examples of eosinophilic mediators. ${ }^{15}$ Neutrophils produce different mediators (for example IL-6 and TNF- $\alpha$ ), resulting in airway narrowing and increased inflammation. ${ }^{15}$ In addition, in the late phase reaction, nitric oxide synthase (NOS) causes production of nitric oxide (NO) 
in airway epithelial and endothelial cells. ${ }^{14} \mathrm{NO}$ is involved in regulation of lung function and airway circulation. ${ }^{18}$

\section{Current asthma monitoring strategy}

Currently international evidence based guidelines advise titration of treatment on the basis of the level of asthma control. ${ }^{8,10,19,20}$ Asthma control reflects the level of disease stability. Optimal asthma control is the goal of asthma management and treatment. ${ }^{8,10,19}$ Asthma symptoms, use of rescue medication, lung function, and occurrence of exacerbations determine the level of asthma control. ${ }^{8}$ Asthma symptoms that are taken into account are: coughing, dyspnoea, wheezing and chest tightness during the day or night (nocturnal symptoms), and limitations of activities due to respiratory symptoms. ${ }^{8}$

Several validated questionnaires to assess the level of asthma control in children and adults are available. ${ }^{21-24}$ The use of questionnaires provides a reproducible and an objective measure of asthma control over time. There are validated asthma control questionnaires available for use in children, such as the Asthma Control Questionnaire (ACQ), the Asthma Control Test (ACT) or Childhood Asthma Control Test (C-ACT), and the Asthma Therapy Assessment Questionnaire (ATAQ). ${ }^{24-26}$ The time frame for recall of asthma symptoms differs between questionnaires, for ACQ this is 1 week, whereas $A C T$ and ATAQ reflect a 4-week period. In addition, only the $A C Q$ includes lung function (forced expiratory volume in 1 second $\left(F E V_{1}\right)$ ) in the total asthma control score. ${ }^{25}$

\section{Asthma control not optimal}

Despite proper treatment and evidence based guidelines, asthma is not optimally controlled in many children worldwide. ${ }^{23,27,28}$ Studies showed that also in The Netherlands asthma control fell short of the management goals of asthma guidelines. ${ }^{29,30}$ In the Asthma Insight and Reality in Europe (AIRE) study, only $6 \%$ of children met all criteria for optimal asthma control. ${ }^{29}$ Besides, a study in asthmatic children at an outpatient clinic showed that patients' perception of asthma control was more optimistic than their actual asthma level of control. ${ }^{30}$

Asthma control can be improved by preventing exposure to (non-)specific triggers for asthma inflammation, and by optimisation of pharmacological asthma therapy based on asthma monitoring tools. ${ }^{8}$ It is important to develop more tools to monitor asthma, with the goal to provide a more realistic and complete picture of the health status of an asthmatic child. In this thesis, there is a focus on innovative monitoring strategies. As already mentioned, the room for improvement of monitoring of asthma in children is quite substantial. Figure 1.1 illustrates the process from airway inflammation to the assessment of asthma control by methods that are currently used in clinical care. Possible hypotheses explaining suboptimal monitoring of paediatric asthma are: 
1. Retrospective evaluation of asthma control during clinical visits is susceptible to recall bias and may overestimate the levels of control during a certain time period..$^{31}$ This could result in undertreatment of asthma, and finally in more exacerbations. Daily prospective monitoring of asthma control levels decreases the delay between occurrence of symptoms and assessment of asthma control during scheduled clinical visits, and may decrease the chance of recall bias (figure 1.1).

2. Optimal asthma-specific quality of life (QoL) is an important goal for children with asthma, as mentioned in several (inter)national guidelines. ${ }^{8,10,19}$ Asthma-specific QoL may affect (the evaluation of) asthma control in children. However, in daily clinical practice, QoL may not be measured at all, or not in a validated way. Moreover, no recommendations on how to improve asthma-specific QoL are given in (inter)national guidelines. ${ }^{8,10,19}$ Probably, monitoring QoL in addition to asthma control gives a more complete view of the health status of a child with asthma (figure 1.1).

3. Currently, monitoring of asthma is mostly based on measuring the consequences of airway inflammation (symptoms and lung function), instead of direct assessment of airway inflammation itself. Asthma control is assessed by using questionnaires consisting of a combination of symptoms and lung function. However, it is known that children may perceive their asthma control more optimistically than their actual control as assessed by a validated questionnaire, which may lead to overestimation of asthma control levels. ${ }^{30}$ Overestimation of asthma control can result in undertreatment of asthmatic children, which may be prevented by measuring airway inflammation. Furthermore, a deterioration in symptoms and lung function may be the result of an earlier started increase in airway inflammation. Direct monitoring of airway inflammation may help to objectify airway inflammation in asthma and may help to detect airway inflammation before onset of symptoms (figure 1.1).

Some options for improvement of monitoring with the intended purpose to improve asthma control, will be discussed in the next paragraphs. 
PROCESSES

EVALUATION PARAMETER

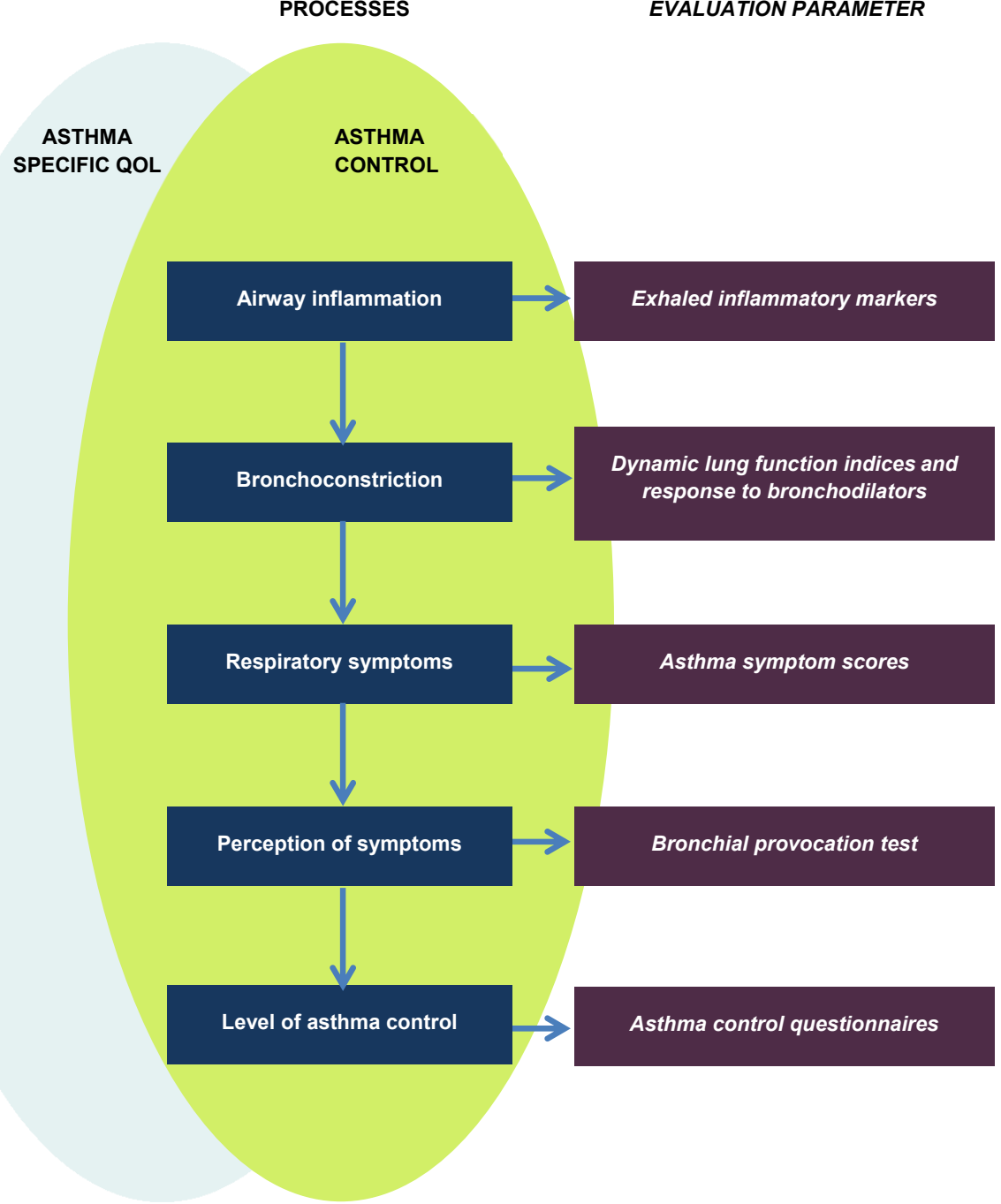

Figure 1.1 Relationship between QoL, asthma control, and processes underlying disease control, as assessed by various methods

\section{Innovative monitoring strategies in childhood asthma}

\section{Electronic monitoring of asthma control at home}

One of the strategies to optimize asthma monitoring and to improve asthma control may be monitoring of asthma control at home. A benefit of home monitoring compared to retrospective monitoring of asthma control during clinical visits, is the decrease of recall bias due to 
prospective sampling of data by home monitoring. ${ }^{32}$

At home, symptoms and lung function parameters can be monitored prospectively and more frequently, which may provide a more complete picture of the real level and pattern of asthma control in patients. Monitoring of symptoms can be performed by using paper or electronic diaries. To prevent retrospective completion of paper symptom diaries, symptom scores can be collected electronically. ${ }^{32}$ Besides symptoms, it is preferable to also collect lung function data, because in children with poor perception of airway obstruction, deterioration of lung function can be missed when using symptom diaries only. ${ }^{30}$ Handheld electronic home monitors that collect both symptoms and lung function parameters are available. If the compliance to home assessments is good, the recall bias that could be present when using retrospective asthma control questionnaires, may be avoided.

\section{Monitoring of asthma-specific quality of life}

Another parameter to monitor asthma is asthma-specific QoL. In guidelines, optimising asthma-specific QOL is one of the goals of management and treatment, but surprisingly little recommendations are given how to reach this. ${ }^{8,20}$ The role of asthma-specific QoL in clinical care is nearly described as well. ${ }^{8,20}$ In guidelines, medication titration takes place based only on asthma control. ${ }^{8,20}$

Asthma-specific QoL refers to the impact that the disease has on the child's QoL. ${ }^{33,34}$ The hypothesis is that monitoring of QoL provides a more complete picture of the overall health of patients and helps to improve treatment and asthma control in these children. There are different asthma-specific QoL instruments available in children. Wilson et al. have reviewed a range of paediatric QoL instruments for use in asthma. ${ }^{33}$ Six asthma-specific QoL questionnaires for children were reviewed. All these questionnaires measured predominantly the health status and functional status in subdomains. ${ }^{33}$ There is less focus on the impact of health and functional status on QoL in the emotion domain. ${ }^{33}$ Therefore, not only the total score of such a questionnaire, but also the domain scores need to be interpreted.

\section{Direct monitoring of airway inflammation}

There are invasive and non-invasive techniques available to measure airway inflammation. Non-invasive techniques are preferred to be used during regular clinical measurements, especially in children.

\section{Induced sputum}

Sputum induction is a technique to assess airway inflammation in children. ${ }^{35-37}$ It consists of a semi-invasive induction procedure by inhalation of an aerosol of hypertonic saline, and allows examination of the cellular and soluble content. ${ }^{36,37}$ The reported success rate in children depends on disease severity and age, and varies between 68 to $100 \% .{ }^{36}$ Not only minor side effects of discomfort and coughing may occur after sputum induction, but also serious airway 
obstruction has been reported, even after inhalation of $\beta_{2}$-agonist before the procedure. ${ }^{37,38}$ For this technique high requirements were reported for technical support, expertise to process, stain, and interpretation of induced sputum samples. ${ }^{37}$

\section{FeNO}

Fractional exhaled Nitric Oxide (FeNO) is a thoroughly studied marker of airway inflammation. ${ }^{39}$ As mentioned before, iNOS synthesize NO from L-arginine. ${ }^{18}$ FeNO is more specific for atopic asthma. ${ }^{40} \mathrm{FeNO}$ is a non-invasive biomarker, with a standardised methodology that is described in proper guidelines. ${ }^{41}$

However, the effectiveness of FeNO assessment in monitoring of asthma is disputable. A Cochrane meta-analysis, based on 6 studies in adults and children, showed that tailoring medication based on FeNO was not more effective than usual care. ${ }^{42}$ This analysis showed that there was no significant reduction of frequency of asthma exacerbations or decrease in severity of asthma symptoms using FeNO testing..$^{42}$

In line with this meta-analysis, De Jongste et al. showed that medication titration based on daily FeNO measurements in asthmatic children was not effective compared to usual care..$^{43}$ In contrast to earlier reported findings, Pletsky et al. showed recently that medication titration based on FeNO might have a positive effect on asthma outcome. ${ }^{39}$ In this randomized controlled trial, researchers found that significantly fewer children in the FeNO group had $\geq 1$ exacerbation(s) compared to the control group, however no statistically significant difference in exacerbation rate was detected between the groups. ${ }^{39}$ It may be that specific subgroups of patients may benefit from monitoring of FeNO, but so far the nature is of these subgroups is unclear.

\section{Markers in Exhaled breath condensate}

Another non-invasive strategy to measure airway inflammation is analysis of inflammatory markers in exhaled breath condensate (EBC). EBC is collected by cooling exhaled air in a condenser system. A turbulent airflow during respiration hypothetically leads to release of small aerosols of the epithelial lining fluid, so called respiratory droplets. ${ }^{44}$ It is hypothesized that these inflammation markers are derived from respiratory droplets of the epithelial lining fluid. ${ }^{45}$

Collection of EBC is suitable for children and infants. Several condenser systems has been developed of which the Ecoscreen is most often used. Another efficient exhaled breath condenser was developed, in which exhaled breath condensates in a double-jacketed glass tube (patent 07102586, Maastricht University Medical Centre). ${ }^{46-49}$

The role of inflammatory markers in EBC for the diagnosis and monitoring of asthma in children is less extensively studied than the role of FeNO. Recently, Thomas et al. showed in a review that inflammatory markers in EBC may be useful in diagnosing and evaluating airway inflammation in paediatric asthma. ${ }^{50}$ 


\section{Volatile organic compounds in exhaled breath}

Volatile organic compounds (VOCs) in exhaled breath originate from different processes inside the body which can be related to disease, metabolism or a pathogen. ${ }^{51,52}$ VOCs that are formed during airway inflammation can be excreted directly into the exhaled breath. During airway inflammation, the oxidative stress that takes place causes production of Reactive Oxygen Species (ROS). ${ }^{53,54}$ These ROS react with lipids, proteins and different nucleic acids. The stable breakdown products of this process, such as hydrocarbons, can be detected in exhaled breath. ${ }^{55}$

In exhaled breath, thousands of VOCs are present which makes it a challenge to capture the specific VOCs related to airway inflammation in asthma. ${ }^{55,56}$ There are different methods to analyse VOCs in exhaled breath. Of these methods, gas chromatography coupled to mass spectrometry (GC-MS) is assumed to be the gold standard in reviews. ${ }^{55-57}$ Using this technique the composition and concentrations of all VOCs in a breath sample can be determined. ${ }^{58}$ Other commonly used methods are: ion mobility spectrometry, proton transfer-reaction-MS and electronic noses. ${ }^{56,59}$ These techniques allow breath analysis in real time. The electronic nose has a different approach from GC-MS, as it measures only a pattern of VOCs without identification of the individual components. ${ }^{56}$

Van de Kant et al. demonstrated in their review that patients with asthma can be distinguished from healthy controls by using profiles of exhaled VOCs, whereas some VOCs may be related to asthma severity. ${ }^{57}$

\section{Objectives of this thesis}

Main objectives of this thesis are:

1. To compare 2 strategies to assess asthma control, namely prospective home monitoring of symptoms and FEV 1 with retrospective assessment by means of the ACQ and lung function during a clinical visit.

2. To determine the longitudinal association between asthma control, clinical characteristics and asthma-specific QoL in children.

3. To explore the association between asthma control and exhaled inflammatory markers (VOCs, FeNO and biomarkers in EBC), and to assess the potential of these exhaled inflammation markers to discriminate between subgroups of children with persistently uncontrolled asthma or persistently controlled asthma.

4. To study the power to predict asthma exacerbations in children by various non-invasive techniques (VOCs, FeNO and biomarkers in EBC). 


\section{Outline of this thesis}

In chapter 2 we compared 2 methods to assess asthma control: a) prospective home monitoring, based on daily assessment of $\mathrm{FEV}_{1}$ and electronic symptom score; b) Asthma Control Questionnaire with retrospective assessment of symptoms and $\mathrm{FEV}_{1}$ during a regular hospital visit. In chapter 3 the longitudinal association between asthma control and disease specific QoL is determined. In addition, the longitudinal association between clinical asthma characteristics (atopy, level of lung function, use of inhalation medication, exacerbation rate) and asthma-specific QoL was assessed. In chapter 4 the longitudinal association between markers in exhaled breath (VOCs, FeNO and biomarkers in EBC) and asthma control is explored. In chapter 5 and 6 the ability of markers in exhaled breath (VOCs, FeNO and biomarkers in EBC) to predict an asthma exacerbation is analysed. Finally, in chapter 7 the main findings of this thesis are discussed and recommendations for future studies are given. 


\section{References}

1. Fact sheet $N^{\circ} 307$. World Health Organization Nov 2013 [cited; Available from: http://www.who.int/ mediacentre/factsheets/fs307/en/index.html

2. Worldwide variation in prevalence of symptoms of asthma, allergic rhinoconjunctivitis, and atopic eczema: ISAAC. The International Study of Asthma and Allergies in Childhood (ISAAC) Steering Committee. Lancet 1998: 351(9111): 1225-1232.

3. Mommers M, Gielkens-Sijstermans C, Swaen GM, van Schayck CP. Trends in the prevalence of respiratory symptoms and treatment in Dutch children over a 12 year period: results of the fourth consecutive survey. Thorax 2005: 60(2): 97-99.

4. van Schayck CP, Smit HA. The prevalence of asthma in children: a reversing trend. The European respiratory journal 2005: 26(4): 647-650.

5. Wijga AH, Smit HA, Poos MJJC. Hoe vaak komt astma voor, hoeveel mensen sterven eraan en neemt dit toe of af? [cited; 4.17:[Available from: www.nationaalkompas.nl/gezondheid-en-ziekte/ ziekte-en-aandoeningen/ademhalingswegen/astma/omvang

6. de Korte-de Boer D, Mommers M, Gielkens-Sijstermans C, Creemers H, Mujakovic S, Feron F. Trends in prevalence of wheeze, eczema, and hay fever in Dutch schoolchildren between 1989 and 2010. Abstract EAACl 2014: Kopenhagen.

7. Martinez FD, Vercelli D. Asthma. Lancet 2013: 382(9901): 1360-1372.

8. Global strategy for asthma management and prevention. Global Initiative for Asthma (GINA) 2012 [cited; Available from: ginasthma.org/local/uploads/files/GINA_Report_March13.pdf

9. Koppelman GH, Los H, Postma DS. Genetic and environment in asthma: the answer of twin studies. The European respiratory journal 1999: 13(1): 2-4.

10. de Jongste JC VE. Astma bij kinderen; herziene richtlijnen van de sectie kinderlongziekten van de NVK [Asthma in children; revised guidelines of the paediatric department of the Dutch Paediatric Society], Amsterdam, 2007.

11. Anderson GP. Endotyping asthma: new insights into key pathogenic mechanisms in a complex, heterogeneous disease. Lancet 2008: 372(9643): 1107-1119.

12. Henderson J, Granell R, Sterne J. The search for new asthma phenotypes. Archives of disease in childhood 2009: 94(5): 333-336.

13. Busse WW, Lemanske RF, Jr. Asthma. The New England journal of medicine 2001: 344(5): 350362.

14. Dodig S, Richter D, Zrinski-Topic R. Inflammatory markers in childhood asthma. Clin Chem Lab Med 2011: 49(4): 587-599.

15. Bloemen K, Verstraelen S, van den Heuvel R, Witters H, Nelissen I, Schoeters G. The allergic cascade: review of the most important molecules in the asthmatic lung. Immunol Lett 2007: 113(1): 6-18.

16. Wills-Karp M, Luyimbazi J, Xu X, Schofield B, Neben TY, Karp CL, Donaldson DD. Interleukin-13: central mediator of allergic asthma. Science 1998: 282(5397): 2258-2261.

17. Barnes PJ, Chung KF, Page CP. Inflammatory mediators of asthma: an update. Pharmacological reviews 1998: 50(4): 515-596.

18. Barnes PJ, Dweik RA, Gelb AF, Gibson PG, George SC, Grasemann H, Pavord ID, Ratjen F, Silkoff PE, Taylor DR, Zamel N. Exhaled nitric oxide in pulmonary diseases: a comprehensive review. Chest 2010: 138(3): 682-692.

19. BTS. BTS/SIGN Guideline on the management of asthma: British Thoracic Society. 2012.

20. Nederland LA. Zorgstandaard Astma Kinderen \& Jongeren. 2013.

21. Juniper EF, Gruffydd-Jones K, Ward S, Svensson K. Asthma Control Questionnaire in children: validation, measurement properties, interpretation. The European respiratory journal 2010: 36(6): 1410-1416.

22. Nguyen JM, Holbrook JT, Wei CY, Gerald LB, Teague WG, Wise RA, American Lung Association Asthma Clinical Research C. Validation and psychometric properties of the Asthma Control Questionnaire among children. The Journal of allergy and clinical immunology 2014: 133(1): 91-97 e91-96.

23. Voorend-van Bergen S, Vaessen-Verberne AA, Landstra AM, Brackel HJ, van den Berg NJ, Caudri 
D, de Jongste JC, Merkus PJ, Pijnenburg MW. Monitoring childhood asthma: web-based diaries and the asthma control test. The Journal of allergy and clinical immunology 2014: 133(6): 1599-1605 e1592.

24. Skinner EA, Diette GB, Algatt-Bergstrom PJ, Nguyen TT, Clark RD, Markson LE, Wu AW. The Asthma Therapy Assessment Questionnaire (ATAQ) for children and adolescents. Disease management : DM 2004: 7(4): 305-313.

25. Juniper EF, O'Byrne PM, Guyatt GH, Ferrie PJ, King DR. Development and validation of a questionnaire to measure asthma control. The European respiratory journal 1999: 14(4): 902-907.

26. Liu AH, Zeiger R, Sorkness C, Mahr T, Ostrom N, Burgess S, Rosenzweig JC, Manjunath R. Development and cross-sectional validation of the Childhood Asthma Control Test. The Journal of allergy and clinical immunology 2007: 119(4): 817-825.

27. Gustafsson PM, Watson L, Davis KJ, Rabe KF. Poor asthma control in children: evidence from epidemiological surveys and implications for clinical practice. Int J Clin Pract 2006: 60(3): 321-334.

28. Rabe KF, Adachi M, Lai CK, Soriano JB, Vermeire PA, Weiss KB, Weiss ST. Worldwide severity and control of asthma in children and adults: the global asthma insights and reality surveys. The Journal of allergy and clinical immunology 2004: 114(1): 40-47.

29. Rabe KF, Vermeire PA, Soriano JB, Maier WC. Clinical management of asthma in 1999: the Asthma Insights and Reality in Europe (AIRE) study. The European respiratory journal 2000: 16(5): 802-807.

30. Hammer SC, Robroeks CM, van Rij C, Heynens J, Droog R, Jobsis Q, Hendriks HJ, Dompeling E. Actual asthma control in a paediatric outpatient clinic population: do patients perceive their actual level of control? Pediatric allergy and immunology : official publication of the European Society of Pediatric Allergy and Immunology 2008: 19(7): 626-633.

31. van den Brink M, Bandell-Hoekstra EN, Abu-Saad HH. The occurrence of recall bias in pediatric headache: a comparison of questionnaire and diary data. Headache 2001: 41(1): 11-20.

32. Okupa AY, Sorkness CA, Mauger DT, Jackson DJ, Lemanske RF, Jr. Daily diaries vs retrospective questionnaires to assess asthma control and therapeutic responses in asthma clinical trials: is participant burden worth the effort? Chest 2013: 143(4): 993-999.

33. Wilson SR, Rand CS, Cabana MD, Foggs MB, Halterman JS, Olson L, Vollmer WM, Wright RJ, Taggart V. Asthma outcomes: quality of life. The Journal of allergy and clinical immunology 2012: 129(3 Suppl): S88-123.

34. Annett RD. Assessment of health status and quality of life outcomes for children with asthma. The Journal of allergy and clinical immunology 2001: 107(5 Suppl): S473-481.

35. ten Brinke A, de Lange C, Zwinderman AH, Rabe KF, Sterk PJ, Bel EH. Sputum induction in severe asthma by a standardized protocol: predictors of excessive bronchoconstriction. American journal of respiratory and critical care medicine 2001: 164(5): 749-753.

36. Gibson PG, Grootendor DC, Henry RL, Pin I, Rytila PH, Wark P, Wilson N, Djukanovic R. Sputum induction in children. The European respiratory journal Supplement 2002: 37: 44s-46s.

37. Paggiaro PL, Chanez P, Holz O, Ind PW, Djukanovic R, Maestrelli P, Sterk PJ. Sputum induction. The European respiratory journal Supplement 2002: 37: 3s-8s.

38. Covar RA, Spahn JD, Martin RJ, Silkoff PE, Sundstrom DA, Murphy J, Szefler SJ. Safety and application of induced sputum analysis in childhood asthma. The Journal of allergy and clinical immunology 2004: 114(3): 575-582.

39. Petsky HL, Li AM, Au CT, Kynaston JA, Turner C, Chang AB. Management based on exhaled nitric oxide levels adjusted for atopy reduces asthma exacerbations in children: A dual centre randomized controlled trial. Pediatric pulmonology 2014: [Epub ahead of print].

40. Franklin PJ, Turner SW, Le Souef PN, Stick SM. Exhaled nitric oxide and asthma: complex interactions between atopy, airway responsiveness, and symptoms in a community population of children. Thorax 2003: 58(12): 1048-1052.

41. American Thoracic S, European Respiratory S. ATS/ERS recommendations for standardized procedures for the online and offline measurement of exhaled lower respiratory nitric oxide and nasal nitric oxide, 2005. American journal of respiratory and critical care medicine 2005: 171(8): 912-930.

42. Petsky HL, Cates CJ, Lasserson TJ, Li AM, Turner C, Kynaston JA, Chang AB. A systematic review and meta-analysis: tailoring asthma treatment on eosinophilic markers (exhaled nitric oxide or sputum eosinophils). Thorax 2012: 67(3): 199-208. 
43. de Jongste JC, Carraro S, Hop WC, Group CS, Baraldi E. Daily telemonitoring of exhaled nitric oxide and symptoms in the treatment of childhood asthma. American journal of respiratory and critical care medicine 2009: 179(2): 93-97.

44. Effros RM, Hoagland KW, Bosbous M, Castillo D, Foss B, Dunning M, Gare M, Lin W, Sun F. Dilution of respiratory solutes in exhaled condensates. American journal of respiratory and critical care medicine 2002: 165(5): 663-669.

45. Hunt J. Exhaled breath condensate: an evolving tool for noninvasive evaluation of lung disease. The Journal of allergy and clinical immunology 2002: 110(1): 28-34.

46. Robroeks CM, Jobsis Q, Damoiseaux JG, Heijmans PH, Rosias PP, Hendriks HJ, Dompeling E. Cytokines in exhaled breath condensate of children with asthma and cystic fibrosis. Annals of allergy, asthma \& immunology : official publication of the American College of Allergy, Asthma, \& Immunology 2006: 96(2): 349-355.

47. Robroeks CM, Rijkers GT, Jobsis Q, Hendriks HJ, Damoiseaux JG, Zimmermann LJ, van Schayck OP, Dompeling E. Increased cytokines, chemokines and soluble adhesion molecules in exhaled breath condensate of asthmatic children. Clinical and experimental allergy : journal of the British Society for Allergy and Clinical Immunology 2010: 40(1): 77-84.

48. Rosias PP, Robroeks CM, Kester A, den Hartog GJ, Wodzig WK, Rijkers GT, Zimmermann LJ, van Schayck CP, Jobsis Q, Dompeling E. Biomarker reproducibility in exhaled breath condensate collected with different condensers. The European respiratory journal 2008: 31(5): 934-942.

49. Rosias PP, Robroeks CM, van de Kant KD, Rijkers GT, Zimmermann LJ, van Schayck CP, Heynens JW, Jobsis Q, Dompeling E. Feasibility of a new method to collect exhaled breath condensate in pre-school children. Pediatric allergy and immunology : official publication of the European Society of Pediatric Allergy and Immunology 2010: 21(1 Pt 2): e235-244.

50. Thomas PS, Lowe AJ, Samarasinghe P, Lodge CJ, Huang Y, Abramson MJ, Dharmage SC, Jaffe A. Exhaled breath condensate in pediatric asthma: promising new advance or pouring cold water on a lot of hot air? a systematic review. Pediatric pulmonology 2013: 48(5): 419-442.

51. Phillips M, Herrera J, Krishnan S, Zain M, Greenberg J, Cataneo RN. Variation in volatile organic compounds in the breath of normal humans. Journal of chromatography B, Biomedical sciences and applications 1999: 729(1-2): 75-88.

52. Smith D, Spanel P, Gilchrist FJ, Lenney W. Hydrogen cyanide, a volatile biomarker of Pseudomonas aeruginosa infection. Journal of breath research 2013: 7(4): 044001.

53. Buszewski B, Kesy M, Ligor T, Amann A. Human exhaled air analytics: biomarkers of diseases. Biomedical chromatography : BMC 2007: 21(6): 553-566.

54. Barnes PJ. Reactive oxygen species and airway inflammation. Free radical biology \& medicine 1990: 9(3): 235-243.

55. Amann A, de Lacy Costello B, Miekisch W, Schubert J, Buszewski B, Pleil J, Ratcliffe N, Risby T. The human volatilome: volatile organic compounds (VOCs) in exhaled breath, skin emanations, urine, feces and saliva. Journal of breath research 2014: 8(3): 034001.

56. Fens N, van der Schee MP, Brinkman P, Sterk PJ. Exhaled breath analysis by electronic nose in airways disease. Established issues and key questions. Clinical and experimental allergy : journal of the British Society for Allergy and Clinical Immunology 2013: 43(7): 705-715.

57. van de Kant KD, van der Sande LJ, Jobsis Q, van Schayck OC, Dompeling E. Clinical use of exhaled volatile organic compounds in pulmonary diseases: a systematic review. Respiratory research 2012: 13: 117.

58. Boots AW, van Berkel JJ, Dallinga JW, Smolinska A, Wouters EF, van Schooten FJ. The versatile use of exhaled volatile organic compounds in human health and disease. Journal of breath research 2012: 6(2): 027108.

59. Fink T, Baumbach JI, Kreuer S. Ion mobility spectrometry in breath research. Journal of breath research 2014: 8(2): 027104. 



\title{
Chapter 2
}

\section{Electronic monitoring of symptoms and lung function to assess asthma control in children}

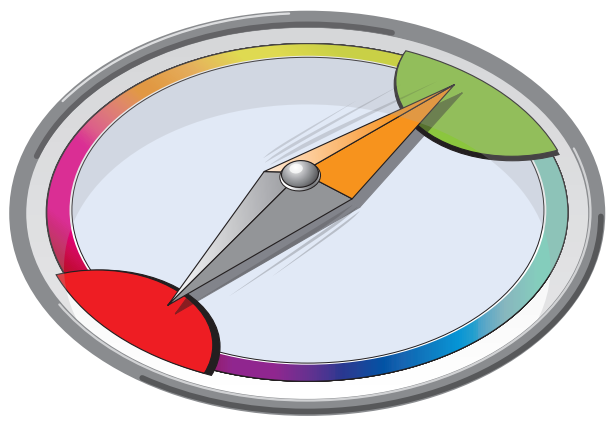

\author{
Van Vliet D \\ Van Horck MWP \\ Van de Kant KDG \\ Vaassen SEM \\ Gulikers S \\ Winkens B \\ Rosias PPR \\ Heynens JW \\ Muris JWM \\ Essers BAB \\ Jöbsis Q \\ Dompeling $\mathrm{E}$
} Annals of Allergy, Asthma \& Immunology 2014; 113: 257-62 


\section{Abstract}

\section{Background}

Asthma remains poorly controlled in children. Home monitoring of asthma control may help to improve the level of asthma control.

\section{Objectives}

To compare 2 methods to assess asthma control: 1) prospective home monitoring, based on daily assessment of forced expiratory volume in 1 second $\left(\mathrm{FEV}_{1}\right)$ and electronic symptom score; 2) Asthma Control Questionnaire (ACQ) with retrospective assessment of symptoms and $\mathrm{FEV}_{1}$.

\section{Methods}

Ninety-six children with asthma were prospectively followed during 1 year. Asthma control was assessed by home monitoring including an electronic symptom score based on Global Initiative for Asthma (GINA) criteria and FEV 1 measurements. In the hospital, the ACQ was completed and $\mathrm{FEV}_{1}$ was measured. Kappa analysis was performed in order to assess levels of agreement between 2 methods.

\section{Results}

Agreement between the 2 methods was low (Kappa coefficient 0.393). In 29 children (37\%), prospective home monitoring was less optimistic than retrospective assessment of asthma control by the ACQ.

\section{Conclusion}

This study demonstrated low agreement between asthma control based on the GINA criteria by means of prospective home monitoring and the hospital ACQ. The prospective home monitor detected more cases of less well controlled asthma than the ACQ. However, optimization of adherence to home monitor use is necessary. 


\section{Introduction}

Asthma control in children is a central goal in evidence based guidelines concerning the management of asthma. In clinical practice, there is room for improvement in the control of asthma in children. ${ }^{1-4}$ Therapy is often titrated based on the Global Initiative for Asthma (GINA) criteria, which are described in the Asthma management and prevention guidelines. ${ }^{3}$ According to these criteria, asthma control is based on symptoms and spirometry. Currently, asthma control is mostly evaluated during consultations with an interval of at least 2 to 3 months between visits. However, evaluating asthma control during clinical visits is vulnerable for recall bias as a result of retrospective assessment of symptoms. It is possible that prospective monitoring of symptoms and lung function, for instance by means of a home monitor, provides a more realistic picture of asthma control levels.

Home monitoring can be advocated as a useful tool in the monitoring of asthma control, because it can prospectively collect symptoms and/or lung function over a period of time. Consequently, home monitoring may give more insight into the day-to-day level of asthma control than regular doctor visits, because symptoms and multiple lung function measurements are assessed more frequently and prospectively. However, some studies reported that home monitoring did not improve asthma control. ${ }^{5-8}$ The limitations of these studies were that symptom scores were not collected electronically and that peak expiratory flow (PEF) rate instead of forced expiratory volume in 1 second $\left(\mathrm{FEV}_{1}\right)$ was recorded. A possible pitfall for the efficacy of a home monitor is adherence to home monitor use.

Therefore, the aim of this study was to compare 2 methods for assessing asthma control in children: 1) prospective home monitoring, based on daily $\mathrm{FEV}_{1}$ measurements and a daily electronic symptom score; 2) retrospective assessment of symptoms during a clinical visit by means of the Asthma Control Questionnaire (ACQ) and FEV measurements. Finally, adherence to the home monitor use was assessed.

\section{Material and methods}

\section{Study design}

Children aged 6 to 18 years with a diagnosis of asthma were included in a one-year multicentre observational study (clinicaltrial.gov NCT 01239238). This study was carried out in 2 hospitals in the Netherlands (Sittard and Maastricht). All children were treated at the outpatient clinic of these 2 specialized paediatric pulmonology centres for their doctor diagnosed asthma for at least 6 months; and received inhaled corticosteroids (ICS) during the year preceding the study. All children fulfilled the criteria for an asthma diagnosis of the GINA and the Dutch Paediatric Pulmonology Society: 1) recurrent episodes of wheezing, coughing, breathlessness, or chest 
tightness. ${ }^{3,9}$; 2) reversibility to a bronchodilator defined as an increase in $\mathrm{FEV}_{1}$ of $\geq 9 \%$ of predicted value. ${ }^{9,10}$; and/or 3 ) histamine bronchial hyperresponsiveness defined as a $20 \%$ drop in $\mathrm{FEV}_{1}$ caused by histamine inhalation $\leq 8 \mathrm{mg} / \mathrm{ml}$ or less. ${ }^{9}$ Exclusion criteria included cardiac abnormalities, mental retardation, congenital abnormalities, existence of a syndrome, active smoking, immunotherapy or no technical satisfactory performance of lung function and exhaled nitric oxide measurements.

Ethical approval was obtained by the Medical Ethical Committee of the Maastricht University Medical Centre. All parents, and children 12 years and older, signed an informed consent form at the start of the study.

\section{Study parameters}

Regular clinical visits took place every 2 months. During every clinical visit, the ACQ was filled out, $\mathrm{FEV}_{1}$ was measured, and other measurements were performed as described below. In addition, daily home monitor data were collected.

\section{Home monitoring}

Daily monitoring was performed using a Jaeger Asthma Monitor, the AM2+ (ERT, Hoechberg, Germany). The AM2+ home monitor is a handheld spirometer that was used to measure $\mathrm{FEV}_{1}$. In addition, an asthma symptom score was recorded electronically, which was based on the GINA-criteria for asthma control (Table S2.1, Supporting information). ${ }^{3}$ All lung function values and symptom scores were stored in the device. At the first clinical visit, children and parents were carefully instructed how to use the home monitor, how to answer and interpret the symptom score, and to perform a correct $\mathrm{FEV}_{1}$ manoeuvre. Children were asked to perform $3 \mathrm{FEV}_{1}$ manoeuvres with maximal effort. The highest $\mathrm{FEV}_{1}$ value of each day was selected. Participants were instructed to daily use the home monitor at the same time, and to transfer data into a secured web based portal twice a week (Aventana $\mathrm{GmbH}$, Hoechberg, Germany). Data were checked every week by a through instructed medical intern. Patients who did not send their data received a reminder, to increase adherence. Adherence to home monitor use during the study was defined as no missing data more than 5 of the 7 days on average.

For assessment of asthma control by home monitoring 1 week prior to clinical visit, the exclusion criterion was applied of more than 2 of the 7 days missing home monitor data prior to clinical visit. To compare asthma control based on ACQ with home measured asthma control, the home monitoring asthma control over 1 week prior to clinical visit was calculated on the basis of the GINA criteria for asthma control. ${ }^{3}$

\section{Measures during clinical visits}

Children were evaluated at the hospital by a trained research nurse or physician every 2 months. During each clinical visit, the following parameters were assessed: 1) Asthma control level (ACQ of Juniper et al. $\left.)^{11,12}, 2\right)$ disease specific quality of life (Paediatric Asthma Quality of 
Life Questionnaire (PAQLQ) of Juniper et al. $)^{13,14}$, 3) Fractional exhaled Nitric Oxide (FeNO), and 4) spirometry before and after bronchodilatation.

Patients completed the Dutch version of the ACQ, which assesses the asthma control level over the past 7 days. ${ }^{12}$ The following cut-off points for level of control were used: controlled asthma, ACQ 0.75 or less; partly controlled asthma ACQ score of greater than 0.75 to 1.5; uncontrolled asthma, ACQ score greater than 1.5. The PAQLQ was used to assess the asthma specific quality of life. The questions represent 3 domains concerning symptoms, activity limitations, and emotional function. The range in scores is from 1 to 7 , which represents poor to good quality of life. ${ }^{13,14}$ All children older than 10 years filled out the questionnaires without help from their parents. When needed, children younger than 10 years were assisted by their parents.

FeNO was measured online by a NIOX analyser (NIOX MINO, Aerocrine, Solna, Sweden). The measurements were performed according the American Thoracic Society/European Respiratory Society (ATS/ERS) criteria for children. ${ }^{15}$

Dynamic spirometry was performed by means of the ZAN 100 spirometer, according to ATS/ERS standards (nSpire Health $\mathrm{GmbH}$, Oberthulba, Germany). ${ }^{16}$ The highest value of 3 technically correct maximal expiratory flow volume (MEFV) curves was used for analysis. Recorded parameters included: $F E_{1}$, forced vital capacity (FVC) and maximum expiratory flow at $50 \%$ of $\mathrm{FCV}\left(\mathrm{MEF}_{50}\right)$. All parameters were expressed as a percentage of the predicted value. Subsequently, the patient inhaled $400 \mu \mathrm{g}$ Salbutamol. After 15 minutes, a second lung function was performed in order to test for reversibility. Patients were instructed to stop shortacting bronchodilators at least 8 hours and long-acting bronchodilators at least 48 hours before testing. Reversibility was defined as an increase in $\mathrm{FEV}_{1}$ of at least $9 \%$ of predicted value.

Bronchial hyperresponsiveness was evaluated by bronchial histamine challenge testing ${ }^{17}$ This test was performed at the start of the study. At first, an aerosol of buffered saline was inhaled, followed by aerosols of histamine solutions with doubling concentrations of 0.03 to $16 \mathrm{mg} /$ $\mathrm{ml}$, at intervals of 5 minutes. Spirometry manoeuvres were performed $0.5,1.5$ and 2 minutes after inhalation of each solution. The required concentration of histamine to produce a $20 \%$ decrease of $\mathrm{FEV}_{1}\left(\mathrm{PC}_{20}\right)$ was calculated. After reaching the threshold, children inhaled 800 microgram salbutamol, followed by 3 MEFV curves. A total of $16 \%$ of the $\mathrm{PC}_{20}$ histamine tests were missing because of recurrent active airway infections, inability to stop antihistamines or bronchodilators, and calibration errors of the histamine nebulizer.

Atopy was objectified by Phadiatop infant (Phadia, Uppsala, Sweden), radioallergosorbent assay (Pharmacia, Uppsala, Sweden), or Allergen Skin test, which were performed in the past or during the study for clinical purposes. 
Patients were treated according to the Paediatric Pulmonology section of the Dutch Society of Paediatrics. ${ }^{9}$ Medication was strictly titrated based on level of asthma control according to the GINA guidelines during regular clinical visits. Physicians did not use the home monitor data to titrate medication. Moreover, patients were asked not to modify their treatment on the basis of home monitoring data. Treatment adherence was measured by using the Medication Adherence Report Scale. ${ }^{18}$ This questionnaire consists of 9 questions with an answer scale from 1 to 5 . The sum of all answers is reported with a range of 9 to 45 , which represents poor to good adherence to medication use.

\section{Statistical analysis}

Numerical variables are expressed as mean and standard deviation (SD), or as median and inter quartile ranges (IQR). Categorical variables are expressed as number and percentage. Comparison of characteristics between groups was performed with independent-samples T-test for parametric data and the Mann-Whitney $U$ test for nonparametric data. Categorical variables were compared using the Chi-square. The $p$-values below 0.05 were considered statistically significant. Data were analysed by using SPSS statistical software version 20 (SPSS Inc., Chicago, Illinois).

One set of asthma control levels at home and in hospital of each patient was used to compare asthma control outcome of the 2 methods. Home monitor measurements during the runin phase, which included clinical visits 1 and 2, were not used for analysis, because the home monitor was not regularly used in that period. Therefore, from clinical visit 3 to 7 , the first complete set of level of asthma control assessed by home monitor and hospital ACQ was selected for each patient. Agreement between home measurements and hospital measurements for assessment of asthma control was analysed by linear weighted Cohen's $\kappa$ coefficient. ${ }^{19}$ 


\section{Results}

\section{Patient characteristics}

Ninety-six children with asthma participated. Most children were atopic, had well-controlled asthma at baseline, and experienced a good disease-specific quality of life (table 2.1). There was no clinical important difference in baseline characteristics among the centres, but there was a small difference in age (difference of 1 year).

Table 2.1 Patient baseline characteristics of total population and each centre

\begin{tabular}{|c|c|c|c|}
\hline & Total $n=96$ & Centre $A n=51$ & Centre $B \mathrm{n}=45$ \\
\hline Sex male, n (\%) & $50(52)$ & $27(53)$ & $23(51)$ \\
\hline Mean age [range] in years & $10[6-17]$ & $9[6-17]$ & $10[7-15]$ \\
\hline $\mathrm{FEV}_{1} \%$ predicted value, mean $\pm \mathrm{SD}$ & $96.8 \pm 14.2$ & $95.4 \pm 15.5$ & $98.4 \pm 12.7$ \\
\hline $\begin{array}{l}\text { Bronchodilator response, delta } \mathrm{FEV}_{1} \% \\
\text { predicted value, mean } \pm \mathrm{SD}\end{array}$ & $6.6 \pm 8.5$ & $6.7 \pm 9.8$ & $6.5 \pm 7.0$ \\
\hline ICS use, $\%$ & 94 & 90 & 98 \\
\hline $\begin{array}{l}\text { Fluticasone daily dosage or equivalent, } \\
\text { mean } \pm S D\end{array}$ & $269 \pm 175$ & $295 \pm 202$ & $240 \pm 134$ \\
\hline ACQ, median [IQR] & $0.6[0.3-1]$ & $0.5[0.3-1.0]$ & $0.6[0.1-1.1]$ \\
\hline PAQLQ total score, median [IQR] & $6.4[5.9-6.7]$ & $6.3[5.8-6.7]$ & $6.6[6.0-6.8]$ \\
\hline FeNO, ppb: median [IQR] & $12.5[8.0-31.0]$ & $13.0[8.0-35.0]$ & $12.0[8.0-27.0]$ \\
\hline $\begin{array}{l}\mathrm{PC}_{20} \text { histamine test, } \mathrm{mg} / \mathrm{mL} \text { : median } \\
{\left[\mathrm{IQR}^{*}\right.}\end{array}$ & $1.2[0.3-2.9]$ & $1.0[0.3-2.3]$ & $1.4[0.4-3.2]$ \\
\hline Atopic, $\%^{\dagger}$ & 76 & 77 & 76 \\
\hline $\begin{array}{l}\text { Completed home monitor data, \%: } \\
\text { median [IQR] }\end{array}$ & $70.6[51.4-87.8]$ & $69.6[52.5-88.4]$ & $70.9[78.0-87.2]$ \\
\hline
\end{tabular}

ACQ, Asthma Control Questionnaire; Centre A, Maastricht; Centre B, Sittard; FeNO, Fractional exhaled Nitric Oxide; FEV , forced expiratory volume in 1 second; ICS, Inhaled Corticosteroids; IQR, Inter Quartile Range; PAQLQ, Paediatric Asthma Control Quality of Life Questionnaire; SD, Standard Deviation. ${ }^{*} \mathrm{PC}_{20}$ histamine test: concentration of histamine inducing a $20 \%$ drop in $\mathrm{FEV}_{1}$.

${ }^{\dagger}$ Atopy is defined as a positive Phadiatop (Phadia, Uppsala, Sweden), or a positive allergen skin test. 
Seven patients were excluded from the analysis (figure 2.1). Six of these patients dropped out before the third clinical visit and did not have all technical properties to perform home assessments in the run-in phase. One patient did not use the home monitor because of personal constraints. In addition, 11 patients were excluded from the comparative analysis of asthma control between both methods, due to missing home monitor data of more than 2 of the 7 days (figure 2.1).

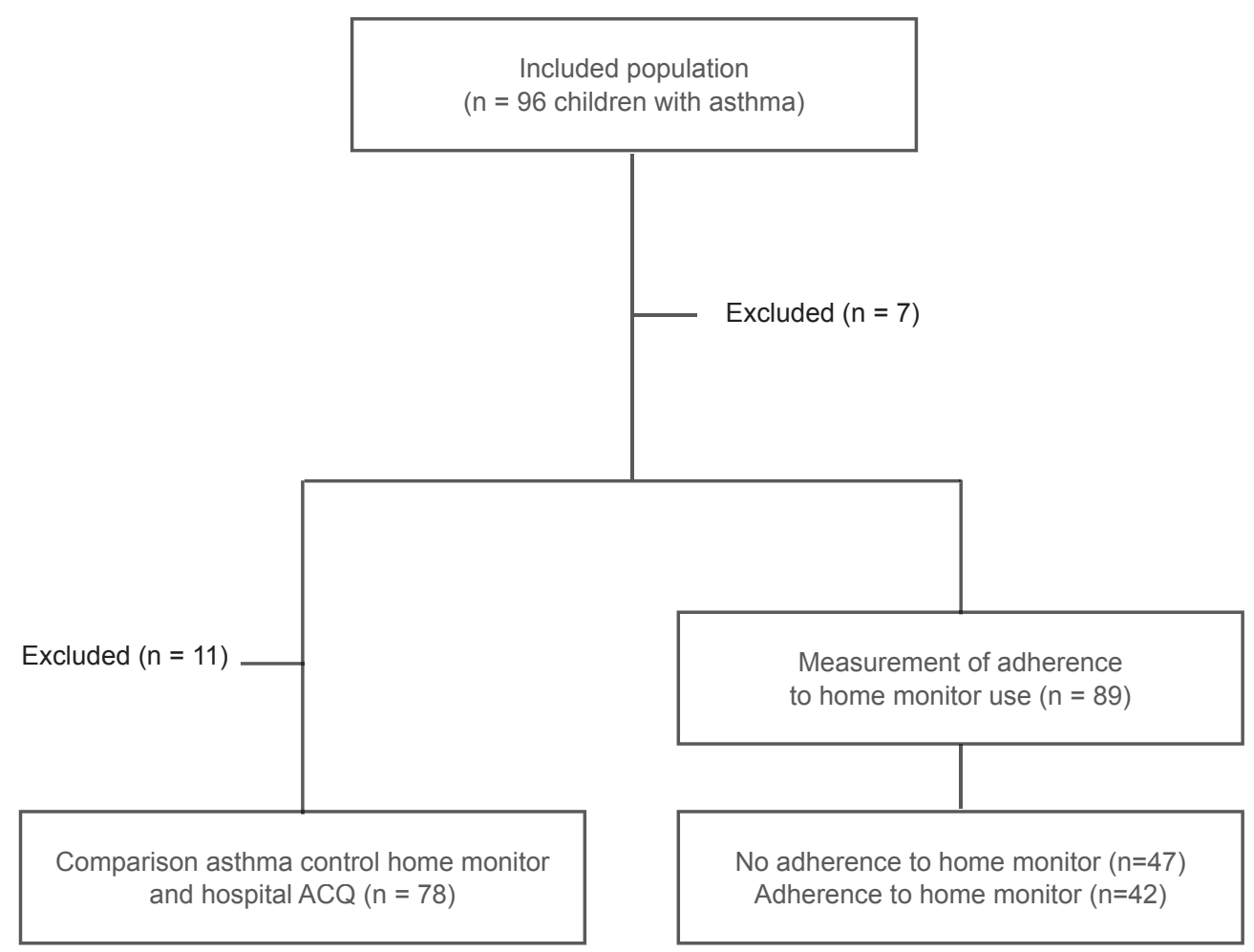

Figure 2.1 Overview of patients included in the study and number of patients for analysis

\section{Comparison asthma control level according to home monitor assessments and hospital ACQ scores}

For 78 children, a comparison could be made between the classification of asthma control by the home monitor assessments and the ACQ score (table 2.2). There was low agreement between the 2 instruments to distinguish between 3 levels of asthma control (linear weighted $\mathrm{K}=0.393 ; 95 \% \mathrm{Cl}, 0.244-0.543)$. In $54 \%$ of the children there was agreement between the 2 methods with respect to level of asthma control. However, by means of the home monitor, more than twice as much cases of partly controlled asthma were found compared to the ACQ (33 of 78 patients with the home monitor versus 16 of 78 patients with the ACQ). Moreover, 
in 29 of 68 children, the home monitor evaluated asthma control 1 or 2 classes lower than the ACQ (categories $\mathrm{D}, \mathrm{G}$ and $\mathrm{H}$ in table 2.2). These 29 children with a lower home monitor asthma control level than the ACQ result, were compared with the 36 children in whom there was agreement between the home monitor and the ACQ result 7 days before the clinical visit (categories $\mathrm{A}$ and $\mathrm{E}$ in table 2.2). It appeared that $\mathrm{FEV}_{1} \%$ predicted value, $\mathrm{FEV}_{1} / \mathrm{NC}$, and MEF50 \% predicted value were significantly lower (table 2.3 ), which indicated that the home monitor gave a better reflection of asthma control than the ACQ.

Table 2.2 Classification asthma control on the basis of the GINA guidelines and ACQ scores

\begin{tabular}{|c|c|c|c|c|c|c|c|}
\hline \multirow[b]{2}{*}{$\begin{array}{l}\text { Home monitor } \\
\text { controlled asthma }\end{array}$} & \multicolumn{2}{|c|}{$\begin{array}{l}\text { ACQ controlled } \\
\text { asthma* }\end{array}$} & \multicolumn{2}{|c|}{$\begin{array}{l}\text { ACQ partly controlled } \\
\text { asthma* }\end{array}$} & \multicolumn{2}{|c|}{$\begin{array}{l}\text { ACQ uncontrolled } \\
\text { asthma* }\end{array}$} & \multirow{2}{*}{\begin{tabular}{|l} 
Total \\
32
\end{tabular}} \\
\hline & 29 & A & 3 & B & 0 & C & \\
\hline $\begin{array}{l}\text { Home monitor partly } \\
\text { controlled asthma }\end{array}$ & 22 & $D$ & 7 & E & 4 & $\mathrm{~F}$ & 33 \\
\hline $\begin{array}{l}\text { Home monitor } \\
\text { uncontrolled asthma }\end{array}$ & 1 & G & 6 & $\mathrm{H}$ & 6 & I & 13 \\
\hline Total & 52 & & 16 & & 10 & & 78 \\
\hline
\end{tabular}

Cut-off points $A C Q \leq 0.75$ controlled asthma; $0.75<A C Q \leq 1.5$ partly controlled asthma; $A C Q>1.5$ uncontrolled asthma. 
Table 2.3 Comparison of asthma features between children with lower asthma control according to the home monitor and children with agreement between both methods (concerning controlled/partly controlled asthma)

\begin{tabular}{|c|c|c|c|}
\hline & $\begin{array}{l}\text { Children with agreement } \\
\text { between methods } \\
\text { concerning controlled and } \\
\text { partly controlled asthma }\end{array}$ & $\begin{array}{l}\text { Children with lower asthma } \\
\text { control according to home } \\
\text { monitor }^{b}\end{array}$ & $p$-value \\
\hline $\mathrm{FEV}_{1} \%$ predicted value, mean $\pm \mathrm{SD}$ & $102.1 \pm 13.2$ & $94.2 \pm 12.9$ & $0.02^{*}$ \\
\hline FVC $\%$ predicted value, mean \pm SD & $101.1 \pm 11.7$ & $99.1 \pm 10.4$ & 0.47 \\
\hline $\mathrm{FEV}_{1} / \mathrm{VC}$, mean $\pm \mathrm{SD}$ & $85.5 \pm 7.5$ & $80.9 \pm 10.2$ & $0.04^{*}$ \\
\hline $\begin{array}{l}\text { MEF50 } \% \text { predicted value, } \\
\text { mean } \pm \text { SD }\end{array}$ & $85.5 \pm 24.5$ & $71.4 \pm 19.8$ & $0.01^{*}$ \\
\hline $\begin{array}{l}\mathrm{FEV}_{1} \% \text { predicted value after } \\
\text { bronchodilator, median [IQR] }\end{array}$ & $103.5[98.3-113.3]$ & $102.0[92.5-108.0]$ & 0.23 \\
\hline $\begin{array}{l}\mathrm{FEV}_{1} / \mathrm{VC} \text { after bronchodilator, } \\
\text { median }[\mathrm{QQR}]\end{array}$ & $90.0[82.3-92.8]$ & $87.0[78.5-90.5]$ & 0.12 \\
\hline FeNO, ppb: median [IQR] & $12.5[9.0-30.8]$ & $13.0[8.0-28.5]$ & 0.76 \\
\hline PAQLQ total score, median [IQR] & $7.0[6.0-7.0]$ & $7.0[6.0-7.0]$ & 0.64 \\
\hline
\end{tabular}

FeNO, Fractional exhaled Nitric Oxide; $F_{E V}$, forced expiratory volume in 1 second; FVC, forced vital capacity; IQR, Inter Quartile Range; $\mathrm{MEF}_{50}$, mean expiratory flow at $50 \%$; PAQLQ, Paediatric Asthma Control Quality of Life Questionnaire; SD, Standard Deviation; VC, vital capacity.

${ }^{a}$ Cells AE from table $2.2(n=36)$

${ }^{\mathrm{b} C e l l s ~ D G H}$ from table $2.2(n=29)$

\section{Adherence of home monitor use}

Median completed data of all children was $69 \%$ (IQR, $53 \%-89 \%$ ). A total of $47 \%$ of the study population was adherent to the home monitor use. Comparing the adherent and the nonadherent group, a significantly higher FeNO was found at baseline in the non-adherent group. Children who were less adherent to home monitor use had higher baseline ACQ-scores and higher FeNO levels (Table S2.2, Supporting information). This finding indicated that children with partly controlled and uncontrolled asthma, and patients with higher FeNO values were less willing to use the monitor.

\section{Discussion}

This study found low agreement between the asthma control levels based on the prospective home monitor data compared to the retrospective hospital ACQ score. By means of the home monitor, twice as much cases with partly controlled asthma were found than with the hospital ACQ. Moreover, in $37 \%$ of the children with a lower asthma control according to the home monitor compared with the $A C Q$, lung function levels $\left(\mathrm{FEV}_{1}, \mathrm{FEV}_{1} / \mathrm{VC}\right.$ and MEF50) were 
significantly lower, a finding that further supports the reliability and validity of the home monitor data. These findings confirm our hypothesis that prospective monitoring of symptoms and lung function by means of a home monitor provides a more realistic picture of asthma control levels than retrospective assessment of asthma control during consultations in the hospital with 2 to 3 months intervals between visits. However, the adherence to the home monitor was too low and should be optimized.

\section{Assessment of asthma control: home monitoring versus ACQ}

To our knowledge, there are no other studies investigating the use of a home monitor in paediatric asthma in which electronic symptom scores and $\mathrm{FEV}_{1}$ were combined. However, the low agreement between home measured asthma control based on the GINA criteria and the ACQ found in the present study, is in concordance with earlier studies that retrospectively evaluated the assessment of level of asthma control on the basis of the GINA criteria and the ACQ ( $\mathrm{K}$ index of 0.44 and 0.27 in the studies by Korn and colleagues, and by Olaguibel and colleagues; respectively). ${ }^{20,21}$ In these studies, asthma control was based on the GINA criteria measured using a retrospective questionnaire. Prospective assessment of the GINA based asthma control at home in the current study is preferable, because recall bias is ruled out. ${ }^{22}$ This recall bias may also have affected the study by Brouwer and colleagues, which examined the association between home measured PEF and $\mathrm{FEV}_{1}$ to assess asthma severity. ${ }^{23}$ In this study, electronic home spirometry parameters were related to asthma severity assessed by written home diaries. Home PEF values showed poor agreement with asthma severity. ${ }^{23}$

\section{Effect of home monitoring on asthma control}

We searched for studies that evaluated the influence of daily electronic monitoring of $\mathrm{FEV}_{1}$ and symptoms on asthma control levels in children. However, such a study that includes both electronically recorded $\mathrm{FEV}_{1}$ and symptoms in children, has not been performed so far. The study of Jan et al. reported that home monitoring of PEF and internet symptoms was effective in a randomized controlled trail (RCT) that included 164 asthmatic children with asthma. This study compared self-management based on daily PEF and internet symptom scores with written diaries. Internet-based telemonitoring of PEF and symptoms resulted in improvement of asthma control. ${ }^{24}$ Furthermore, Rasmussen and colleagues conducted an RCT in 300 adults with asthma. ${ }^{25}$ This RCT compared internet based management to monitor asthma control (i.e. PEF and electronic symptom score) with evaluation by general practitioner or specialist. ${ }^{25}$ Significant improvement of asthma symptoms, quality of life, lung function and airway responsiveness was found in the intervention group compared to evaluation by the specialist. There are also studies in which home monitoring was not effective. These studies were limited by small study populations or home monitoring did not include electronic symptom scores or $\mathrm{FEV}_{1} \cdot{ }^{5-7}$ 
Strengths of this study are the substantial number of included children, the one-year prospective character, the electronic home monitor with recording of symptoms and $\mathrm{FEV}_{1}$ at home, and the simultaneous assessment of the ACQ and the FEV during each clinical visit. Poor perception of symptoms may cause underestimation of asthma control by both methods. Besides, in some children younger than 10 years, completion of the ACQ was complicated by lack of understanding of included words or timeline. However, this effect was reduced by completion of questionnaires with an interviewer in young children. Moreover, we have added $\mathrm{FEV}_{1}$ to symptoms, which reduces underestimation of asthma control levels due to poor perceivers.

How can findings be explained? The most likely explanation for the difference in asthma control between the 2 methods is the exclusion of recall bias by means of electronic home assessment of asthma control. Another important finding of this study is the relative low adherence to home monitor use, and higher FeNO levels and higher ACQ scores in the nonadherent children compared to the adherent children. During the recruitment of patients, we observed that patients refused to attend this study because their life's and school activities were experienced as busy. This was also often a reason that patients reported for no adherence to home monitor use. Moreover, technical problems can arise with the software or hardware communication, stressing the importance of a robust and patient-friendly device. Technical problems can arise during installation of software on computers and transmission of data to the portal. The combination of lack of time and previous technical problems resulted in reluctance with respect to use of the home monitor in this study. The technology of electronic home monitors and communication with databases needs to be improved.

The clinical implication of this study is that home monitoring could be an additional tool to assist health professionals in improving management of asthma in children.

In this study, we found that children with worse adherence had higher FeNO levels and that this group consisted of slightly more children with partly controlled and uncontrolled asthma. This finding needs attention because this group in particular may benefit from a better adherence to the use of the monitor. One question is how adherence rates can be increased in this group? In our study daily home monitoring of symptoms and lung function was applied. First, it is likely that the adherence to the monitor will increase when a lower frequency of measurements is asked from parents and children. In case of no respiratory symptoms and good asthma control, one can imagine that 1 or 2 assessments per week may be sufficient, whereas daily monitoring may be necessary in case of more symptoms or increased use of $\aleph_{2}$-agonists. Second, the adherence to the home monitor may increase when parents and children can directly contact the medical team and/or have an extra clinical evaluation in case asthma control deteriorates. Third, it is essential to have a monitor that is easy to use. The monitor should have an application that makes it easy an effortless to send data to the 
hospital. The monitor used in this study has room for improvement in this regard. Fourth, constant communication with children and parents about the purpose and advantages of the proper use of the home monitor may help to increase the motivation of children and parents to adhere to the home monitor. The effect of these suggestions to increase adherence to home monitor use should be subject of future studies.

In our study we aimed to apply a strict cutoff point to assess asthma level of control with the home monitor. Further studies should investigate which adherence rate is sufficient to reliably assess the level of asthma control. Potentially, with less frequent use of the home monitor, the level of asthma control could be reliably assessed. Less frequent use of the home monitor could increase the adherence rate to home monitor use. Furthermore, in an RCT the effectiveness of titration of medication in asthmatic children based on home monitored electronic symptoms and $\mathrm{FEV}_{1}$ needs to be proven. Outcome variables of this RCT should include asthma control, moderate or severe asthma exacerbation rate, health care costs (e.g. emergency department visits due to asthma exacerbations), and quality of life. Management based on home monitoring probably improves asthma control, and may result in a decrease of regular clinical visits and reduction in costs of health care.

In conclusion, we found low agreement between the asthma control levels based on the prospective home monitor data and the retrospective hospital ACQ score. By means of the home monitor, twice as much cases with partly controlled asthma were found than with the hospital ACQ. Adherence to home monitor use needs to be further optimized to increase the clinical usefulness to measuring disease control in children with asthma. 


\section{Supporting information}

Table S2.1 Home monitor symptom questionnaire

Question Answers options

(score per answer)

Did you have any complaints of your asthma (0) No complaints

(cough, wheeze, dyspnoea) last night?

(1) One time awake

(2) Two times awake

(3) Three or more times awake

Did you have any complaints of your asthma

(0) No complaints

(cough, wheeze, dyspnoea) during the day?

(1) One short period

(2) Two short periods

(3) Three or more periods

Did you have limitations of activity due to asthma

(0) Not limited

symptoms during the day?

(1) Slightly limited

(2) Fairly limited

(3) Extremely limited

Number of times in need of rescue medication

Did you take your asthma medication today?
Number
(1) Yes
(0) No 
Table S2.2 Comparison of patient baseline characteristics of the non- adherent and adherent group with respect to the home monitor use

\begin{tabular}{llll}
\hline & $\begin{array}{l}\text { Non-adherent } \\
(\mathrm{n}=47)\end{array}$ & $\begin{array}{l}\text { Adherent } \\
(\mathrm{n}=42)\end{array}$ & p-value \\
\hline Participating centre A, \% & 53 & 52 & 0.97 \\
Sex male, $\mathrm{n}(\%)$ & $27(57)$ & $22(52)$ & 0.10 \\
Mean age [range] years & $9[6-16]$ & $10[6-17]$ & 0.22 \\
FEV ${ }_{1} \%$ predicted value, mean $\pm \mathrm{SD}$ & $96.9 \pm 10.7$ & $98.5 \pm 14.2$ & 0.55 \\
Bronchodilator response, & $6.4 \pm 8.8$ & $5.4 \pm 8.4$ & 0.61 \\
delta FEV $\%$ predicted, mean $\pm \mathrm{SD}$ & & & \\
Fluticasone daily dosage or equivalent, & $257 \pm 157$ & $257 \pm 165$ & 0.88 \\
mean \pm SD & & & \\
ACQ, median [IQR] & $0.6[0.3-1.4]$ & $0.4[0.1-0.9]$ & 0.05 \\
PAQLQ total score, median [IQR] & $6.4[5.7-6.7]$ & $6.6[6.0-6.7]$ & 0.36 \\
FeNO, ppb: median [IQR] & $16.0[9.0-35.0]$ & $9.5[5.8-20.0]$ & 0.03 \\
PC ${ }_{20}$ histamine test, mg/mL: median [IQR] & $1.2[0.3-2.3]$ & $1.9[0.7-3.6]$ & 0.09 \\
Atopic, \% $^{\dagger}$ & 57 & 50 & 0.79 \\
MARS-9, mean $\pm \mathrm{SD}^{*}$ & $37.0 \pm 3.9$ & $38.3 \pm 2.8$ & 0.09 \\
\hline
\end{tabular}

$A C Q$, Asthma Control Questionnaire; Centre A, Maastricht; FEV ${ }_{1}$, forced expiratory volume in 1 second; FeNO, Fractional exhaled Nitric Oxide; IQR, Inter Quartile Range; MARS, Medication Adherence Report Scale; PAQLQ, Paediatric Asthma Control Quality of Life Questionnaire; SD, standard deviation.

"Bronchial hyperresponsiveness to histamine: concentration of histamine inducing a $20 \%$ drop in $\mathrm{FEV}_{1}$.

${ }^{\dagger}$ Atopy is defined as a positive Phadiatop; or a positive allergen skin test. 


\section{References}

1. Rabe KF, Adachi M, Lai CK, Soriano JB, Vermeire PA, Weiss KB, Weiss ST. Worldwide severity and control of asthma in children and adults: the global asthma insights and reality surveys. The Journal of allergy and clinical immunology 2004: 114(1): 40-47.

2. Gustafsson PM, Watson L, Davis KJ, Rabe KF. Poor asthma control in children: evidence from epidemiological surveys and implications for clinical practice. Int J Clin Pract 2006: 60(3): 321-334.

3. (GINA) GIfA. Global strategy for asthma management and prevention. . http://wwwginaasthmacom 2012.

4. Society BT. British guideline on management of asthma. 2009.

5. Deschildre A, Beghin L, Salleron J, lliescu C, Thumerelle C, Santos C, Hoorelbeke A, Scalbert M, Pouessel G, Gnansounou M, Edme JL, Matran R. Home telemonitoring (forced expiratory volume in $1 \mathrm{~s}$ ) in children with severe asthma does not reduce exacerbations. The European respiratory journal 2012: 39(2): 290-296.

6. Wensley D, Silverman M. Peak flow monitoring for guided self-management in childhood asthma: a randomized controlled trial. American journal of respiratory and critical care medicine 2004: 170(6): 606-612.

7. Willems DC, Joore MA, Hendriks JJ, Nieman FH, Severens JL, Wouters EF. The effectiveness of nurse-led telemonitoring of asthma: results of a randomized controlled trial. Journal of evaluation in clinical practice 2008: 14(4): 600-609.

8. Thompson AK, Juniper E, Meltzer EO. Quality of life in patients with allergic rhinitis. Annals of allergy, asthma \& immunology : official publication of the American College of Allergy, Asthma, \& Immunology 2000: 85(5): 338-347; quiz 347-338.

9. de Jongste JC. Astma bij kinderen; herziene richtlijnen van de sectie kinderlongziekten van de NVK [Asthma in children; revised guidelines of the paediatric department of the Dutch Paediatric Society], Amsterdam, 2007.

10. Dales RE, Spitzer WO, Tousignant P, Schechter M, Suissa S. Clinical interpretation of airway response to a bronchodilator. Epidemiologic considerations. Am Rev Respir Dis 1988: 138(2): 317320.

11. Juniper EF. Assessing asthma control. Current allergy and asthma reports 2007: 7(5): 390-394.

12. Juniper EF, Gruffydd-Jones K, Ward S, Svensson K. Asthma Control Questionnaire in children: validation, measurement properties, interpretation. The European respiratory journal 2010: 36(6): 1410-1416.

13. Juniper EF, Guyatt GH, Feeny DH, Ferrie PJ, Griffith LE, Townsend M. Measuring quality of life in the parents of children with asthma. Qual Life Res 1996: 5(1): 27-34.

14. Juniper EF, Svensson K, Mork AC, Stahl E. Modification of the asthma quality of life questionnaire (standardised) for patients 12 years and older. Health Qual Life Outcomes 2005: 3: 58.

15. American Thoracic S, European Respiratory S. ATS/ERS recommendations for standardized procedures for the online and offline measurement of exhaled lower respiratory nitric oxide and nasal nitric oxide, 2005. American journal of respiratory and critical care medicine 2005: 171(8): 912-930.

16. Wanger J, Clausen JL, Coates A, Pedersen OF, Brusasco V, Burgos F, Casaburi R, Crapo R, Enright P, van der Grinten CP, Gustafsson P, Hankinson J, Jensen R, Johnson D, Macintyre N, McKay R, Miller MR, Navajas D, Pellegrino R, Viegi G. Standardisation of the measurement of lung volumes. The European respiratory journal 2005: 26(3): 511-522.

17. Joos GF, O'Connor B. Indirect airway challenges. European Respiratory Journal 2003: 21(6): 10501068.

18. Horne R, Weinman J. Self-regulation and self-management in Asthma: exploring the role of illness perceptions and treatment beliefs in explaining non-adherence to preventer medication. Psychology and Health 2002: 17(1): 17-32.

19. Fleiss JL. Statistical Methods for Rates and Proportions. 2nd Edition ed. Wiley, New York, 1981.

20. Korn S, Both J, Jung M, Hubner M, Taube C, Buhl R. Prospective evaluation of current asthma control using ACQ and ACT compared with GINA criteria. Annals of allergy, asthma \& immunology : official publication of the American College of Allergy, Asthma, \& Immunology 2011: 107(6): 474- 
479.

21. Olaguibel JM, Quirce S, Julia B, Fernandez C, Fortuna AM, Molina J, Plaza V, Group MS. Measurement of asthma control according to Global Initiative for Asthma guidelines: a comparison with the Asthma Control Questionnaire. Respiratory research 2012: 13: 50.

22. Okupa AY, Sorkness CA, Mauger DT, Jackson DJ, Lemanske RF, Jr. Daily diaries vs retrospective questionnaires to assess asthma control and therapeutic responses in asthma clinical trials: is participant burden worth the effort? Chest 2013: 143(4): 993-999.

23. Brouwer AF, Roorda RJ, Brand PL. Home spirometry and asthma severity in children. The European respiratory journal 2006: 28(6): 1131-1137.

24. Jan RL, Wang JY, Huang MC, Tseng SM, Su HJ, Liu LF. An internet-based interactive telemonitoring system for improving childhood asthma outcomes in Taiwan. Telemedicine journal and e-health : the official journal of the American Telemedicine Association 2007: 13(3): 257-268.

25. Rasmussen LM, Phanareth K, Nolte H, Backer V. Internet-based monitoring of asthma: a long-term, randomized clinical study of 300 asthmatic subjects. The Journal of allergy and clinical immunology 2005: 115(6): 1137-1142. 



\section{Chapter 3}

\section{Longitudinal relationships between asthma specific QoL and asthma control in children}

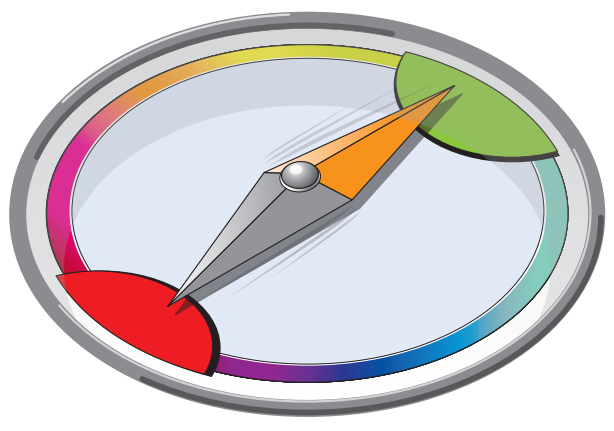

Van Vliet D Essers BAB Winkens B Heynens JW Muris JWM Jöbsis $Q$ Dompeling $\mathrm{E}$ 


\section{Abstract}

\section{Background}

Managing persistent paediatric asthma includes optimizing both asthma control and asthmaspecific quality of life (QoL). However, it is unknown to what extent asthma-specific QoL is related to asthma control or other clinical asthma characteristics over time.

\section{Objectives}

To determine in children, longitudinally:

1. the association between asthma control and asthma-specific QoL;

2. the relationship between clinical asthma characteristics and asthma-specific QoL.

\section{Methods}

In an one-year prospective study, asthma-specific QoL, asthma control, dynamic lung function indices, fractional exhaled nitric oxide, occurrence of exacerbations, and use of rescue medication were assessed during clinical visits every 2 months. Associations between asthma clinical characteristics and asthma-specific QoL were analysed using linear mixed models.

\section{Results}

In this cohort (96 children), improvement of asthma control was longitudinally associated with increase of asthma-specific QoL ( $p$-value<0.01). Clinical characteristics associated with a decrease of asthma-specific QoL were: increased use of $\beta_{2}$-agonists, occurrence of wheezing episodes in the year before the study, occurrence of an asthma exacerbation in the 2 months prior to clinical visit, and decreased lung function ( $p$-values $\leq 0.01$ ).

\section{Conclusion}

Asthma control and asthma-specific QoL were longitudinally associated, but were not mutually interchangeable. In addition, specific clinical characteristics were related to asthma-specific QoL over time. 


\section{Introduction}

Respiratory symptoms have a significant influence on the daily life of children with asthma. Therefore, monitoring of both asthma control and quality of life (QoL) is important. However, international and national guidelines briefly mention optimal QoL as an important objective in asthma management, but offer no guidance on how or when to base clinical decisions on asthma-specific QoL. ${ }^{1-3}$

Since guidelines recommend medication titration predominantly based on asthma control, additional knowledge about the relationship between paediatric asthma control and asthmaspecific QoL longitudinally is important. ${ }^{1-3}$ To date, published data show that asthma control was correlated to asthma-specific QoL in a cross-sectional way, but several important questions remain. First, the longitudinal association between asthma control and asthma-specific QoL is unclear. ${ }^{4-12}$ Second, there is no information available about the course and variation of asthma-specific QoL in children. This information may give insight into the frequency with which asthma-specific QoL should be monitored in clinical care. Third, in some studies, overlap of questions in the instruments that were used to measure control and asthma-specific QoL could have overestimated the correlation between these 2 variables. Fourth, very little is known about the longitudinal relationship between asthma-specific QoL and clinical asthma characteristics such as the use of rescue medication, daily dose of inhaled corticosteroids, exacerbation rate, lung function, atopy, airway inflammation (e.g. Fractional exhaled Nitric Oxide (FeNO) levels), and bronchial hyperresponsiveness.

Although it is generally assumed that these asthma characteristics affect QoL, there are no longitudinal data in children to confirm this.

The objectives of this study are to determine the association over time:

1. between asthma control and asthma-specific QoL;

2. between clinical asthma characteristics (e.g. daily dosage of inhaled corticosteroids, lung function impairment, use of rescue medication, FeNO, occurrence of asthma exacerbations) and asthma-specific QoL.

\section{Methods}

\section{Study design and patients}

Children with persistent asthma aged 6-17 years were included in this one-year longitudinal cohort study (clinicaltrial.gov NCT 01239238). Patients were recruited at the outpatient clinics of 2 clinical centres (Sittard and Maastricht) in the Netherlands. All asthmatic children were treated at the outpatient clinic of these 2 specialized paediatric pulmonology centres for at least 6 months and had received inhaled corticosteroids (ICS) in the year preceding the study. 
All children met the Global Initiative for Asthma (GINA) criteria and the criteria of the Dutch Society of Paediatrics for an asthma diagnosis: 1) recurrent episodes of wheezing, coughing, breathlessness, or chest tightness ${ }^{1,3} ; 2$ ) reversibility to a bronchodilator defined as an increase in forced expiratory volume in 1 second $\left(\mathrm{FEV}_{1}\right)$ of $\geq 9 \%$ of predicted value ${ }^{3,13}$; and/or 3 ) bronchial hyperresponsiveness to histamine defined as a $20 \%$ drop in $\mathrm{FEV}_{1}$ after inhalation of histamine $\leq 8 \mathrm{mg} / \mathrm{ml} .{ }^{3}$ Patients were excluded in the case of cardiac abnormalities, mental retardation, congenital abnormalities or existence of a syndrome, active smoking, immunotherapy or no technical satisfactory performance of lung function measurements.

For this study, ethical approval was obtained by the Medical Ethical Committee of the Maastricht University Medical Centre. All parents and children aged twelve years and older signed an informed consent form before the start of the study.

\section{Study parameters}

Every 2 months, regular outpatient visits at the hospital took place. During these clinical visits, measurements of asthma control, lung function, FeNO and asthma-specific QoL were taken by a trained research nurse or a medical doctor.

\section{Questionnaires on asthma control and asthma-specific QoL}

Asthma control was assessed by using 2 methods: 1) Asthma Control Questionnaire (ACQ) and 2) based on the GINA criteria. ${ }^{14,15}$ The following cut-off points for level of control were used: $A C Q \leq 0.75$ controlled asthma; $0.75<A C Q \leq 1.5$ partly controlled; $A C Q>1.5$ uncontrolled asthma. In addition, asthma control level during the previous 2 weeks was assessed by scoring symptoms in combination with $\mathrm{FEV}_{1}$ assessment, as recommended in the GINA Asthma management and prevention - guidelines. ${ }^{1}$

To assess the asthma-specific QoL, children completed the Paediatric Asthma Quality of Life Questionnaire (PAQLQ). ${ }^{7,10,16}$ The standardized version of PAQLQ contains 23 questions in 3 domains, i.e., activity limitations, symptoms and emotional function. The range in scores is from 1-7, which represents poor to good asthma-specific QoL.7 All children completed the $A C Q$ and PAQLQ by themselves, so interference of parents was avoided as much as possible.

\section{FeNO}

Children performed a FeNO online measurement using a NIOX analyser (NIOX MINO, Aerocrine, Solna, Sweden) according to ATS/ERS standards. ${ }^{17}$

\section{Dynamic spirometry and reversibility}

Patients were instructed to stop short-acting bronchodilators at least 8 hours, and longacting bronchodilators at least 48 hours before measurement. First, dynamic spirometry was performed by means of the ZAN 100 spirometer, according to ATS/ERS standards (nSpire Health $\mathrm{GmbH}$, Oberthulba, Germany). ${ }^{18}$ The highest value of 3 correctly performed maximal 
expiratory flow volume (MEFV) curves was used for analysis. Recorded parameters included $\mathrm{FEV}_{1}$, forced vital capacity (FVC), and maximum expiratory flow at $50 \%$ of FVC $\left(\mathrm{MEF}_{50}\right)$, all expressed as a percentage of the predicted value. Second, the patient inhaled $400 \mu \mathrm{g}$ Salbutamol, and after 15 minutes lung function measurements were repeated in order to test for reversibility to a bronchodilator.

\section{Bronchial hyperresponsiveness}

Bronchial hyperresponsiveness at baseline was evaluated by the histamine challenge test. ${ }^{19}$ At first, an aerosol of buffered saline was inhaled, followed by aerosols of histamine solutions with doubling of concentrations from $0.03 \mathrm{mg} / \mathrm{mL}$ to $16 \mathrm{mg} / \mathrm{mL}$, at intervals of 5 minutes. The FEV 1 was measured at 30,90 and 120 seconds after completed inhalation. The percentage decline in $\mathrm{FEV}_{1}$ was calculated and the test was stopped when a drop of $20 \%$ in FEV 1 occurred $\left(\mathrm{PC}_{20}\right)$, or the highest concentration of $16 \mathrm{mg} / \mathrm{mL}$ was administered. The $\mathrm{PC}_{20}$ threshold was calculated from a log concentration versus dose response curve. After reaching the threshold, children inhaled 800 microgram salbutamol, followed by 3 MEFV curves.

\section{Atopy}

Sensitization to allergens was objectified by the Phadiatop (Phadia, Uppsala, Sweden), RAST (Pharmacia, Uppsala, Sweden) or Allergen Skin test. These tests were performed preceding the study or at baseline.

\section{Definition of exacerbation}

The definition of an asthma exacerbation was based on the latest ATS/ERS guideline. ${ }^{20}$

\section{ISAAC questionnaire}

Parents completed electronically the ISAAC questionnaire (International Study of Asthma and Allergies in Childhood). ${ }^{21}$ The items focusing on asthma symptoms were used for statistical analysis. $94 \%$ of all parents completed the ISAAC questionnaire.

\section{Exposure to second-hand smoke}

Parental smoking was assessed using an electronic questionnaire, which was completed by $94 \%$ of all parents. Passive smoking or exposure to second-hand smoke was defined as smoking of one or both parents in the presence of the child.

\section{Medication titration}

Patients were treated according to the GINA guideline. ${ }^{1}$ Medication titration was performed on the basis of asthma control levels based on the GINA criteria (table 3.1). 
Table 3.1 Criteria for medication titration (step-up, no change or step-down)

Step up
Uncontrolled asthma in 1 visit, or
Partly controlled asthma during 2 consecutive visits

\section{No change in treatment}

One visit controlled asthma, or

One visit partly controlled asthma

\section{Step down}

Two consecutive visits controlled asthma

\section{Data collection}

The collected data were checked and cleaned by an independent monitoring board (Clinical Trial Centre Maastricht). All recorded data during visits were stored in a secured database. In addition, all electronic questionnaires were completed at home.

\section{Data analysis}

Description of baseline characteristics occurred as follows: numerical variables were expressed as mean and standard deviation (SD), or as median and inter quartile ranges (IQR, i.e. $25^{\text {th }}-75^{\text {th }}$ percentile); categorical variables were expressed as numbers and percentages. Variation of baseline PAQLQ scores for different asthma control levels was described as mean and standard deviation. In addition, at baseline the coefficient of variation was calculated for each asthma control level ( $C V=$ mean/standard deviation).

To control for interdependency between repeated measurements in the same participant, linear mixed models were used. ${ }^{22}$ All participants were included in the analysis, also children who dropped out during the study. In the mixed models, the PAQLQ total scores and thereafter the domains were included as dependent variable. First, the course of PAQLQ scores during the study was tested for significance in a simple model without correction of any clinical variable. Second, in order to analyse the association between asthma control and the PAQLQ scores, the ACQ and the GINA asthma control levels were included as an independent variable separately. Third, clinical characteristics $\mathrm{FEV}_{1}$ percentage of predicted value and $\beta_{2}$-agonist use were included in a new model, while asthma control was excluded. Asthma symptoms represent 1 domain of the PAQLQ; therefore, symptoms were not included as a separate independent variable in any model. Besides, in all models age, sex, trial site, season, bronchial hyperresponsiveness, atopy, exposure to second-hand smoke, FeNO, inhaled daily dose of corticosteroids were included as independent variables. The $p$-values $<0.05$ were considered significant. Data were analysed using SPSS 20 (SPSS Inc., Chicago IL, USA). 


\section{Results}

\section{Patient characteristics}

A total number of 96 children with asthma participated in this longitudinal study. The majority of subjects were atopic, experienced a relatively good asthma-specific QoL, and had severe bronchial hyperresponsiveness despite the use of a moderate daily dose of inhaled corticosteroids. Active parental smoking was reported in $26 \%$ of the children, whereas exposure to second-hand smoke was reported in $8 \%$ of the children (table 3.2). There were no clinical important differences in baseline characteristics between the 2 centres.

Table 3.2 Patient baseline characteristics of total population $(n=96)$

\begin{tabular}{|c|c|}
\hline Mean age [range], in years & $10[6-17]$ \\
\hline Sex male/female, $\mathrm{n}$ & $50 / 46$ \\
\hline ACQ score, median [IQR] & $0.6[0.3-1]$ \\
\hline PAQLQ total score, median [IQR] & $6.4[5.9-6.7]$ \\
\hline Symptoms domain, median [IQR] & $6.4[5.5-6.7]$ \\
\hline Activity limitations domain, median [IQR] & $6.2[5.3-6.6]$ \\
\hline Emotional functioning domain, median [IQR] & $6.9[6.5-7.0]$ \\
\hline FeNO, ppb: median [IQR] & $12.5[8.0-31.0]$ \\
\hline $\mathrm{FEV}_{1} \%$ predicted, mean $\pm \mathrm{SD}$ & $96.8 \pm 14.2$ \\
\hline Reversibility, increase in $\mathrm{FEV}_{1} \%$ predicted: mean $\pm \mathrm{SD}$ & $6.6 \pm 8.5$ \\
\hline ICS dose of inhaled fluticasone or equivalent, mean \pm SD $^{*}$ & $269 \pm 175$ \\
\hline $\mathrm{PC}_{20}, \mathrm{mg} / \mathrm{mL}:$ median $[\mathrm{IQR}]^{\dagger}$ & $1.2[0.3-2.9]$ \\
\hline Atopic, $\mathrm{n} \%{ }^{\ddagger}$ & 76 \\
\hline Wheezing episodes past year, \% & 58 \\
\hline Parental smoking, \% & 26 \\
\hline Exposure to second-hand smoke, $\%$ & 8 \\
\hline
\end{tabular}

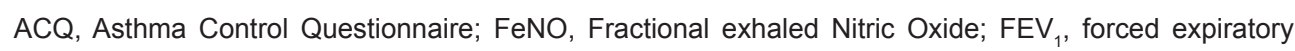
volume in 1 second; ICS, Inhaled corticosteroids; IQR, Inter Quartile Range; PAQLQ, Paediatric Asthma Control Quality of Life Questionnaire; SD, Standard Deviation.

* $94 \%$ of the children used ICS at baseline.

${ }^{+} \mathrm{PC}_{20}$ : concentration of histamine inducing a $20 \%$ drop in $\mathrm{FEV}_{1}$.

${ }^{\ddagger}$ Atopy is defined as a positive Phadiatop (Phadia, Uppsala, Sweden), or a positive allergen skin test.

\section{Course and variability of asthma-specific QoL during the study}

Overall asthma-specific QoL and asthma control improved during the year ( $p$-value $<0.01$ ) (figure 3.1). The mean level of the symptoms and activity limitations domain was lower than the level of the emotional functioning domain (figure 3.1), this emotional functioning domain showed in $46 \%$ of the children a maximum score of 7 at baseline. 
The variability of PAQLQ total scores at baseline was larger in partly or uncontrolled children $(C V=19 \%)$, than in controlled children $(C V=6 \%)$. This variability is also shown in figure 3.2 , where all measurements during the study of all children are included.

Figure 3.1 Overview of the course of PAQLQ and ACQ score during 1 year

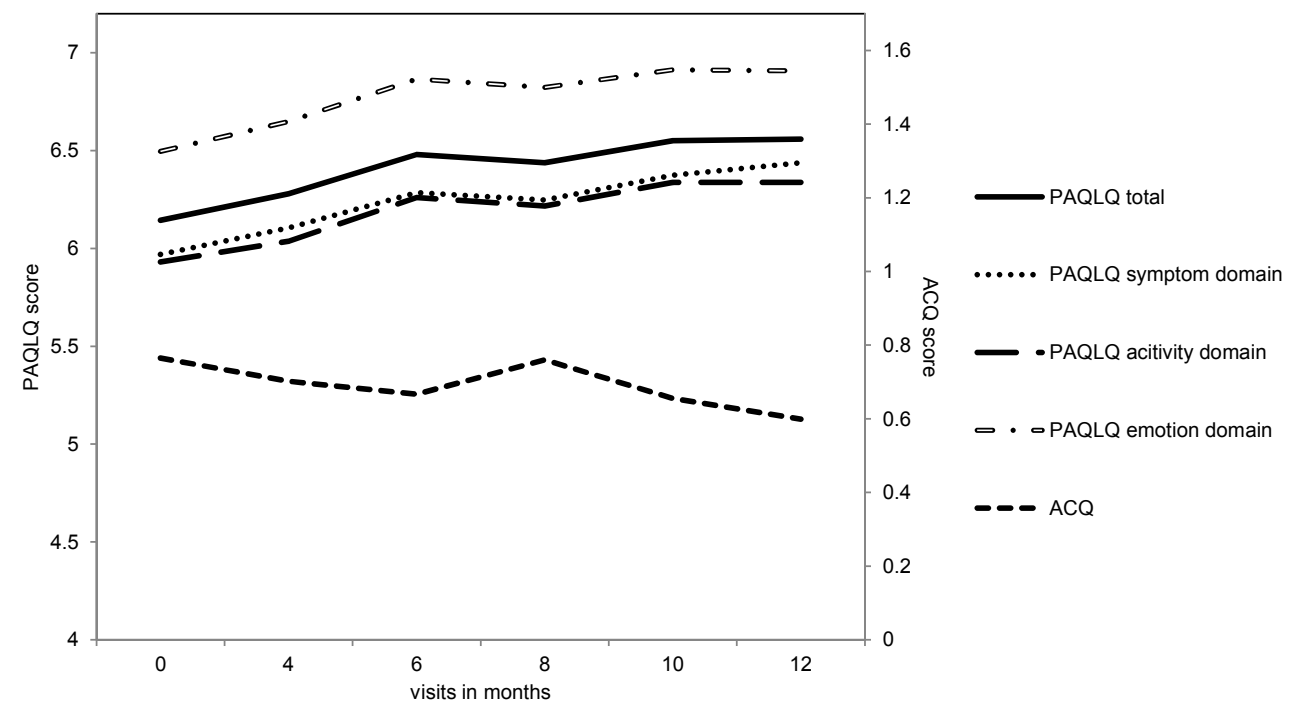




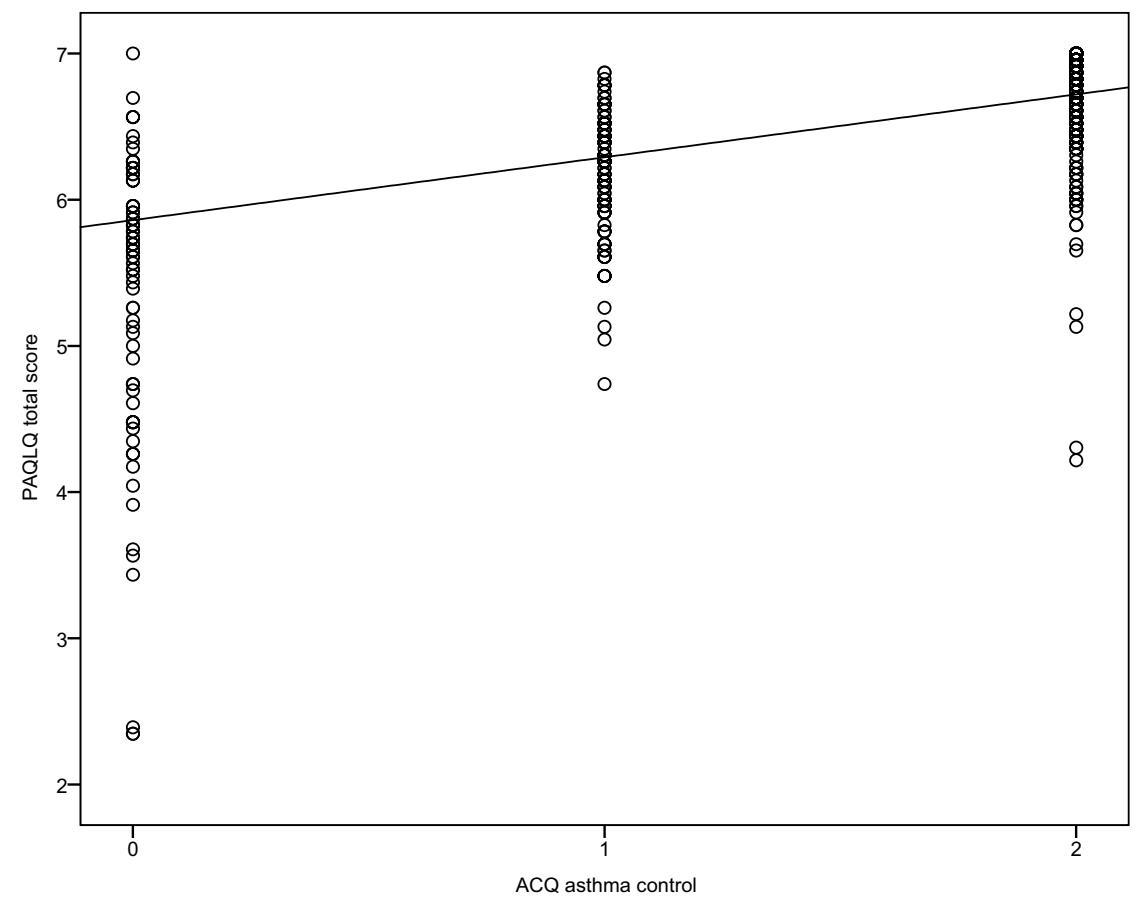

Figure 3.2 Association between ACQ asthma control and PAQLQ total score in a linear mixed model: all measurements during 1 year are included*

* The regression line is based on the model in which the ACQ level of asthma control is included; the estimates of this model are given in table 3.3a. For factors in the equation other than ACQ asthma control, mean values were used. $A C Q$ asthma control: $0=$ uncontrolled, $1=$ partly controlled, $2=$ controlled

\section{Association between asthma control and PAQLQ scores during 1 year follow-up}

Asthma control based on ACQ had the strongest longitudinal association with PAQLQ total scores compared to occurrence of wheezing episodes in the preceding year and the occurrence of an exacerbation in the previous 2 months ( $p$-value (estimate); <0.01 (0.43)) (table 3.3a). The estimate of 0.43 means that an improvement of asthma control from uncontrolled to partly controlled or from partly controlled to controlled resulted in an increase of the PAQLQ total score of 0.43 . Therefore, deterioration of asthma control from controlled to uncontrolled was associated with a clinically relevant decrease in PAQLQ total score of 0.86 . Also with PAQLQ subdomains, asthma control had the strongest association of all clinical characteristics. The estimates for the subdomains were highest for the symptoms, activity limitation and, small but significant for the emotional functioning domain ( $p$-value (estimate) $[95 \% \mathrm{Cl}]$; <0.01 $(0.05)$ $[0.03,0.08]$ ) (not in table 3.3a). 
뭏ํㅎㅎำ
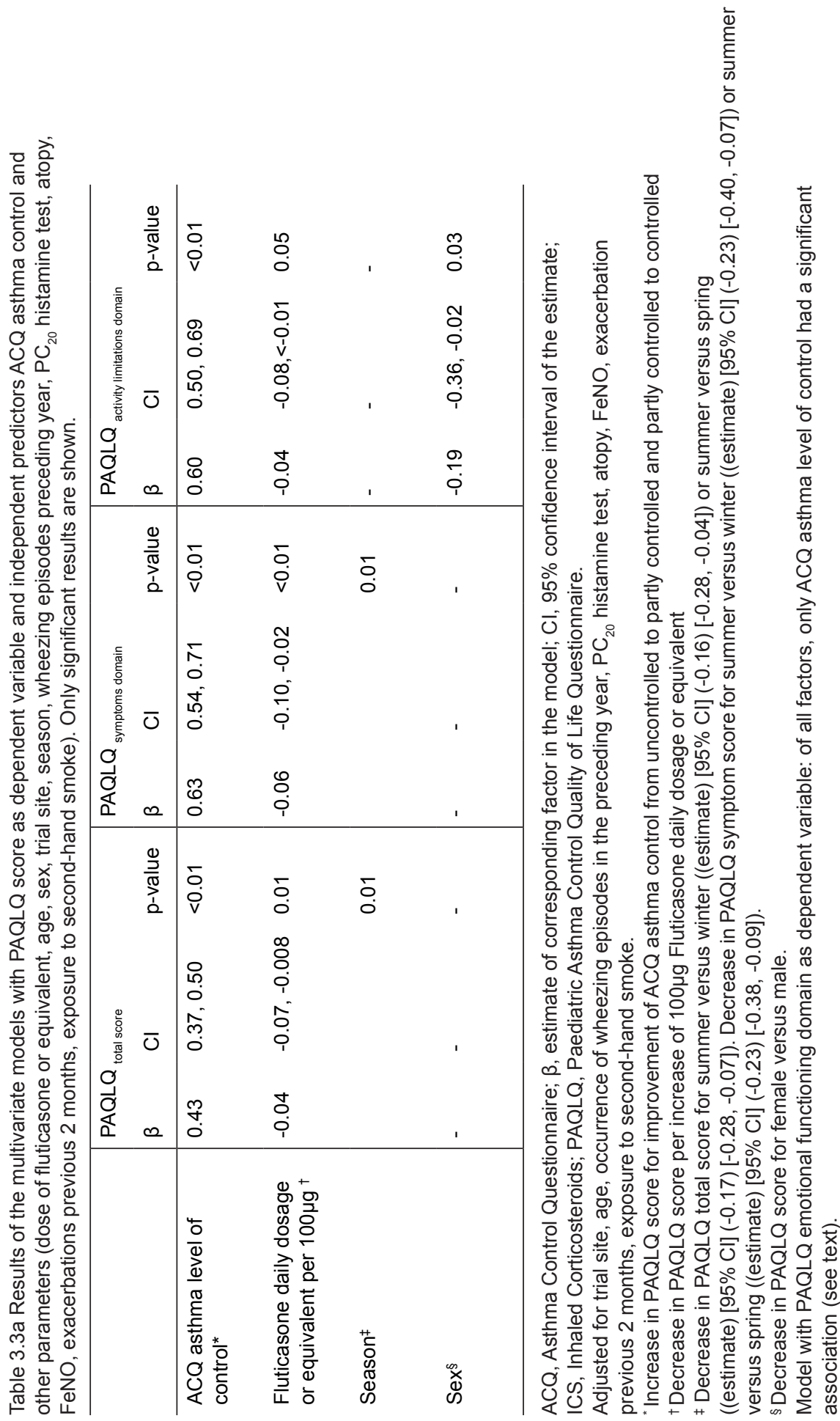
We also performed an analysis with asthma control according to the GINA criteria. Similarly to asthma control based on the ACQ, a strong association longitudinally with the PAQLQ total score and a comparable pattern for the PAQLQ domains was found (table 3.3b). Additionally, occurrence of wheezing episodes in the preceding year was associated with PAQLQ total score. Of all PAQLQ domains, the emotional functioning domain had the smallest association with asthma control based on the GINA criteria (p-value (estimate) [95\% Cl]; <0.01 (0.09) [0.05, 0.13]) (not in table 3.3b). All models were adjusted for clinical characteristics as described in the method section.

\section{Factors independently related to PAQLQ scores during 1 year follow-up}

Finally, a model consisting of all predefined clinical characteristics except the ACQ or the GINA asthma control showed that 3 factors were independently associated with a decrease in PAQLQ total scores: 1) an increased use of $\beta_{2}$-agonists (table 3.4 and figure 3.3 ), 2) occurrence of wheezing episodes in the year preceding the study and, 3) occurrence of an asthma exacerbation in the 2 months preceding the PAQLQ assessments (table 3.4). Although $\mathrm{FEV}_{1}$ percentage of predicted value was also significantly associated with the PAQLQ total score, the estimates were small ( $p$-value (estimate); $<0.01(0.05)$ ) (table 3.4 , figure 3.4 ). The daily dose of inhaled corticosteroids and FeNO levels were not longitudinally associated with PAQLQ scores (table 3.4). In contrast to the model in which the asthma control was included, no factor in this model was associated with the PAQLQ emotional functioning domain. 


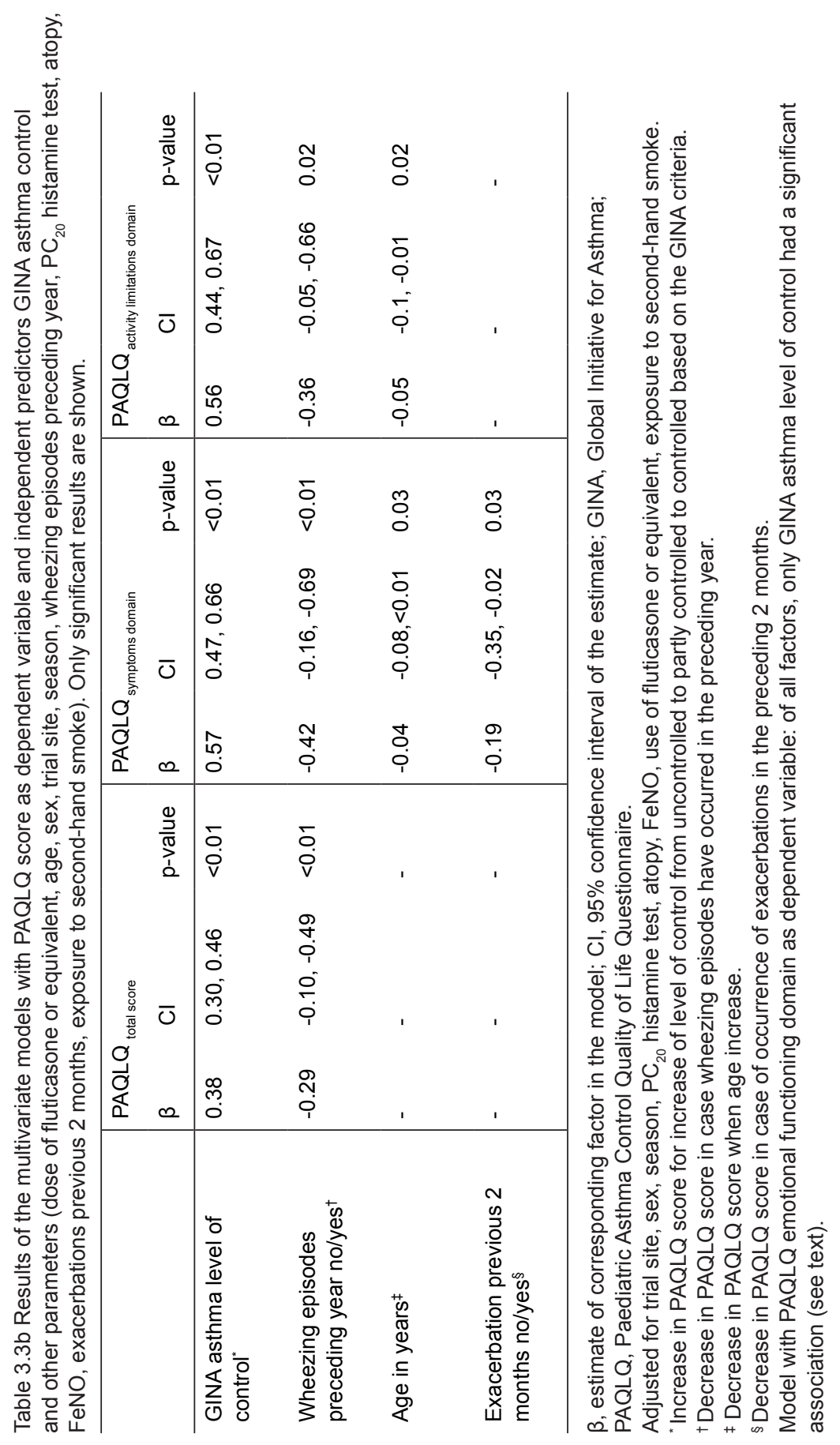




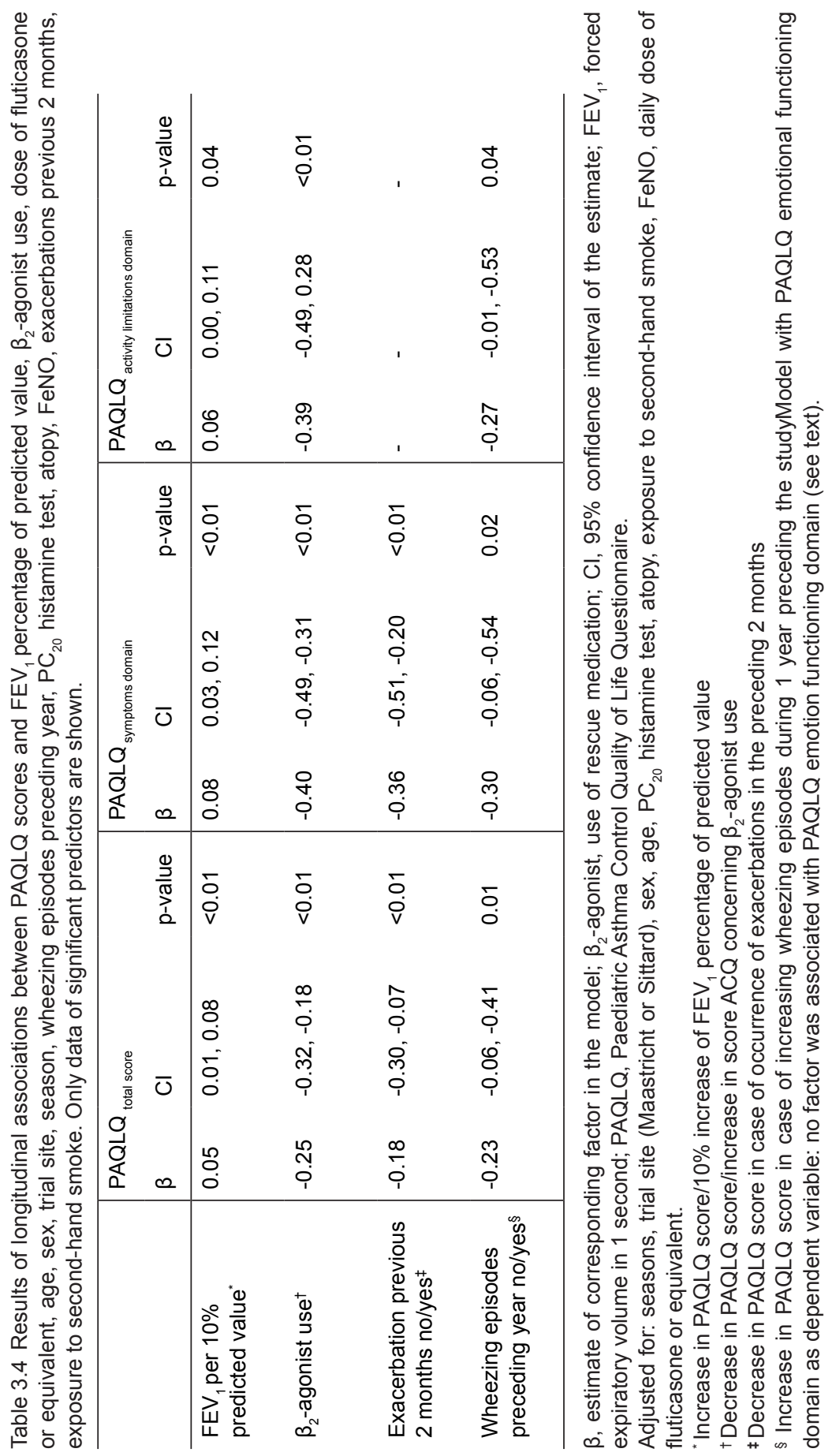




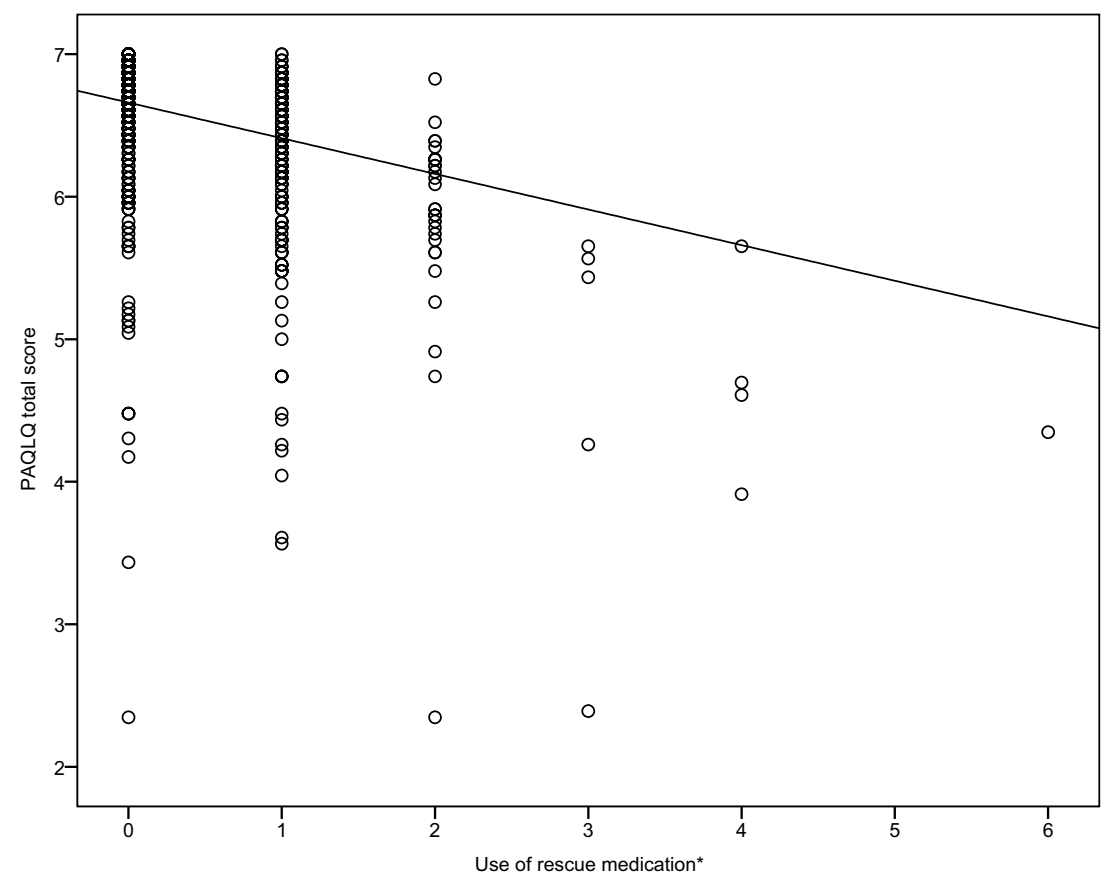

Figure 3.3 Association between $\beta_{2}$-agonist use and PAQLQ total score in a linear mixed model: all measurements during 1 year are included ${ }^{\dagger}$

* Use of rescue medication during the week preceding the clinical visit: $0=0$ puffs most days, $1=1-2$ puffs most days, $2=3-4$ puffs most days, $3=5-8$ puffs most days, $4=9-12$ puffs most days, $5=13-16$ puffs most days, $6=$ more than 16 puffs most days.

$\dagger$ The regression line is based on the model in which the asthma control levels were excluded, the estimates of this model are given in table 3.4. For factors in the equation other than use of rescue medication, mean values were used. 


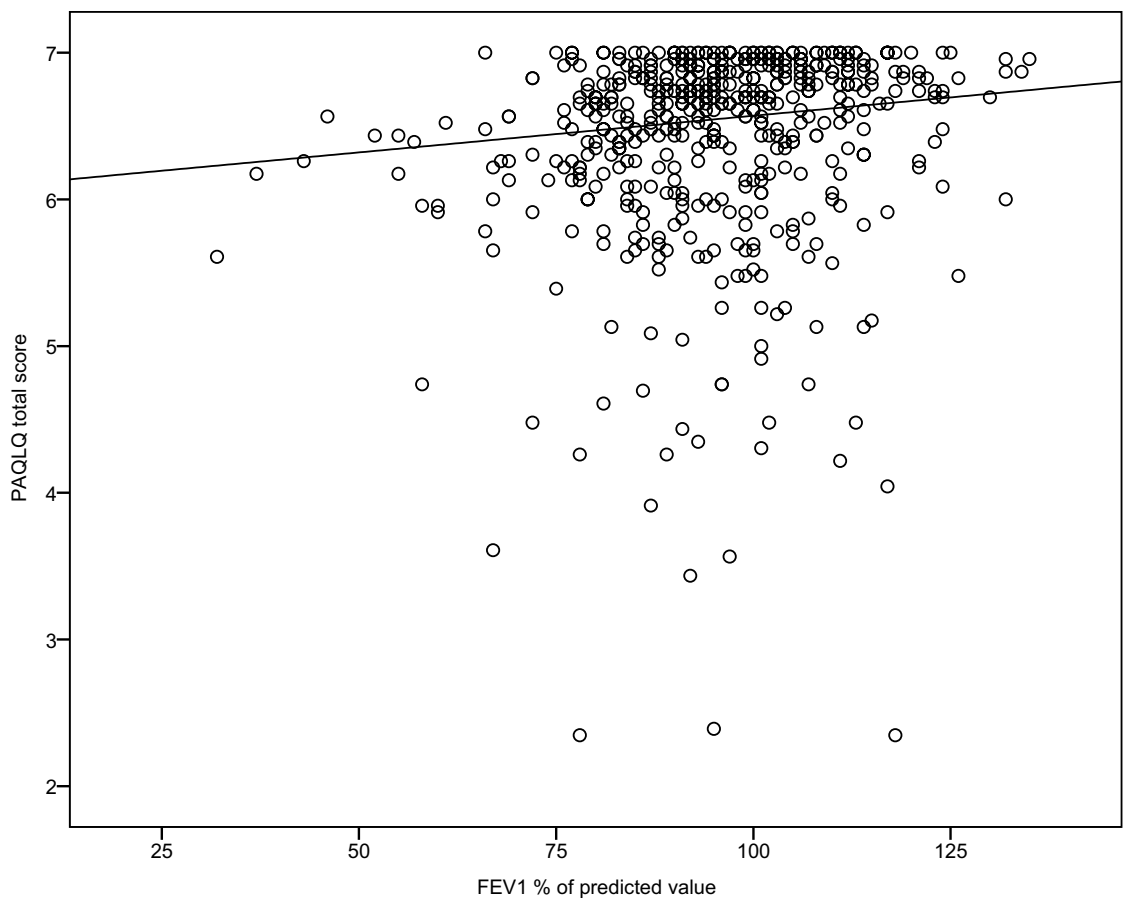

Figure 3.4 Association between lung function and PAQLQ total score in a linear mixed model: all measurements during 1 year are included*

* The regression line is based on the model in which the asthma control levels were excluded, the estimates of this model are given in table 3.4. For factors in the equation other than $\mathrm{FEV}_{1}$ percentage of predicted value, mean values were used. 


\section{Discussion}

Deterioration of asthma control was associated with a clinically relevant decrease in paediatric asthma-specific QoL (PAQLQ) score during 1 year. In addition, the level of asthma control as assessed by the ACQ and according to the GINA criteria, were to the same extent independently related to asthma-specific QOL. Moreover, we found that an increase in $\beta_{2}$ agonist use, occurrence of an exacerbation in the previous 2 months, and the occurrence of wheezing episodes in the preceding year were associated with a decrease in paediatric asthma-specific QoL. Of all domains, asthma control was most strongly associated with the symptoms and activity limitations domain and weakly associated with the emotional functioning domain of the PAQLQ.

This prospective study showed that $\beta_{2}$-agonist use, the occurrence of an exacerbation in the previous 2 months and the occurrence of wheezing episodes in the preceding year were related to paediatric asthma-specific QoL. Lung function impairment as assessed by the $\mathrm{FEV}_{1}$ percentage of predicted value had a weak association with asthma-specific QoL. This finding is in line with a meta-analysis which determined the degree of association between lung function and subjective measures in 8994 children and adults from 27 randomized controlled trials. ${ }^{23}$ In this meta-analysis, there was a moderate correlation found between lung function and asthma-specific QoL comparing time points 0 and 12 weeks. ${ }^{23}$ Moreover, we found no association between a measure of airway inflammation (FeNO) and asthma-specific QoL. This finding is consistent with findings of De Jongste et al. in a study of 151 children with atopic asthma, in which medication was titrated based on FeNO plus symptom telemonitoring, or symptom monitoring only. ${ }^{24}$ Daily FeNO monitoring did not improve asthma control or asthmaspecific QoL completed by caregivers. ${ }^{24}$ Furthermore, the association between asthma level of control and asthma-specific QoL we found is consistent with other studies focusing on asthma-specific QoL in children.-11,25

A strength of our longitudinal study is that it provides insight into the longitudinal associations between clinical asthma characteristics and asthma-specific QoL. This is valuable information since asthma is a chronic disease. ${ }^{26}$ Furthermore the PAQLQ questionnaire in this study was completed by children and not by their parents. This is preferable, because previous studies have shown that parents are not able to indicate the quality of life of their child. ${ }^{27,28} \mathrm{~A}$ limitation of our study may be the absence of additional demographic parameters. However, we predefined 1 factor with a negative influence on asthma that is associated with social economic status, namely exposure to second-hand smoke. Another limitation may be the relatively high emotional functioning domain scores at baseline. This may limit the possibility to find associations with other variables over time. However, in this study, a significant increase in PAQLQ total scores was demonstrated and significant associations with asthma control 
were found for this total score and the other domains.

How can the findings of our study be explained? First, there is a close association between asthma control and asthma-specific QoL, suggesting that the actual level of disease control determines to a large extent the perceived disease specific QoL. However, we also found that asthma control and asthma-specific QoL are not mutually interchangeable. These variables reflect 2 different aspects of asthma as shown in figure 3.2; at a certain level of asthma control, there is still a considerable variation in levels of asthma-specific QoL, even in children with controlled asthma. Second, the increase in the PAQLQ total scores in this study could be a study effect. This may be explained by the strict titration of asthma medication based on the GINA criteria every 2 months. This explanation is supported by our finding that asthma control levels also improved during the 1 year study period and these were independently related to PAQLQ total scores. Third, we found that wheezing episodes in the year preceding the study, the occurrence of exacerbations in the 2 months prior to the clinical visit and use of $\beta_{2}$-agonist were related to a lower asthma-specific QoL. These findings confirm that exacerbations have significant impact on the experienced well-being of children with asthma. It is known that exacerbations often require urgent care or even emergency care visits, and are a source of anxiety and uncertainty in both children and parents. More use of $\beta_{2}$-agonist will be linked to an increase in asthma symptoms, to limitations in physical activity and possibly to extra clinical visits. ${ }^{1}$ This appeared to have a negative influence on asthma-specific QoL in this longitudinal study. Fourth, in contrast to use of $\beta_{2}$-agonist, we found no substantial influence of the daily dose of inhaled corticosteroids on asthma-specific QoL. This is probably because the ICS dose is more correlated to the chronic course of the disease and has no direct symptomrelieving effect, whereas $\beta_{2}$-agonist are more related to acute increases in disease activity and have a direct effect on symptoms. Moreover, the side effects of ICS are often mild.

The findings of our study imply that in persistent paediatric asthma, the level of asthma control or the presence of other clinical characteristics cannot be used as a substitute of asthmaspecific QoL. We found an association between asthma control based on ACQ and all PAQLQ domains. However, some children with controlled asthma had relatively low asthma-specific QoL (figure 3.2). Therefore, our results should encourage doctors to measure asthma-specific QoL in children during clinical contacts independently of asthma control levels. In the future, more data on how to optimize asthma-specific QoL in children with asthma are needed.

In conclusion, in this longitudinal study we found a strong relationship between paediatric asthma-specific QoL and asthma control. Moreover, increase of $\beta_{2}$-agonist use, occurrence of wheezing episodes in the year preceding the study, and occurrence of an asthma exacerbation during the study were negatively related to asthma-specific QoL in children. 


\section{References}

1. Global strategy for asthma management and prevention. Global Initiative for Asthma (GINA) 2012 [cited; Available from: ginasthma.org/local/uploads/files/GINA_Report_March13.pdf

2. National Heart Lung and Blood Instutute NAEaPP. Expert panel Report 3: Guidelines for the diagnosis and management of asthma. 2007.

3. de Jongste JC. Astma bij kinderen; herziene richtlijnen van de sectie kinderlongziekten van de NVK [Asthma in children; revised guidelines of the paediatric department of the Dutch Paediatric Society], Amsterdam, 2007.

4. Burkhart PV, Svavarsdottir EK, Rayens MK, Oakley MG, Orlygsdottir B. Adolescents with asthma: predictors of quality of life. J Adv Nurs 2009: 65(4): 860-866.

5. Dean BB, Calimlim BC, Sacco P, Aguilar D, Maykut R, Tinkelman D. Uncontrolled asthma: assessing quality of life and productivity of children and their caregivers using a cross-sectional Internet-based survey. Health Qual Life Outcomes 2010: 8: 96.

6. Gandhi PK, Kenzik KM, Thompson LA, DeWalt DA, Revicki DA, Shenkman EA, Huang IC. Exploring factors influencing asthma control and asthma-specific health-related quality of life among children. Respiratory research 2013: 14: 26.

7. Juniper EF, Guyatt GH, Feeny DH, Ferrie PJ, Griffith LE, Townsend M. Measuring quality of life in children with asthma. Qual Life Res 1996: 5(1): 35-46.

8. Juniper EF, Wisniewski ME, Cox FM, Emmett AH, Nielsen KE, O'Byrne PM. Relationship between quality of life and clinical status in asthma: a factor analysis. The European respiratory journal 2004: 23(2): 287-291.

9. Okelo SO, Wu AW, Krishnan JA, Rand CS, Skinner EA, Diette GB. Emotional quality-of-life and outcomes in adolescents with asthma. J Pediatr 2004: 145(4): 523-529.

10. Raat H, Bueving HJ, de Jongste JC, Grol MH, Juniper EF, van der Wouden JC. Responsiveness, longitudinal- and cross-sectional construct validity of the Pediatric Asthma Quality of Life Questionnaire (PAQLQ) in Dutch children with asthma. Qual Life Res 2005: 14(1): 265-272.

11. Schmier JK, Manjunath R, Halpern MT, Jones ML, Thompson K, Diette GB. The impact of inadequately controlled asthma in urban children on quality of life and productivity. Annals of allergy, asthma \& immunology : official publication of the American College of Allergy, Asthma, \& Immunology 2007: 98(3): 245-251.

12. Annett RD, Bender BG, Skipper B, Allen C. Predicting moderate improvement and decline in pediatric asthma quality of life over 24 months. Qual Life Res 2010: 19(10): 1517-1527.

13. Dales RE, Spitzer WO, Tousignant P, Schechter M, Suissa S. Clinical interpretation of airway response to a bronchodilator. Epidemiologic considerations. Am Rev Respir Dis 1988: 138(2): 317320.

14. Juniper EF, Gruffydd-Jones K, Ward S, Svensson K. Asthma Control Questionnaire in children: validation, measurement properties, interpretation. The European respiratory journal 2010: 36(6): 1410-1416.

15. Juniper EF, O'Byrne PM, Guyatt GH, Ferrie PJ, King DR. Development and validation of a questionnaire to measure asthma control. The European respiratory journal 1999: 14(4): 902-907.

16. Juniper EF, Svensson K, Mork AC, Stahl E. Modification of the asthma quality of life questionnaire (standardised) for patients 12 years and older. Health Qual Life Outcomes 2005: 3: 58.

17. American Thoracic S, European Respiratory S. ATS/ERS recommendations for standardized procedures for the online and offline measurement of exhaled lower respiratory nitric oxide and nasal nitric oxide, 2005. American journal of respiratory and critical care medicine 2005: 171(8): 912-930.

18. Miller MR, Hankinson J, Brusasco V, Burgos F, Casaburi R, Coates A, Crapo R, Enright P, van der Grinten CP, Gustafsson P, Jensen R, Johnson DC, Maclntyre N, McKay R, Navajas D, Pedersen OF, Pellegrino R, Viegi G, Wanger J, Force AET. Standardisation of spirometry. The European respiratory journal 2005: 26(2): 319-338.

19. Sterk PJ, Fabbri LM, Quanjer PH, Cockcroft DW, O'Byrne PM, Anderson SD, Juniper EF, Malo JL. Airway responsiveness. Standardized challenge testing with pharmacological, physical and sensitizing stimuli in adults. Report Working Party Standardization of Lung Function Tests, 
European Community for Steel and Coal. Official Statement of the European Respiratory Society. The European respiratory journal Supplement 1993: 16: 53-83.

20. Reddel HK, Taylor DR, Bateman ED, Boulet LP, Boushey HA, Busse WW, Casale TB, Chanez P, Enright PL, Gibson PG, de Jongste JC, Kerstjens HA, Lazarus SC, Levy ML, O'Byrne PM, Partridge MR, Pavord ID, Sears MR, Sterk PJ, Stoloff SW, Sullivan SD, Szefler SJ, Thomas MD, Wenzel SE, American Thoracic Society/European Respiratory Society Task Force on Asthma C, Exacerbations. An official American Thoracic Society/European Respiratory Society statement: asthma control and exacerbations: standardizing endpoints for clinical asthma trials and clinical practice. American journal of respiratory and critical care medicine 2009: 180(1): 59-99.

21. Asher MI, Keil U, Anderson HR, Beasley R, Crane J, Martinez F, Mitchell EA, Pearce N, Sibbald B, Stewart AW, et al. International Study of Asthma and Allergies in Childhood (ISAAC): rationale and methods. The European respiratory journal 1995: 8(3): 483-491.

22. Fitzmaurice GM LN, Ware JH. Applied longitudinal analysis, New York, 2004.

23. Carranza Rosenzweig JR, Edwards L, Lincourt W, Dorinsky P, ZuWallack RL. The relationship between health-related quality of life, lung function and daily symptoms in patients with persistent asthma. Respiratory medicine 2004: 98(12): 1157-1165.

24. de Jongste JC, Carraro S, Hop WC, Group CS, Baraldi E. Daily telemonitoring of exhaled nitric oxide and symptoms in the treatment of childhood asthma. American journal of respiratory and critical care medicine 2009: 179(2): 93-97.

25. Petsios KT, Priftis KN, Hatziagorou E, Tsanakas JN, Antonogeorgos G, Matziou VN. Determinants of quality of life in children with asthma. Pediatric pulmonology 2013: 48(12): 1171-1180.

26. Mancuso CA, Peterson MG. Different methods to assess quality of life from multiple follow-ups in a longitudinal asthma study. J Clin Epidemiol 2004: 57(1): 45-54.

27. Annett RD, Bender BG, DuHamel TR, Lapidus J. Factors influencing parent reports on quality of life for children with asthma. The Journal of asthma : official journal of the Association for the Care of Asthma 2003: 40(5): 577-587.

28. Eiser C, Morse R. Can parents rate their child's health-related quality of life? Results of a systematic review. Qual Life Res 2001: 10(4): 347-357. 



\section{Chapter 4}

\section{Exhaled inflammatory markers discriminate between children with persistently controlled and uncontrolled asthma}

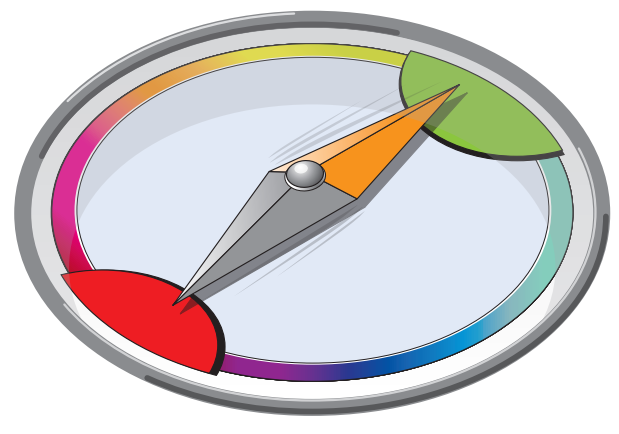

Van Vliet $D^{*}$ Smolinska $A^{*}$ Jöbsis $Q$ Rosias PPR Muris JWM Dallinga JW Van Schooten FJ Dompeling $E$ *Shared first authorship 


\section{Abstract}

\section{Background}

The relationship between exhaled inflammatory markers and asthma control in children is unclear.

\section{Objectives}

1. To explore the association between inflammatory markers in exhaled breath (fractional exhaled nitric oxide (FeNO), exhaled volatile organic compounds (VOCs), different cytokines/chemokines in exhaled breath condensate (EBC)) and asthma control.

2. To assess whether exhaled inflammatory markers are able to discriminate between children with persistently controlled/uncontrolled asthma during subsequent clinical visits.

\section{Methods}

Asthmatic children ( $n=96)$ were followed up in a one-year prospective observational study. Every 2 months, the following parameters were assessed: asthma control, FeNO, lung function $\left(\mathrm{FEV}_{1}, \mathrm{FEV}_{1} / \mathrm{VC}\right)$, VOCs in exhaled breath by means of gas chromatography timeof-flight mass spectrometry, and cytokines/chemokines in EBC (IL-1 $\alpha$, IL-5, IL-6, IL-8, IL-13, IL-17 and TNFa). Random Forrest was used to analyse the relationship between exhaled inflammation markers and asthma control (Asthma Control Questionnaire on a continuous scale and on a dichotomous scale). For each model, patients were randomly selected for a training set and validation set. To assess the accuracy of classification models, receiver operating characteristic-curves (ROC-curves) were generated and sensitivity, specificity were calculated.

\section{Results}

No significant association was found between exhaled inflammation markers and asthma control (on a continuous or dichotomous scale): the area under the ROC curve for asthma level of control was $49 \%$. However, the classification of subgroups of children with persistently controlled or uncontrolled asthma during all clinical visits based on exhaled VOCs resulted in area under ROC-curve of $86 \%$, with a sensitivity of $81 \%$ and a specificity of $67 \%$. Adding FeNO and markers in EBC to this model, did not lead to more accurate classification (area under ROC-curve 87\%).

\section{Conclusion}

There was no association between exhaled inflammatory markers and asthma control in children. However, children with persistently controlled or uncontrolled asthma during subsequent clinical visits could be discriminated by a set of 15 most discriminating VOCs. 


\section{Introduction}

Asthma is characterized by chronic airway inflammation with increased airway responsiveness, resulting in respiratory symptoms and a decrease of lung function. ${ }^{1}$ The level of asthma control is determined by the clinician taking respiratory symptoms, use of rescue medication, limitation in daily activities, and lung function into consideration. ${ }^{2}$ The dose of the asthma medication should be carefully titrated to the minimal dose required to maintain control, in order to reduce the risk of adverse effects. ${ }^{2-4}$ However, in general, symptoms and lung function may not give a complete picture of asthma stability, and in poor perceivers symptoms are not reliable to assess asthma control. ${ }^{5}$

Therefore, the question is whether airway inflammation markers may reflect asthma control levels, or could function as a complementary asthma monitoring tool beside symptoms and lung function. Exhaled breath consists of a complex gas mixture, in which single or multiple inflammation markers can be analysed. Fractional exhaled nitric oxide (FeNO) is a single, extensively studied marker, which is clinically applicable and standardized. ${ }^{6}$ However, results of studies investigating the correlation between FeNO and asthma control or studies investigating the efficacy of FeNO in management of asthma in children are contradictory. ${ }^{7-16}$ Furthermore, the potential of inflammatory markers in exhaled breath condensate (EBC) have been explored, but it is questionable whether these markers are clinically useful in asthma management. ${ }^{7,17,18}$ In addition, the detection of the low concentration of biomarkers in EBC is challenging.

In contrast, exhaled volatile organic compounds (VOCs) could be more easily detected than markers in EBC and have showed potential to predict asthma exacerbations in children. ${ }^{19}$ This suggests that VOCs may reflect airway inflammation and also asthma stability and control. Probably, a set of exhaled VOCs alone or combined with FeNO and markers in EBC, indicate the level of asthma control.

Therefore, the aims of this study are:

1. to explore the association between inflammatory markers in exhaled breath (fractional exhaled nitric oxide (FeNO), exhaled volatile organic compounds (VOCs), different cytokines and chemokines in exhaled breath condensate (EBC)) and asthma control.

2. to assess whether exhaled inflammatory markers are able to discriminate between children with persistently controlled/uncontrolled asthma during subsequent clinical visits. 


\section{Methods}

\section{Participants}

The study consisted of 96 children aged 6-18 years with persistent asthma. All children had daily treatment with inhaled corticosteroids (ICS) during the year preceding the study. Children with an objectified asthma diagnosis according to the Global Initiative for Asthma (GINA) and the guidelines of the Dutch Society of Paediatrics were included in the study ${ }^{20}: 1$ ) presence of asthma symptoms ${ }^{2,4} ; 2$ ) reversibility to a $\beta_{2-}$ agonist defined as an increase in forced expiratory volume in 1 second $\left(\mathrm{FEV}_{1}\right)$ of $\geq 9 \%$ of predicted value $\mathrm{u}^{4,17,21}$; and/or 3 ) presence of bronchial hyperresponsiveness, defined as a $>20 \%$ drop in $\mathrm{FEV}_{1}$ after the inhalation of histamine with a concentration $\leq 8 \mathrm{mg} / \mathrm{ml} .{ }^{4}$ Children were excluded from the study in case of: 1) technically unsatisfactory performance of lung function measurements; 2) presence of cardiac abnormalities; 3) mental retardation; 4) congenital abnormalities or existence of a syndrome; 5) active smoking; or 6) treatment with immunotherapy during the study.

\section{Ethical statement}

Written informed consent was obtained from all parents and from children aged 12 years and older. The study protocol was approved by the Medical Ethical Committee of the Maastricht University Medical Centre.

\section{Study design}

A longitudinal observational study was conducted at the paediatric outpatient department (clinicaltrial.gov NCT 01239238). Participants visited the hospital every 2 months during 1 year. Regular measurements were performed: completion of Asthma Control Questionnaire (ACQ) and the GINA respiratory symptom score, online FeNO assessment, collection of VOCs exhaled breath, collection of EBC, and performance of dynamic spirometry.

\section{Asthma control}

Asthma control was assessed using the ACQ. ${ }^{22}$ The cut-off point for uncontrolled asthma was an ACQ score of $>0.75$. Besides, asthma control was also evaluated according to the GINAcriteria and used to titrate medication. ${ }^{2}$ This assessment was based on a respiratory symptom score (frequency of wheeze, cough or dyspnoea during day or night, number of inhalations of rescue medication and limitations of activities) of the last 2 weeks preceding a clinical visit and lung function ( $\mathrm{FEV}_{1} \%$ of predicted value) at a clinical visit. The clinicians were blinded for the results of the ACQ.

\section{Sampling and analysis of exhaled inflammatory markers}

FeNO was obtained online using a NIOX analyser (NIOX MINO, Aerocrine, Solna, Sweden) according to American Thoracic Society/European Respiratory Society (ATS/ERS) criteria. ${ }^{6}$ 
In order to sample exhaled VOCs children inflated a 5 litre inert bag (Tedlar bag, SKC Ltd, Dorset, UK) as reported previously. ${ }^{23}$ Children were asked to inhale deeply and exhale slowly through a resistant free valve. All sample collections took place in the same room. Directly after inflation of the bag, the exhaled VOCs were stored in air-tight capped tubes containing active carbon (carbograph 1 TD/CarbopackX, Markes International, Llantrisant, Wales, UK). Before reuse the Tedlar bags were flushed twice with nitrogen, as described previously. ${ }^{23}$ Chemical analysis was performed with gas chromatography-time-of-flight-mass spectrometry (GC-TOF-MS). ${ }^{24,25}$ The following 3 phases were passed: 1) heating of the tubes to $270^{\circ} \mathrm{C}$ in order to release captured VOCs; 2) separation of VOCs by GC; and 3) detection of VOCs by TOF-MS.

To collect EBC an optimized borosilicate glass condenser system was used. ${ }^{17}$ The collection procedure of EBC took 10 minutes, as described previously. ${ }^{17}$ Immediately after collection of $\mathrm{EBC}$, the acidity of $\mathrm{EBC}$ was measured without de-aeration ( $\mathrm{pHenominal}$ handheld $\mathrm{pH}$-meter, typePH1000H, and Sentix mic-micro-S7 pH sensor, VWR International B.V., NL, Germany). Inflammatory markers IL-1a, IL-5, IL-6, IL-8, IL-13, IL-17 and TNF $\alpha$ in EBC were determined using a commercially available high sensitivity bead-based flow immunoassays with the BioPlex 100 analyser (Millipore, St Charles, MO, USA), as previously described. ${ }^{26}$

\section{Dynamic spirometry and reversibility}

Maximal expiratory flow volume (MEFV) curves were measured by means of ZAN 100 spirometer (nSpire Health $\mathrm{GmbH}$, Oberthulba, Germany), according to ATS/ERS standards. ${ }^{27}$ Short-acting bronchodilators were withheld 8 hours and long-acting bronchodilators 48 hours before testing. The highest value of 3 correctly performed manoeuvres was used for analysis. Subsequently, $400 \mu \mathrm{g}$ salbutamol was administered via a spacer. After 15 minutes, 3 MEFV curves were obtained again, in order to assess the response in $\mathrm{FEV}_{1}$ after administration of a $\beta_{2}$-agonist.

\section{Bronchial hyperresponsiveness}

Bronchial hyperresponsiveness was determined by a bronchial histamine challenge test. ${ }^{27}$ After inhalation of an aerosol of buffered saline, aerosols of histamine solutions were inhaled with doubling concentrations from $0.03 \mathrm{mg} / \mathrm{mL}$ to $16 \mathrm{mg} / \mathrm{mL}$, at intervals of 5 minutes. $\mathrm{FEV}_{1}$ was measured at 30,90 and 120 seconds after a complete inhalation of a solution. Bronchial challenge test was stopped when $\mathrm{FEV}_{1}$ dropped $20 \%$ or more $\left(\mathrm{PC}_{20}\right)$, or when the highest concentration of $16 \mathrm{mg} / \mathrm{mL}$ histamine was inhaled. The provocative concentration that led to $20 \%$ drop of $\mathrm{FEV}_{1}$ was calculated by linear interpolation of the last 2 points on the log doseresponse curve. After reaching the threshold, children inhaled 800 microgram salbutamol, followed by 3 MEFV manoeuvres. 


\begin{abstract}
Atopy
Criteria for presence of atopy were a reported positive Phadiatop® (Phadia, Uppsala, Sweden), Radio Allergo Sorbent Test (RAST) (Pharmacia, Uppsala, Sweden) or Allergen Skin test.
\end{abstract}

\title{
Asthma treatment protocol during study
}

Asthma medication was adjusted based on the GINA asthma level of control. ${ }^{2}$ Other parameters namely FeNO, exhaled VOCs or markers in EBC were not taken into account. The medication titration steps were performed according to the GINA guidelines and the guidelines of the Paediatric Pulmonology section of the Dutch Society of Paediatrics. ${ }^{2,4}$ If children had controlled asthma during 2 consecutive clinical visits, ICS were tapered off. Step up took place in case of partly controlled asthma during 2 consecutive clinical visits or uncontrolled asthma during 1 clinical visit.

\section{Statistical data analysis}

The output of GC-TOF-MS was first pre-processed. ${ }^{28}$ Parametric numerical variables are summarized as means and standard deviations (SD), nonparametric variables as medians and inter quartile ranges (IQR, i.e. $25^{\text {th }}-75^{\text {th }}$ percentile), whereas for categorical variables the frequency tables and percentages are reported.

\section{Data pre-processing of GC-TOF-MS data}

Pre-processing of GC-MS data was performed to reduce fluctuations during chemical analysis (i.e. changes in temperature, column ageing, and/or unknown changes in machine conditions) as well by physiological variation. Data pre-processing consisted of 6 steps: 1) selection of retention index 1.3 - 23 minutes; 2 ) noise removal via wavelet transformation and baseline correction using P-splines; 3) warping by means of correlation optimized warping 28 ; 4) the area under the peaks in the chromatograms was calculated; 5) area under the peaks and corresponding mass spectra were combined; 6) data were normalized which reduces the influence of random variation between the chromatograms of all samples by probabilistic quotient normalization; and 7) all pre-processed data were log transformed.

\section{Random Forest modelling}

For the study objectives, Random Forest (RF) technique was used. The data were randomly assigned into a training (consisting of $80 \%$ of samples) and a validation set. To improve modelling of the underlying distribution in the data, the random splitting was repeated 800 times. The training set was used for optimization steps (i.e. variable selection) and for developing a classification or regression model. The test set was subsequently used to validate the constructed model. Since, multiple measurements are available per individual, the selection of samples into training and validation set was performed on a patient level. This means that the validation set always contained all measurements belonging to the same subject. Thus 
the RF classification or regression model was never trained on part of measurements of the same subject and tested on the remaining measurements of the same subject. Moreover, to diminish the influence of inter-individual variation, centering per individual was performed. This allows converting all the relative compound concentrations to fluctuations around zero for each individual instead of around the population mean. In other words, biological mean for each individual was set to zero.

In order to investigate the association between asthma control and inflammatory markers, RF was used to construct either regression or classification models. The regression model was constructed to find associations between the exhaled inflammatory markers and ACQ scores. Outcomes of the regression model were presented in a plot showing observed and predicted ACQ scores of the validation set. In addition, Root Mean Square Error (RMSE) of prediction was reported, which represents the accuracy of the model and basically is the SD of the differences between predicted ACQ values and measured $A C Q$ values.

In order to exclude the possibility that exhaled VOCs were not associated to ACQ score itself, but only associated to asthma levels of control, also RF as classification model took place on all available samples. In case of RF classification model the performance is shown as sensitivity and specificity of the validation set. In addition, Receiver Operating Characteristic (ROC) curves were constructed of the validation sets.

Finally, RF as classification model was performed to study the ability of exhaled VOCs to discriminate between 2 subgroups: children with persistently controlled or uncontrolled asthma during subsequent clinical visits. To investigate the added value of cytokines, chemokines in EBC and FeNO, all RF models were performed for exhaled VOCs alone or the combination of all exhaled markers.

Data pre-processing and RF modelling were performed using Matlab version R2013a.

Comparative tests were performed to analyse whether co-factors at baseline (medical centre, season, sex, age, lung function ( $\mathrm{FEV}_{1} \%$ of predicted value or bronchodilator response), atopy, number of exacerbations of a child, daily dose of ICS and second hand smoking) were associated with persistently controlled or uncontrolled asthma during clinical visits. An independent samples T-test was used to compare parametric data, the Mann-Whitney $U$ test for nonparametric data and the Chi-square for categorical variables, whereas $p$-values below 0.05 were considered significant. Additionally, to exclude the chance that co-factors could have biased the results concerning identification of subgroups, Spearman correlation was calculated for continuous co-factors at baseline and intensities of selected exhaled VOCs. To test the difference of exhaled VOCs between seasons, the Friedman test was performed (SPSS version 20.0, SPSS Inc., Chicago IL, USA). 


\section{Results}

\section{Patients}

96 children with asthma were included, of which the majority was atopic and had well controlled asthma (table 4.1). The subject characteristics of the 2 clinical centres were comparable (data are not shown). Thirteen children dropped out during the study because of the following (non-medical) reasons: too much effort for fulfilling study obligations $(n=6)$, loss of motivation $(n=2)$, the study was experienced as too confronting with respect to asthma $(n=1)$, different expectations of the study $(n=1)$, hyperventilation symptoms during lung function testing $(n=1)$.

Table 4.1 Patient characteristics at baseline

\begin{tabular}{|c|c|}
\hline & Total $n=96$ \\
\hline Sex male, \% & 52 \\
\hline Age in years, mean [range] & $10[6-17]$ \\
\hline $\mathrm{FEV}_{1} \%$ predicted value, mean $\pm \mathrm{SD}$ & $96.8 \pm 14.2$ \\
\hline Bronchodilator response, delta $\mathrm{FEV}_{1}$ as $\%$ predicted value: mean $\pm \mathrm{SD}$ & $6.6 \pm 8.5$ \\
\hline ICS use, \% & 94 \\
\hline Fluticasone daily dosage or equivalent, mean $\pm \mathrm{SD}^{*}$ & $269 \pm 175$ \\
\hline$A C Q$, median $[I Q R]$ & $0.6[0.3-1]$ \\
\hline FeNO, ppb: median [IQR] & $12.5[8.0-31.0]$ \\
\hline $\mathrm{PC}_{20}, \mathrm{mg} / \mathrm{mL}:$ median $[\mathrm{IQR}]^{\dagger}$ & $1.2[0.3-2.9]$ \\
\hline Atopy, $\%^{\ddagger}$ & 76 \\
\hline
\end{tabular}

$\mathrm{FEV}_{1}$, forced expiratory volume in 1 second; SD, Standard Deviation; ICS, Inhaled Corticosteroids; ACQ, Asthma Control Questionnaire; IQR, Inter Quartile Range; PAQLQ, Paediatric Asthma Control Quality of Life Questionnaire; FeNO, Fractional exhaled Nitric Oxide.

* Six children did not use ICS at baseline.

${ }^{+} \mathrm{PC}_{20}$ : concentration of histamine inducing a $20 \%$ drop in $\mathrm{FEV}_{1} .16 \%$ of the $\mathrm{PC}_{20}$ tests were missing, because of recurrent airway infections during clinical visits, inability to stop antihistamines or bronchodilators, or calibration errors of the histamine nebulizer.

₹Atopy is defined as a positive Phadiatop (Phadia, Uppsala, Sweden), or RAST, or a positive allergen skin test. In $3 \%$ of the children, an allergy test was missing.

In total, 574 chromatograms were accessible for statistical analysis. The data matrix after preprocessing comprised 2,416 different VOCs. For analysis of the subgroups of patients with controlled asthma $(n=34)$ and uncontrolled asthma $(n=9)$ during all follow-up visits, 202/217 and $47 / 52$ chromatograms were available respectively.

\section{Association between exhaled inflammatory markers and asthma control using all samples}

The regression model based on RF to explore the association between exhaled VOCs and ACQ scores, showed a RMSE of prediction of 1.8 , which indicates a low overall correlation 
between specific exhaled VOCs and the ACQ scores. The variation of prediction error was wide in the whole range of ACQ scores (figure 4.1). The addition of FeNO or markers in EBC to this model did not lead to an increased association with the ACQ scores, compared to the model where only exhaled VOCs were included.

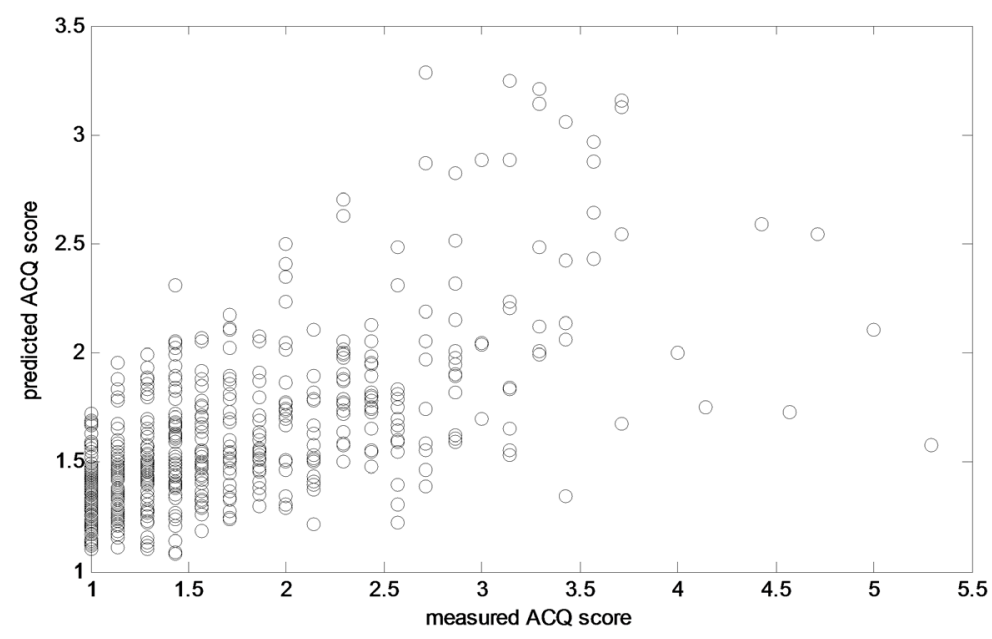

Figure 4.1 Observed and predicted ACQ score based on exhaled VOCs analysed by using RF linear regression

The RF classification model to assess controlled or uncontrolled asthma based on exhaled VOCs resulted in an overall correct classification in $48 \%$ of the cases (sensitivity $55 \%$, specificity $45 \%$, area under ROC-curve $49 \%$ ) (figure 4.2). The accuracy of classifying controlled or uncontrolled asthma hardly improved by adding markers in EBC or FeNO to the model (area under ROC-curve 51\%). 


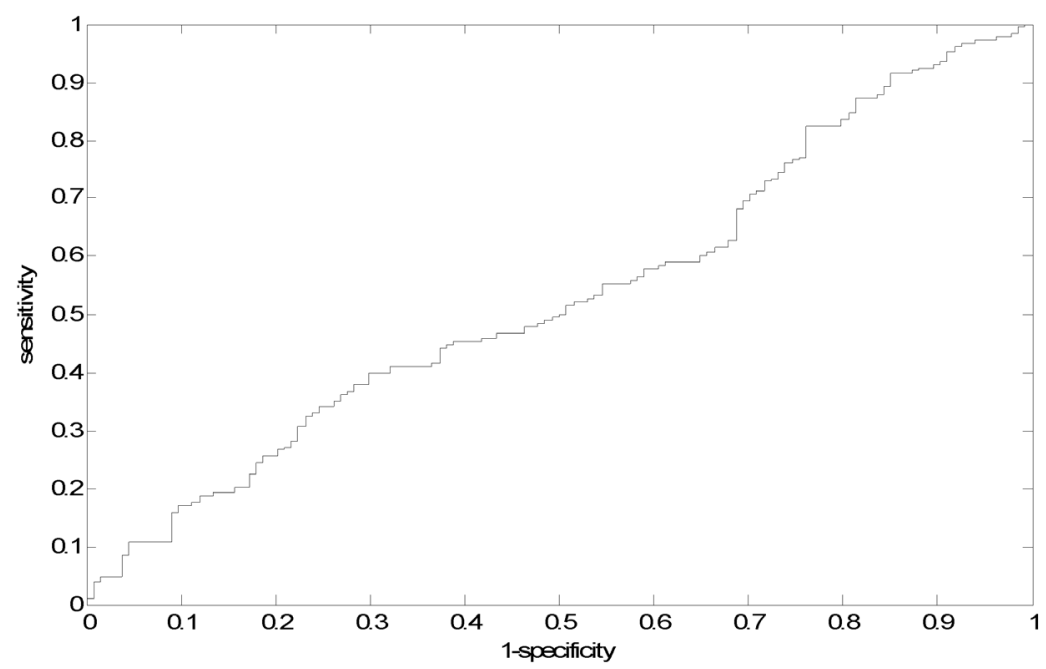

Figure 4.2 ROC-curve (AUC 49\%) based on the RF classification model for controlled or uncontrolled asthma during clinical visits, based on exhaled VOCs

\section{Classification of subgroups with persistently uncontrolled or controlled asthma}

Based on a combination of 15 VOCs, children with persistently controlled versus uncontrolled asthma could be classified with an overall correct prediction rate of $70 \%$. The area under the ROC-curves was $86 \%$ (figure 4.3 ) and the sensitivity was $81 \%$ with a specificity of $67 \%$. Adding markers in EBC or FeNO to this classification model did not significantly improve the performance of this model (area under the ROC-curve $87 \%$, figure not shown). When the clinical baseline characteristics of these 2 subgroups were analysed, it appeared that children with persistently uncontrolled asthma had significantly lower $\mathrm{FEV}_{1} \%$ of predicted value, higher daily dose of ICS, increased bronchial hyperresponsiveness, and more exacerbations during the one-year study period compared to children with persistently controlled asthma during clinical visits (table 4.2). 


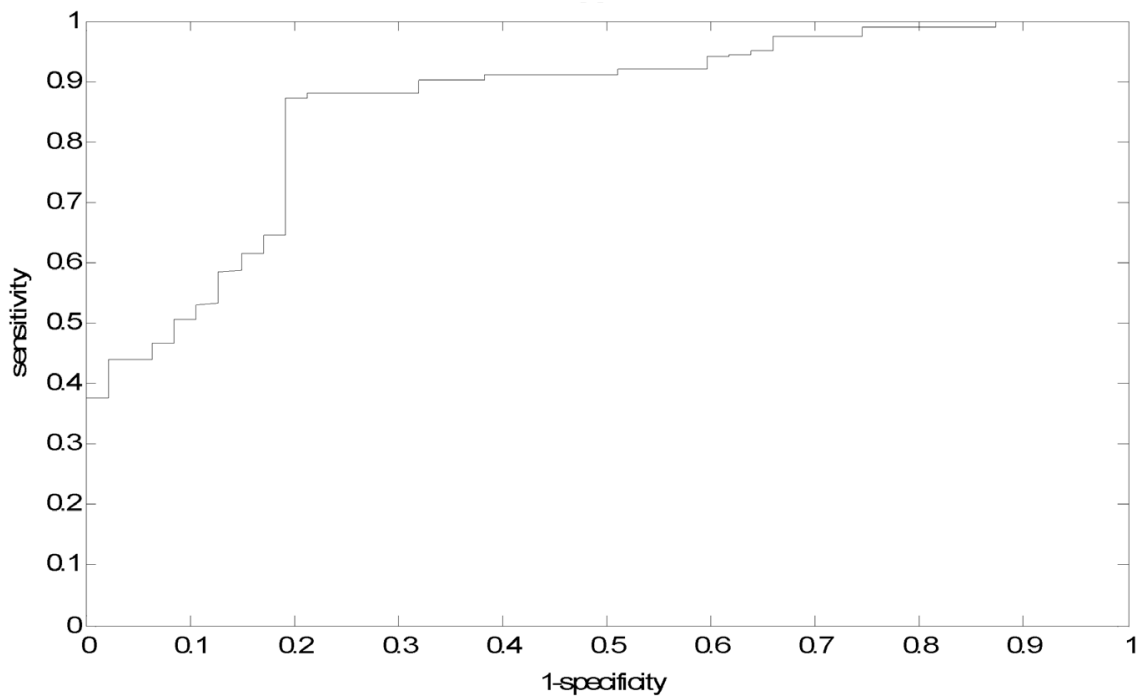

Figure 4.3 ROC-curve (AUC 86\%) based on 15 exhaled VOCs, in only children with persistently controlled versus persistently uncontrolled asthma during clinical visits 
Table 4.2 Comparison of baseline characteristics and exacerbations during the study of patient subgroups

\begin{tabular}{|c|c|c|c|c|}
\hline & $\begin{array}{l}\text { persistently } \\
\text { controlled }^{\text {a }} \\
n=34\end{array}$ & $\begin{array}{l}\text { variable asthma } \\
\text { control }^{b} \\
n=53\end{array}$ & $\begin{array}{l}\text { persistently } \\
\text { uncontrolled }^{c} \\
n=9\end{array}$ & $p$-value ${ }^{a, c}$ \\
\hline Sex male, $\mathrm{n}(\%)$ & $18(53)$ & $30(57)$ & $2(22)$ & 0.10 \\
\hline Age in years, median [IQR] & $9[7-13]$ & $9[7-11]$ & $12[11-13]$ & $0.04^{*}$ \\
\hline $\begin{array}{l}\mathrm{FEV}_{1} \% \text { predicted value, } \\
\text { median [IQR] }\end{array}$ & $104.0[99.8-111.5]$ & $93.0[85.0-102.5]$ & $88.0[71.5-96.0]$ & $<0.01^{*}$ \\
\hline $\begin{array}{l}\text { Bronchodilator response, or } \\
\text { delta } \mathrm{FEV}_{1} \text { as } \% \text { predicted } \\
\text { value: median [IQR] }\end{array}$ & $3.0[0.0-10.0]$ & $6.5[3.0-11.0]$ & $9.0[4.0-18.0]$ & 0.06 \\
\hline $\begin{array}{l}\text { Fluticasone daily dosage or } \\
\text { equivalent, median [IQR] }\end{array}$ & $250[125-263]$ & $250[125-313]$ & $312[312-500]$ & $<0.01^{*}$ \\
\hline FeNO, ppb: median [IQR] & $11.5[7.5-35.0]$ & $13.0[8.0-31.0]$ & $13.0[8.5-31.0]$ & 0.65 \\
\hline $\mathrm{PC}_{20}, \mathrm{mg} / \mathrm{mL}:$ median $[\mathrm{IQR}]^{\dagger}$ & $2.3[1.0-4.8]$ & $0.8[0.3-1.9]$ & $0.3[0.1-0.6]$ & $<0.01^{*}$ \\
\hline Atopy, $\%$ ‡ & 81 & 72 & 78 & 0.82 \\
\hline $\begin{array}{l}\text { Exacerbations during study, } \\
\text { median [IQR] }\end{array}$ & $0[0-1]$ & $1[0-1]$ & $2[0-3]$ & $0.02^{*}$ \\
\hline
\end{tabular}

a: children with persistently controlled asthma during clinical visits; $b$ : children with fluctuations of asthma level of control during study; c: children with persistently uncontrolled asthma during clinical visits.

FeNO, Fractional exhaled Nitric Oxide; FEV , forced expiratory volume in 1 second; IQR, Inter Quartile Range.

* $\mathrm{p}$-value $<0.05$

$+\mathrm{PC}_{20}$ : concentration of histamine inducing a $20 \%$ drop in $\mathrm{FEV}_{1}$.

${ }^{\ddagger}$ Atopy is defined as a positive Phadiatop (Phadia, Uppsala, Sweden), or RAST, or a positive allergen skin test.

The correlation of these 15 discriminating VOCs with the co-variables lung function ( $\mathrm{FEV}_{1} \%$ of predicted value), bronchodilator response ( $\mathrm{FEV}_{1} \%$ of predicted value), use of $\beta_{2}$-agonists and daily dose of ICS at baseline, was only significant but weak in 5 cases. In addition no significant differences in intensities of these 15 VOCs were found between medical centres, seasons, sexes, children with or without bronchial hyperresponsiveness, presence/absence of atopy or parental smoking.

\section{Discussion}

In the present study the associations between exhaled inflammation markers and asthma control, and the ability of these markers to discriminate between subgroups of asthmatic children with uncontrolled or controlled asthma during the one-year study period, were explored. No longitudinal association between individual exhaled inflammation markers and asthma control was found. However, it was possible to discriminate between subgroups of 
children with persistently uncontrolled and controlled asthma during clinical visits on the basis of a set of exhaled VOCs; the area under the ROC-curve was $86 \%$. EBC markers and FeNO had no additional value on the classification of these 2 asthmatic subgroups by exhaled VOCs. This suggests that a set of exhaled VOCs may be useful to identify subgroups of children with persistently uncontrolled or controlled asthma during follow-up visits.

Although asthma control and exhaled inflammatory markers were not directly associated, a set of exhaled VOCs differentiated between the subgroups of children with persistently uncontrolled and controlled asthma during clinical visits. This suggests that overall exhaled inflammatory markers and asthma control are not related or interchangeable. Studies with FeNO also showed a poor relation between asthma control and FeNO; whereas addition of FeNO to asthma control assessments resulted in a higher percentage of detected uncontrolled asthma by FeNO and lung function. ${ }^{15,16,29}$ Respiratory symptoms and lung function deterioration are the consequences of increased airway inflammation. Therefore, it is conceivable that a worsening of symptoms and lung function is not already present when inflammation is increasing, which may explain the low correlation between these non-invasive inflammation markers and asthma control.

However, the absence of a relationship between asthma control and inflammation markers does not imply that monitoring of airway inflammation is not valuable. In fact they probably reflect other aspects of the disease and it may be useful to monitor certain (non-invasive) inflammation markers besides asthma control. Indeed we found that a set of 15 exhaled VOCs was able to discriminate between patients with persistently controlled or uncontrolled disease. So instead of a close link between these VOCs and asthma control at certain time points, it seems that these exhaled VOCs could reflect a more favourable or less favourable course of the disease, which may be of clinical benefit. In addition, in an earlier study it was shown that exhaled VOCs were able to predict exacerbations in children with asthma. ${ }^{19}$ These findings together support the concept that an increase in airway inflammation precedes the deterioration in lung function, symptoms and asthma control. ${ }^{29}$ Although there is need for additional data and studies, it appears that a set of exhaled VOCs may early detect a subgroup of asthmatic children with a more severe clinical course or even asthma exacerbations. This is supported by findings of Fitzpatrick et al., who showed that severe asthma characterized by poor symptom control despite treatment with high-dose ICS could be differentiated from mild to moderate asthma by lung function indices and FeNO. ${ }^{30}$ However, EBC markers and exhaled VOCs were not part of their study.

What are the strengths and limitations of the current study? GC-TOF-MS allows detecting a broad range of exhaled VOCs. Therefore the chance to find asthma specific exhaled VOCs was increased by applying GC-TOF-MS. Another strength was the inclusion of a validation 
set beside the training set to perform statistical analysis, which has increased the reliability of the study results. Furthermore, medication was strictly titrated on the basis of the GINAcriteria. ${ }^{2}$ Thus the 2 subgroups of patients with persistently controlled or uncontrolled asthma during clinical visits were not caused by inadequate treatment decisions of the doctor, or differences in treatment strategies between doctors. Beside these strengths, this study also has some limitations. A low number of patients with persistently uncontrolled asthma at clinical visits lowered the power of the model to classify persistently controlled versus uncontrolled asthma. The low number of individuals with persistently uncontrolled asthma may be due to the strict protocol to titrate medication. Although the subgroup of persistently controlled asthma demonstrated optimally controlled disease at regular visits, some of these patients experienced an exacerbation between visits. On average, the exacerbation rate was significantly lower in the subgroup with persistently controlled disease during clinical visits compared to the uncontrolled group. The occurrence of exacerbation in the persistently controlled group could have led to more heterogeneity in exhaled VOCs in the persistently controlled group and a less accurate classification. Finally, children with uncontrolled asthma during all clinical visits had a significant higher mean daily dose of ICS compared to the children that were controlled during clinical visits. It is unlikely that difference in doses of ICS between the uncontrolled and controlled subgroups are responsible for the differences in exhaled VOCs, because no and only 1 weak correlations were found between ICS daily dose and intensities of the 15 selected VOCs.

What are the implications of the data? Inflammatory markers in exhaled breath may form a clinically valuable tool to discriminate between subgroups of asthmatic patients. Based on the current data, exhaled VOCs may identify children with persistently uncontrolled or controlled asthma, which has the benefit that switching to another type of ICS or tapering off inhaled medication could take place both at an earlier stage. Besides, it would be interesting to investigate in the future, whether exhaled VOCs can predict stable disease or loss of control in children with controlled asthma. This could give clinicians the opportunity to taper off maintenance medication earlier in patients with controlled disease. Furthermore, information about exhaled VOCs that are indicative for persistently uncontrolled asthma in children, may improve knowledge of the pathogenetic background of asthma in this subgroup. However, the inflammatory process is complex and by using GC-TOF-MS, a whole range of exhaled VOCs was measured in a relatively small sample size. Therefore, this study needs to be repeated in a larger sample of asthmatic children.

In conclusion, exhaled inflammatory markers were not associated with asthma control levels in children. However, a set of exhaled VOCs was able to identify children with persistently uncontrolled and controlled asthma during subsequent clinical visits. 


\section{References}

1. Busse WW, Lemanske RF, Jr. Asthma. The New England journal of medicine 2001: 344(5): 350362.

2. Global strategy for asthma management and prevention. Global Initiative for Asthma (GINA) 2012 [cited; Available from: ginasthma.org/local/uploads/files/GINA_Report_March13.pdf

3. BTS. BTS/SIGN Guideline on the management of asthma: British Thoracic Society. 2012.

4. de Jongste JC. Astma bij kinderen; herziene richtlijnen van de sectie kinderlongziekten van de NVK [Asthma in children; revised guidelines of the paediatric department of the Dutch Paediatric Society], Amsterdam, 2007.

5. Hammer SC, Robroeks CM, van Rij C, Heynens J, Droog R, Jobsis Q, Hendriks HJ, Dompeling E. Actual asthma control in a paediatric outpatient clinic population: do patients perceive their actual level of control? Pediatric allergy and immunology : official publication of the European Society of Pediatric Allergy and Immunology 2008: 19(7): 626-633.

6. American Thoracic S, European Respiratory S. ATS/ERS recommendations for standardized procedures for the online and offline measurement of exhaled lower respiratory nitric oxide and nasal nitric oxide, 2005. American journal of respiratory and critical care medicine 2005: 171(8): 912-930.

7. Rosias PP, Dompeling E, Dentener MA, Pennings HJ, Hendriks HJ, van lersel MP, Jobsis Q. Childhood asthma: exhaled markers of airway inflammation, asthma control score, and lung function tests. Pediatric pulmonology 2004: 38(2): 107-114.

8. Khalili B, Boggs PB, Shi R, Bahna SL. Discrepancy between clinical asthma control assessment tools and fractional exhaled nitric oxide. Annals of allergy, asthma \& immunology : official publication of the American College of Allergy, Asthma, \& Immunology 2008: 101(2): 124-129.

9. Malinovschi A, Pizzimenti S, Sciascia S, Heffler E, Badiu I, Rolla G. Exhaled breath condensate nitrates, but not nitrites or FENO, relate to asthma control. Respiratory medicine 2011: 105(7): 10071013.

10. Michils A, Baldassarre S, van Muylem A. Exhaled nitric oxide and asthma control: a longitudinal study in unselected patients. The European respiratory journal 2008: 31(3): 539-546.

11. Piacentini GL, Peroni DG, Bodini A, Bonafiglia E, Rigotti E, Baraldi E, Liu AH, Boner AL. Childhood Asthma Control Test and airway inflammation evaluation in asthmatic children. Allergy 2009: 64(12): 1753-1757.

12. Petsky HL, Cates CJ, Li A, Kynaston JA, Turner C, Chang AB. Tailored interventions based on exhaled nitric oxide versus clinical symptoms for asthma in children and adults. Cochrane Database Syst Rev 2009(4): CD006340.

13. de Jongste JC, Carraro S, Hop WC, Group CS, Baraldi E. Daily telemonitoring of exhaled nitric oxide and symptoms in the treatment of childhood asthma. American journal of respiratory and critical care medicine 2009: 179(2): 93-97.

14. Petsky HL, Li AM, Au CT, Kynaston JA, Turner C, Chang AB. Management based on exhaled nitric oxide levels adjusted for atopy reduces asthma exacerbations in children: A dual centre randomized controlled trial. Pediatric pulmonology 2014: [Epub ahead of print].

15. Vijverberg SJ, Koster ES, Koenderman L, Arets HG, van der Ent CK, Postma DS, Koppelman $\mathrm{GH}$, Raaijmakers JA, Maitland-van der Zee AH. Exhaled NO is a poor marker of asthma control in children with a reported use of asthma medication: a pharmacy-based study. Pediatric allergy and immunology : official publication of the European Society of Pediatric Allergy and Immunology 2012: 23(6): 529-536.

16. Yavuz ST, Civelek E, Sahiner UM, Buyuktiryaki AB, Tuncer A, Karabulut E, Sekerel BE. Identifying uncontrolled asthma in children with the childhood asthma control test or exhaled nitric oxide measurement. Annals of allergy, asthma \& immunology : official publication of the American College of Allergy, Asthma, \& Immunology 2012: 109(1): 36-40.

17. Robroeks CM, van Vliet D, Jobsis Q, Braekers R, Rijkers GT, Wodzig WK, Bast A, Zimmermann $\mathrm{LJ}$, Dompeling E. Prediction of asthma exacerbations in children: results of a one-year prospective study. Clinical and experimental allergy : journal of the British Society for Allergy and Clinical Immunology 2012: 42(5): 792-798. 
18. Thomas PS, Lowe AJ, Samarasinghe P, Lodge CJ, Huang Y, Abramson MJ, Dharmage SC, Jaffe A. Exhaled breath condensate in pediatric asthma: promising new advance or pouring cold water on a lot of hot air? a systematic review. Pediatric pulmonology 2013: 48(5): 419-442.

19. Robroeks CM, van Berkel JJ, Jobsis Q, van Schooten FJ, Dallinga JW, Wouters EF, Dompeling E. Exhaled volatile organic compounds predict exacerbations of childhood asthma in a 1-year prospective study. The European respiratory journal 2013: 42(1): 98-106.

20. van Vliet D, van Horck M, van de Kant K, Vaassen S, Gulikers S, Winkens B, Rosias P, Heynens J, Muris J, Essers B, Jobsis Q, Dompeling E. Electronic monitoring of symptoms and lung function to assess asthma control in children. Annals of allergy, asthma \& immunology : official publication of the American College of Allergy, Asthma, \& Immunology 2014: 113(3): 257-262 e251.

21. Dales RE, Spitzer WO, Tousignant P, Schechter M, Suissa S. Clinical interpretation of airway response to a bronchodilator. Epidemiologic considerations. Am Rev Respir Dis 1988: 138(2): $317-$ 320.

22. Juniper EF, Gruffydd-Jones K, Ward S, Svensson K. Asthma Control Questionnaire in children: validation, measurement properties, interpretation. The European respiratory journal 2010: 36(6): 1410-1416.

23. Buszewski B, Kesy M, Ligor T, Amann A. Human exhaled air analytics: biomarkers of diseases. Biomedical chromatography : BMC 2007: 21(6): 553-566.

24. Amann A, de Lacy Costello B, Miekisch W, Schubert J, Buszewski B, Pleil J, Ratcliffe N, Risby T. The human volatilome: volatile organic compounds (VOCs) in exhaled breath, skin emanations, urine, feces and saliva. Journal of breath research 2014: 8(3): 034001.

25. Fens N, van der Schee MP, Brinkman P, Sterk PJ. Exhaled breath analysis by electronic nose in airways disease. Established issues and key questions. Clinical and experimental allergy : journal of the British Society for Allergy and Clinical Immunology 2013: 43(7): 705-715.

26. van Vliet D, Alonso A, Rijkers G, Heynens J, Rosias P, Muris J, Jöbsis Q, Dompeling E. Prediction of asthma exacerbations in children by innovative exhaled inflammatory markers: results of a longitudinal study. PloS One 2015: 10(3): e0119434.

27. Sterk PJ, Fabbri LM, Quanjer PH, Cockcroft DW, O'Byrne PM, Anderson SD, Juniper EF, Malo JL. Airway responsiveness. Standardized challenge testing with pharmacological, physical and sensitizing stimuli in adults. Report Working Party Standardization of Lung Function Tests, European Community for Steel and Coal. Official Statement of the European Respiratory Society. The European respiratory journal Supplement 1993: 16: 53-83.

28. Smolinska A, Hauschild AC, Fijten RR, Dallinga JW, Baumbach J, van Schooten FJ. Current breathomics-a review on data pre-processing techniques and machine learning in metabolomics breath analysis. Journal of breath research 2014: 8(2): 027105.

29. Plaza V, Ramos-Barbon D, Munoz AM, Fortuna AM, Crespo A, Murio C, Palomino R, Investigators ES. Exhaled nitric oxide fraction as an add-on to ACQ-7 for not well controlled asthma detection. PloS One 2013: 8(10): e77085.

30. Fitzpatrick AM, Gaston BM, Erzurum SC, Teague WG, National Institutes of Health/National Heart L, Blood Institute Severe Asthma Research P. Features of severe asthma in school-age children: Atopy and increased exhaled nitric oxide. The Journal of allergy and clinical immunology 2006: 118(6): 1218-1225. 



\title{
Chapter 5
}

\section{Can exhaled volatile organic compounds predict asthma exacerbations in children?}

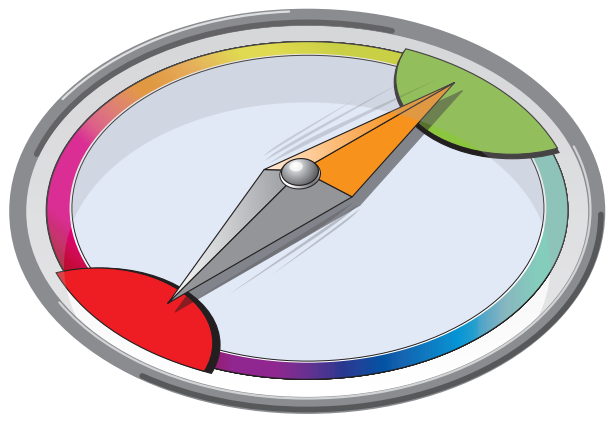

\author{
Van Vliet D \\ Smolinska A \\ Jöbsis Q \\ Rosias PPR \\ Muris JWM \\ Dallinga JW \\ Dompeling $E$ \\ Van Schooten FJ
}




\section{Abstract}

\section{Background}

Asthma control falls short of current goals of asthma management guidelines. Non-invasive monitoring of airway inflammation may help to improve the level of asthma control in children.

\section{Objectives}

1. To identify a set of exhaled volatile organic compounds (VOCs) that is most predictive for an asthma exacerbation in children.

2. To determine the chemical background of predictive VOCs.

\section{Methods}

In a one-year prospective observational study, 96 asthmatic children were studied . At clinical visits with an interval of 2 months, asthma control, fractional exhaled nitric oxide, lung function $\left(F_{1}, F_{1} V_{1} / V C\right)$ and VOCs in exhaled breath by means of gas chromatography time-of-flight mass spectrometry, were determined. Random Forrest classification modelling was used to select predictive VOCs, followed by building of receiver operating characteristic-curves (ROCcurves).

\section{Results}

An inverse relation between the predictive power of a set of VOCs and time between sampling of exhaled breath and the onset of an exacerbation was found. The sensitivity and specificity of the model predicting exacerbations 14 days after sampling were $88 \%$ and $75 \%$, respectively. The area under the ROC-curve was $90 \%$. The sensitivity for prediction of asthma exacerbations within 21 days after sampling was $63 \%$. In total, 7 VOCs were selected for the classification model: 3 aldehydes, 1 hydrocarbon, 1 ketone, 1 aromatic compound, and 1 undefined VOC.

\section{Conclusion}

VOCs in exhaled breath showed potential to predict asthma exacerbations in children within 14 days after sampling. Before use in clinical practice, the validity to predict asthma exacerbations should be studied in a larger cohort. 


\section{Introduction}

Worldwide asthma is the most common chronic inflammatory disease in children. ${ }^{1}$ Despite proper treatment, asthma is not optimally controlled in many children and adults. ${ }^{1-3}$ Low asthma control may manifest in an asthma exacerbation, which is characterized by an increase in respiratory symptoms and more need for inhaled $\beta_{2}$-adrenergic agonists as rescue medication. In addition, exacerbations are accompanied by extra clinical visits, loss of quality of life, absence from school or work of the parents, and high direct and indirect medical costs. ${ }^{4}$

International guidelines advise to titrate inhaled corticosteroids (ICS) based on asthma control, which is determined by symptoms, lung function and occurrence of asthma exacerbations. ${ }^{5-7}$ Probably, airway inflammation is already increased, before the presentation of symptoms and lung function deterioration is manifest. Therefore, assessment of markers of airway inflammation in addition to clinical characteristics, may result in an earlier detection of loss of asthma control and/or asthma exacerbation. This may enable doctors to treat airway inflammation at an early stage, which may prevent asthma exacerbations and improve asthma control.

Non-invasive assessment of airway inflammation is possible by analysis of volatile markers in exhaled breath, namely Fractional exhaled Nitric Oxide (FeNO) and Volatile Organic Compounds (VOCs). FeNO is extensively studied, however there is no consensus on the role of FeNO as a marker for monitoring of asthma. ${ }^{8-10}$ VOCs are formed during airway inflammation after reaction of reactive oxygen species (ROS) with cell membranes..$^{11,12}$ In exhaled breath a variety of VOCs can be detected and specific VOCs probably reflect asthmatic airway inflammation. ${ }^{13-19}$

To date, the number of studies on exhaled VOCs in children with asthma is limited. Studies show that a set of exhaled VOCs can discriminate between asthmatic children and healthy controls. ${ }^{13,17-19}$ The ability of exhaled VOCs to assess the level of asthma control was studied only in adults. ${ }^{20}$ In 40 children of the prospective 'InFLammation Asthma Monitoring study (FLAME)' we found that a combination of 6 VOCs was able to predict asthma exacerbations. ${ }^{16}$ To further determine such a set of VOCs specific for prediction of asthma exacerbations, it is necessary to validate the previous findings in a newly recruited population.

Therefore, the aims of the current study were:

1. to identify a set of exhaled VOCs that is most predictive for an asthma exacerbation in children;

2. to determine the chemical background of predictive VOCs. 


\section{Methods}

\section{Study design and patients}

For this one-year observational prospective cohort study, children between 6 and 18 years old with doctor-diagnosed asthma were recruited (clinicaltrial.gov NCT 01239238). All children were treated at the outpatient clinic of 2 specialized paediatric pulmonology centres in the Netherlands for at least 6 months. All children used ICS during the year preceding the study. Children with asthma fulfilled the diagnostic criteria of the Global Initiative for Asthma (GINA) and the guidelines of the Dutch Society of Paediatrics ${ }^{21}: 1$ ) presence of asthma ${ }^{5,6} ; 2$ ) reversibility to a $\beta_{2}$ agonist defined as an increase in forced expiratory volume in 1 second $\left(F E V_{1}\right)$ of $\geq 9 \%$ of predicted value ${ }^{6,22,23}$; and/or 3) presence of bronchial hyperresponsiveness, defined as a > $20 \%$ drop in $\mathrm{FEV}_{1}$ after the inhalation of histamine with a concentration $\leq 8 \mathrm{mg} / \mathrm{ml} .{ }^{6}$ Exclusion criteria were: 1) technically unsatisfactory performance of lung function measurements; 2) presence of cardiac abnormalities; 3) mental retardation; 4) congenital abnormalities or existence of a syndrome; 5) active smoking; or 6) treatment with immunotherapy during the study. Ethical approval was obtained from the Medical Ethical Committee of the Maastricht University Medical Centre. Informed consent was signed by all parents and by children aged 12 years and over.

\section{Study parameters}

Every 2 months, regular clinical visits took place. During each visit, the same order of study parameters was maintained: completion of Asthma Control Questionnaire (ACQ), GINA respiratory symptom score, online FeNO assessment, collection of exhaled breath (VOCs), and dynamic spirometry.

\section{Questionnaires}

Asthma control was determined by using the ACQ and a GINA respiratory symptom score. ${ }^{24}$ The ACQ cut-off points used for level of asthma control were: $A C Q \leq 0.75$ (controlled asthma); $0.75<A C Q \leq 1.5$ (partly controlled); and ACQ>1.5 (uncontrolled asthma). Tailoring of the dose of medication was only based on asthma control according to the GINA-criteria. ${ }^{5}$ For that purpose, respiratory symptoms during the 2 weeks preceding a clinical visit were recorded and $\mathrm{FEV}_{1} \%$ of predicted value at a clinical visit was used. Respiratory symptoms consisted of the frequency of wheeze, cough or dyspnoea during day or night, number of inhalations of rescue medication, and limitations of activities.

\section{FeNO assessment}

FeNO was assessed online using a NIOX analyser (NIOX MINO, Aerocrine, Solna, Sweden) with an expiratory flow of $50 \mathrm{~mL} / \mathrm{s}$, according to international guidelines. ${ }^{25}$ 


\section{Sampling and chemical analysis of exhaled breath}

Children were asked to inflate a 5 litre inert bag with a resistant free valve (Tedlar bag, SKC Ltd, Dorset, UK). ${ }^{26}$ Children inhaled deeply and exhaled slowly through the valve. To prevent a possible background bias, all samples were collected in the same room at each centre. Immediately after inflation of the bag, collected air was transferred onto stainless-steel two-bed sorption tubes containing active carbon (carbograph 1 TD/CarbopackX, Markes International, Llantrisant, Wales, UK) by pumping. The Tedlar bags were flushed twice with nitrogen before reuse, as described before. ${ }^{26}$

For chemical analysis, gas chromatography-time-of-flight-mass spectrometry (GC-TOF-MS) was used, which is assumed to be the gold standard in recent reviews. ${ }^{27,28}$ Chemical analysis of samples consisted of 3 phases: 1) heating of the tubes to $270^{\circ} \mathrm{C}$ in order to release captured VOCs; 2) separation of VOCs by GC; and 3) detection of VOCs by TOF-MS. Raw data of each sample were used for statistical analysis, as described below.

\section{Dynamic spirometry}

Patients were instructed to stop short-acting bronchodilators at least 8 hours and long-acting bronchodilators at least 48 hours before testing. Dynamic spirometry was performed by means of ZAN 100 spirometer (nSpire Health $\mathrm{GmbH}$, Oberthulba, Germany), according to ATS/ERS standards. ${ }^{29}$ The highest value of 3 correctly performed manoeuvres was used for analysis. $\mathrm{FEV}_{1}$ percentage of predicted value was recorded. In order to assess reversibility to $\beta_{2}$-agonist, 15 minutes after inhalation of $400 \mu \mathrm{g}$ salbutamol a second lung function test was performed.

\section{Bronchial hyperresponsiveness}

Bronchial hyperresponsiveness was only assessed at the start of the study by bronchial histamine challenge test. ${ }^{29}$ At first, an aerosol of buffered saline was inhaled, followed by aerosols of histamine solutions with doubling concentrations from $0.03 \mathrm{mg} / \mathrm{mL}$ to $16 \mathrm{mg} / \mathrm{mL}$, at intervals of 5 minutes. After complete inhalation of a solution, $\mathrm{FEV}_{1}$ was measured at 30,90 and 120 seconds. The percentage decline in $\mathrm{FEV}_{1}$ was calculated and the test was stopped when a drop of $20 \%$ or more in $\mathrm{FEV}_{1}$ occurred $\left(\mathrm{PC}_{20}\right)$, or when the highest concentration of $16 \mathrm{mg} / \mathrm{mL}$ histamine was administered. The $\mathrm{PC}_{20}$ was calculated from a log concentration versus dose response curve. After reaching the threshold, children inhaled 800 microgram salbutamol, followed by 3 maximal expiratory flow volume (MEFV) manoeuvres.

\section{Atopy}

Presence of atopy was defined as positive Phadiatop (Phadia, Uppsala, Sweden), Radio Allergo Sorbent Test (RAST) (Pharmacia, Uppsala, Sweden) or Allergen Skin test. 


\section{Home monitoring}

Daily home monitoring was performed using a home monitor every day approximately at the same time of the day (AM2+, ERT, Hoechberg, Germany). This handheld home monitor recorded respiratory symptom scores based on the GINA-criteria for asthma control and $\mathrm{FEV}_{1}$ values. Children were carefully and repeatedly instructed how to use the home monitor and perform lung function manoeuvres.

\section{Definition of asthma exacerbations}

Exacerbations were defined according to the latest ATS/ERS criteria and were classified as moderate or severe. ${ }^{30}$ The home monitor was used to increase the chance to record all asthma exacerbations. In case of increase of respiratory symptoms, patients were called to the clinic to objectify the exacerbation with physical examination. In case patients were not able to attend the clinic, exacerbations were recorded based on home monitor data.

\section{Asthma treatment protocol during study}

Asthma medication was titrated only based on the GINA asthma level of control. The physician was blinded for the results of FeNO, exhaled VOCs or home monitor results. The medication titration steps were performed according to the GINA guidelines and the guidelines of the Paediatric Pulmonology section of the Dutch Society of Paediatrics. , $^{5}$ If children had controlled asthma during 2 consecutive clinical visits, ICS were tapered off. Step up took place in case of partly controlled asthma during 2 consecutive clinical visits or uncontrolled asthma at 1 clinical visit.

\section{Sample size calculation}

The criterion for sample size calculation was reliable estimation of sensitivity and specificity of the predictive model. We considered a maximum estimation error of sensitivity or specificity of 0.15 . The corresponding standard error is 0.075 . We expected an incidence of exacerbation of $45 \%$, based on the previous FLAME-study. ${ }^{16}$ Using the formula: $\left(\mathrm{SE}=\right.$ sqrt $\left(p^{*}(1-p) / N\right)$, where $\mathrm{p}=$ true sensitivity or specificity, $\mathrm{N}=$ sample size for that group), the $\mathrm{N}$ equals 91 . Assuming a dropout rate of $10 \%$ during 1 year follow-up, the study aimed to include 100 children.

\section{Statistical data analysis}

Statistical analysis of GC-MS raw data consisted of 2 phases: pre-processing of raw data from GC-TOF-MS and classification modelling using Random Forest (RF) to build a predictive model for asthma exacerbations. These phases are described in detail in the review by Smolinska et al. ${ }^{31}$ All analyses were carried out using Matlab version R2013a.

\section{Data pre-processing}

In chromatograms, the peaks of similar compounds can vary between and within patients 
due to biological variance or changes during chemical analysis (i.e. changes in temperature, column ageing, and/or unknown changes in machine conditions). Data pre-processing is performed to reduce this variance in order to obtain more reliable data and to enable the building of prediction models for asthma exacerbation. Data pre-processing consists of 6 steps: 1) selection of retention index $1.3-23$ minutes of each chromatogram for analysis; 2) removal of noise of chromatograms by using wavelet transformation and correction of baseline accordingly; 3) accurate alignment by correlation optimized warping; 4) calculation of the area under the peaks in the chromatograms; 5) combination of area under the peaks and corresponding mass spectra; and 6) normalization to reduce the influence of random variation between the chromatograms of all samples by probabilistic quotient normalization.

\section{Classification modelling}

A classification model was built using the RF technique with 1000 trees. ${ }^{31}$ The accuracy of the statistical model was justified within RF methodology using so called out-of-bag (oob) cases. For each RF tree 33\% of the samples were left out with replacement and were not used in the construction of the classification model (bootstrap aggregation). These left-out cases were used to establish the prediction error (oob error) i.e. performance of the classification model. The VOCs importance is represented as a scale ranging between 0 and 1 . The closer to 1 the more important the compound is.

After selecting the most significant VOCs the final RF model was obtained. In the last step Principal Component Analysis (PCA) was performed using the selected VOCs. The resulted PCA score plot was utilized to visualize: 1) separation of children with and without exacerbation and 2) possible difference in internal and/or external factors between samples of children with an exacerbation 14 days after sampling or without an exacerbation 2 months after sampling. The following possible factors were tested: medical centre, season, sex, age, lung function ( $\mathrm{FEV}_{1} \%$ of predicted value), daily dose of ICS, asthma control, and atopy and parental smoking (not shown). Moreover, the statistical significance of difference of individual VOCs within the different external factors was tested with Mann-Whitney $U$ test or Kruskal Wallis test with respect to 2 or more than 2 categories, respectively.

The study design implicated a range of time between clinical visit and exacerbation from 0 days to 2 months. It is unknown whether VOCs may predict an asthma exacerbation and how many days this prediction lasts. Therefore, RF modelling was first performed with samples of children who experienced an exacerbation 0 to 21 days after a clinical visit. Thereafter, this analysis was repeated with breath samples of children who experienced an exacerbation 0 to 14 days after a clinical visit.

Finally, the selected compounds were identified by comparing measured mass spectra with data from the NIST library (database of the National Institute of Standards and Technology) in combination with spectrum interpretation by an experienced mass-spectrometrist and identification based on retention times of compounds. 


\section{Results}

\section{Patients}

In total 96 children with asthma were included. The majority of children were atopic and $65 \%$ of the children had controlled asthma at baseline (table 5.1). The baseline characteristics of children of the 2 participating centres were comparable (data not shown). Of the 96 children, 13 dropped out during the study. Reasons for loss to follow up were: participation was perceived as too much effort for family and child $(n=6)$, child was not motivated to continue his/her participation $(n=2)$, child was too much confronted with his/her state of disease $(n=1)$, other parental expectations of study participation $(n=1)$, hyperventilation complaints occurred during lung function test at the hospital $(n=1)$. Of these 13 drop-outs, 2 children could not be included in the analysis, because of drop-out after the first visit and the unclarity about the occurrence of exacerbations within 2 months after sampling in these 2 children. The remaining 94 children had in total 622 standard visits during the study. In total, $48 \%$ of 94 children in analysis experienced an asthma exacerbation during the study (table 5.2). The average number of days between sample collection at clinical visit and exacerbation was 33.5 (standard deviation, 23.3; median, 29.5 days).

Table 5.1 Patient characteristics at baseline

\begin{tabular}{|c|c|}
\hline & Total $n=96$ \\
\hline Sex male, n (\%) & $50(52)$ \\
\hline Age in years, mean [range] & $10[6-17$ \\
\hline $\mathrm{FEV}_{1} \%$ predicted value, mean $\pm \mathrm{SD}$ & $96.8 \pm 14.2$ \\
\hline Change in $\mathrm{FEV}_{1} \%$ predicted after ß-agonist, mean $\pm \mathrm{SD}$ & $6.6 \pm 8.5$ \\
\hline ICS use, $\%$ & 94 \\
\hline Fluticasone daily dosage or equivalent, mean \pm SD & $269 \pm 175$ \\
\hline$A C Q$, median $[I Q R]$ & $0.6[0.3-1]$ \\
\hline FeNO, ppb: median [IQR] & $12.5[8.0-31.0]$ \\
\hline $\mathrm{PC}_{20}, \mathrm{mg} / \mathrm{mL}:$ median $[\mathrm{IQR}]$ * & $1.2[0.3-2.9]$ \\
\hline Atopy, $\% \dagger$ & 76 \\
\hline
\end{tabular}

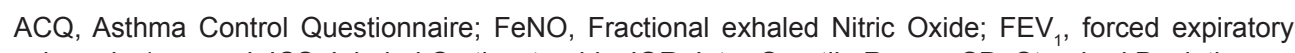
volume in 1 second; ICS, Inhaled Corticosteroids; IQR, Inter Quartile Range; SD, Standard Deviation. ${ }^{*} \mathrm{PC}_{20}$ : concentration of histamine inducing a $20 \%$ drop in $\mathrm{FEV}_{1} .16 \%$ of the $\mathrm{PC}_{20}$ tests were missing, because of recurrent airway infections during clinical visits, inability to stop antihistamines or bronchodilators, or calibration errors of the histamine nebulizer.

${ }^{\dagger}$ Atopy is defined as a positive Phadiatop (Phadia, Uppsala, Sweden), and/or positive RAST, and/or a positive allergen skin prick test. In $3 \%$ of the children, an allergy test was missing. 
Table 5.2 Asthma exacerbation rate during the study ( $\mathrm{n}=94$ children)

\begin{tabular}{lll}
\hline Number of exacerbations & $\mathrm{n}$ patients & Cumulative \% patients \\
\hline 0 & 49 & 52 \\
1 & 24 & 78 \\
2 & 13 & 92 \\
3 & 2 & 97 \\
4 & 3 & 100 \\
\hline
\end{tabular}

\section{Data pre-processing and RF modelling}

In total 574 chromatograms (in total 2416 VOCs) were available for analysis: 497 samples derived from children without an exacerbation and 77 from children with an exacerbation within 2 months after sample collection.

The classification models consisted of 7 VOCs. The first RF classification model was constructed of samples of patients with exacerbation 0 to 14 days after sample collection. In total, 16 samples of 13 patients with an asthma exacerbation 0 to 14 days after sample collection, and 16 randomly chosen control samples were used. The overall correct prediction based on the classification model was $82 \%$, with a sensitivity and a specificity of $88 \%$ and $75 \%$ respectively. The area under the ROC-curve was $90 \%$ (figure 5.1 ). The PCA score plot in figure 5.2 visualizes the separation of 16 cases with an exacerbation 0 to 14 days after exhaled breath collection, and 16 cases without exacerbation within 2 months after sample collection. 


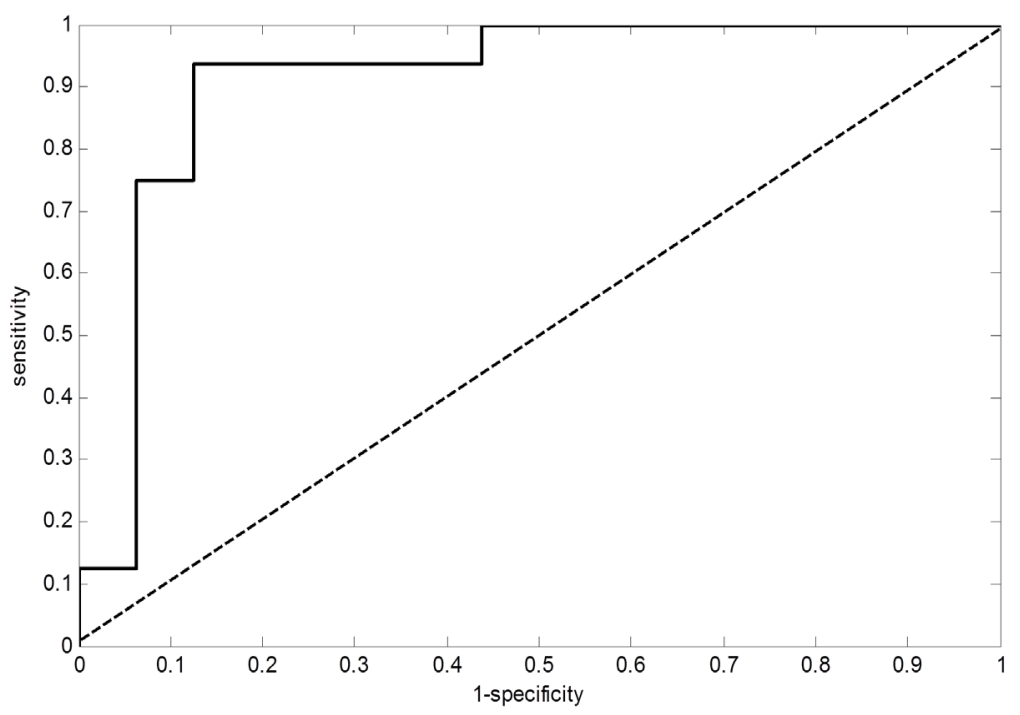

Figure 5.1 ROC-curve based on the final classification model, based on 7 VOCs, for prediction of asthma exacerbations 14 days after clinical visit *

* sensitivity $88 \%$, specificity $75 \%$, area under the ROC-curve $90 \%$

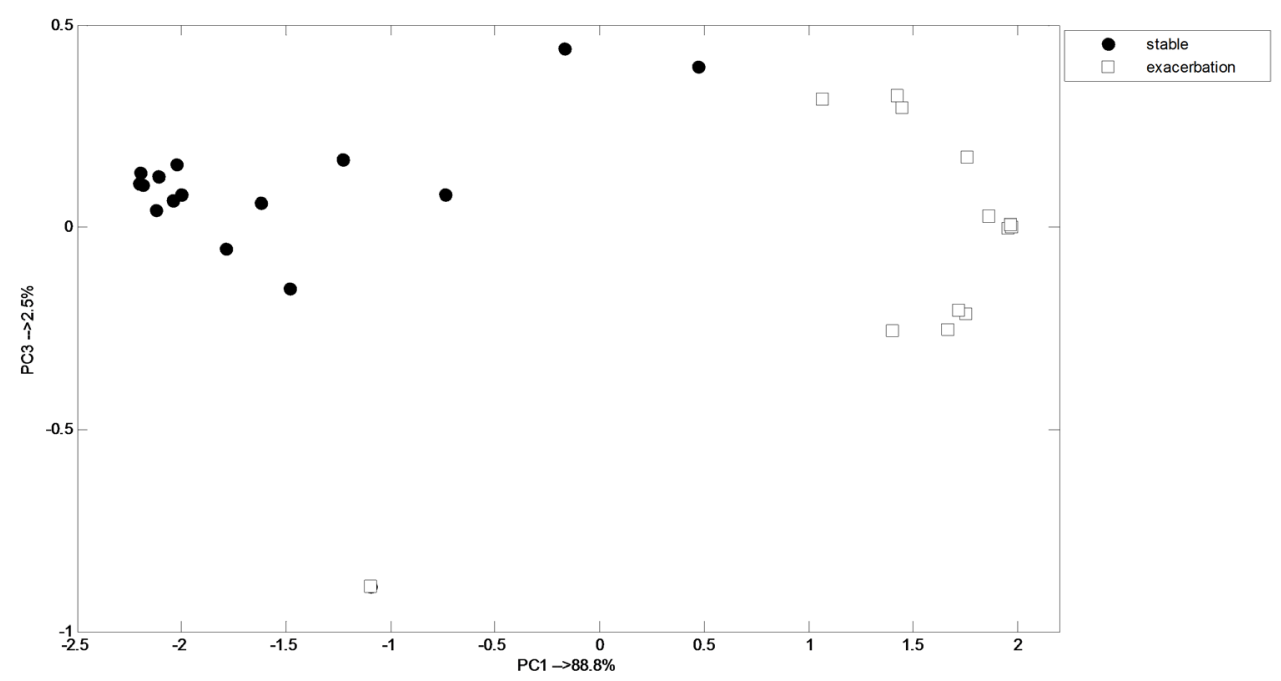

Figure 5.2 PCA score plot of the final classification model for prediction of asthma exacerbations 14 days after clinical visit: separation of stable children $(n=16)$ and children with an exacerbation 14 days after sampling $(n=16)$ 
The second RF classification model consisted of measurements obtained from children with an exacerbation that occurred 0 to 21 days after a clinical visit (24 samples, from 19 children) and 24 randomly chosen control samples. The overall correct prediction based on this model was $65 \%$, with a sensitivity and specificity of $63 \%$ and $67 \%$ respectively.

PCA score plots of the following external factors: medical centre, season, sex, age, lung function ( $\mathrm{FEV}_{1} \%$ of predicted value), daily dose of ICS, asthma control, and atopy and parental smoking (not shown), did not demonstrate an association between these factors and the occurrence of asthma exacerbations (see PCA plots, Supporting information). In addition, there was no statistical significant difference of individual VOCs between subsets of external factors.

\section{Compound identification}

Three predictive VOCs were aldehydes, 1 hydrocarbon (cyclic alkane), 1 ketone, 1 aromatic substance, and $1 \mathrm{VOC}$ could not be identified (table 5.3).

Table 5.3 Identified compounds selected in final classification model

\begin{tabular}{llll}
\hline & Chemical name of compound & Chemical group & Importance $^{*}$ \\
\hline 1 & 1,2-dimethylcyclohexane & cyclic alkane, hydrocarbon & 1.0 \\
2 & 2-ethylhexanal & aldehyde & 0.5 \\
3 & octanal & aldehyde & 0.5 \\
4 & 6,10-dimethyl-5,9-undecadien-2-one & ketone & 0.5 \\
5 & nonanal & aldehyde & 0.3 \\
6 & unknown & unknown & 0.3 \\
7 & 2-methylfuran or 3-methylfuran & aromatic & 0.1 \\
\hline
\end{tabular}

* Importance: range from most important=1 to less important=0.

\section{Discussion}

This study explored the predictive properties of exhaled VOCs for asthma exacerbations in children. A combination of 7 exhaled VOCs correctly predicted $88 \%$ of the asthma exacerbations within 14 days after sampling, which decreased to $63 \%$ within 21 days after sampling. The predictive power was inversely related to the time from sample collection to exacerbation. The identities of the selected VOCs were: 3 aldehydes, 1 hydrocarbon, 1 aromatic substance, and 1 ketone.

In the current study, asthma exacerbations could be predicted based on exhaled VOCs. However, if time to exacerbation increased beyond 2 weeks, the predictive power of the selected 
exhaled VOCs decreased significantly. These results are to some extent in accordance with the findings of the earlier FLAME-study. ${ }^{16}$ In the FLAME-study, the predictive properties of VOCs extended over a longer time period (i.e. $39 \pm 4$ days after sampling) compared to the current study.$^{16}$ In these 2 studies, design and method of sample collection were comparable. Possible explanations for differences between the 2 studies may be: 1) in the current study the pre-processing of the VOC data was improved, and raw data were corrected for column ageing of the chromatograph; 2) dissimilarities in patient characteristics, such as higher mean daily dose of ICS in the current study compared to the FLAME-study.

Other studies have shown that different sets of exhaled VOCs were able to differentiate between (allergic) asthmatic children and healthy controls. ${ }^{13,18,19}$ Additionally, studies in adults showed the potential of VOCs in diagnosing and also monitoring of asthma. ${ }^{14,15}$ These findings in both children and adults suggest that specific exhaled VOCs probably reflect asthmatic airway inflammation.

In the present study, GC-TOF-MS was used to analyse VOCs in exhaled breath. By applying GC-TOF-MS, a whole range of VOCs can be detected, which increases the chance that all relevant asthma-specific exhaled VOCs are detected. During collection of exhaled breath, we did not correct our data for a possible influence of ambient VOCs. ${ }^{13,16}$ There is no consensus in the literature on this topic. The chance that environmental VOCs may have biased the results is small for the following reasons: 1) all VOC samples were collected in the same room at each centre. Therefore, the room air was more or less comparable between children of the same medical centre; 2) PCA plots showed that the centre of participation did not influence the separation of children with and without an exacerbation $0-14$ days after sampling; 3) supervised modelling, i.e. RF, diminished the chance that environmental VOCs may have biased the results.

Beside possible bias by environmental VOCs, the composition of VOCs in breath may also be influenced by unknown intrinsic (e.g. metabolic processes) or extrinsic factors (e.g. diet, environmental air). ${ }^{32,33}$ However, in the present study, intrinsic factors such as sex, age, lung function ( $\mathrm{FEV}_{1} \%$ of predicted value) and atopy, and extrinsic factors such as parental smoking, and daily dose of ICS, were not associated with the occurrence of asthma exacerbations. Finally, there was a low number of samples for the final classification model, which decreased the power of the RF classification model.

How to interpret findings from the current study? The time between sampling and an exacerbation was an important determinant for the predictive power of the exhaled VOCs. This seems logical as, the contact of a child with a specific trigger for an asthma exacerbation such as allergen exposure (e.g. house dust mite) or viral infection could have taken place shortly before clinical presentation of asthma exacerbations. It is known that part of asthma exacerbations originate from already longer existing loss of asthma control since weeks or months. ${ }^{30,34}$ This may be detected by breath analysis more easily. 
When interpreting the 7 predictive VOCs that could predict an asthma exacerbation, 3 VOCs were aldehydes and 1 was a hydrocarbon. This finding is similar to the results of the FLAMEstudy, where most of the predictive VOCs for asthma exacerbations were hydrocarbons. Both aldehydes and hydrocarbons are associated with oxidant-induced damage of unsaturated fatty acids in cell membranes. ${ }^{27,35,36}$ Lipid peroxidation is known as one of the basic mechanisms of airway inflammation in asthma. Therefore, we hypothesize that these VOCs are associated with the presence of asthmatic airway inflammation. The compound putatively identified as 2 or 3-methylfuran is an aromatic compound, is present in cigarette smoke and also previously found to be enhanced in breath of smokers. ${ }^{37}$ It could be that the presence of this compound in exhaled breath in these children is related to passive smoking.

What may be clinical implications of this study? The presented results indicate that a selected set of exhaled VOCs may help to predict asthma exacerbations in children. Moreover, other studies showed that VOCs may also be assessed in real time using handheld devices (e-Noses). ${ }^{28}$ Future research should explore 1) an optimal time interval of sampling VOCs in order to predict asthma exacerbations; 2) the predictive power of exhaled VOCs for asthma exacerbations in an extended number of study subjects in an observational study; and 3) the effectiveness of monitoring asthma and the titration of ICS based on exhaled VOCs in a randomized controlled trial.

In conclusion, 7 selected exhaled VOCs correctly predicted $88 \%$ of the asthma exacerbation within 14 days after sampling. Three of the selected VOCs were aldehydes and 1 hydrocarbon, which are associated with oxidant-induced damage. More data from serial measurements of VOCs in a larger population of asthmatic children are needed. 


\section{Supporting information}

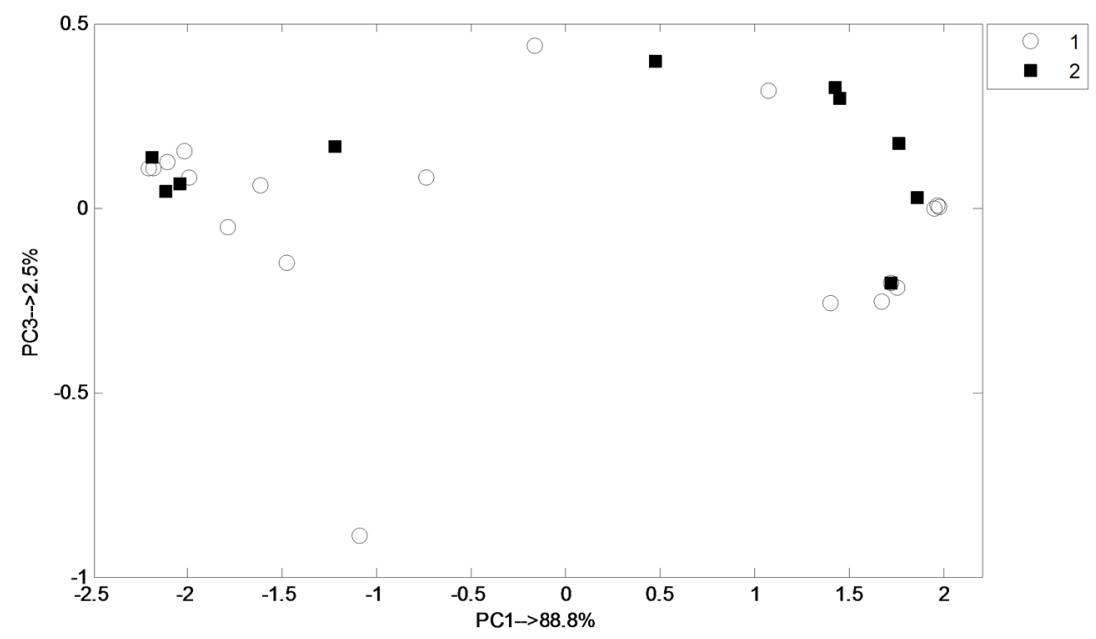

Figure S5.1a External factor: participating centres

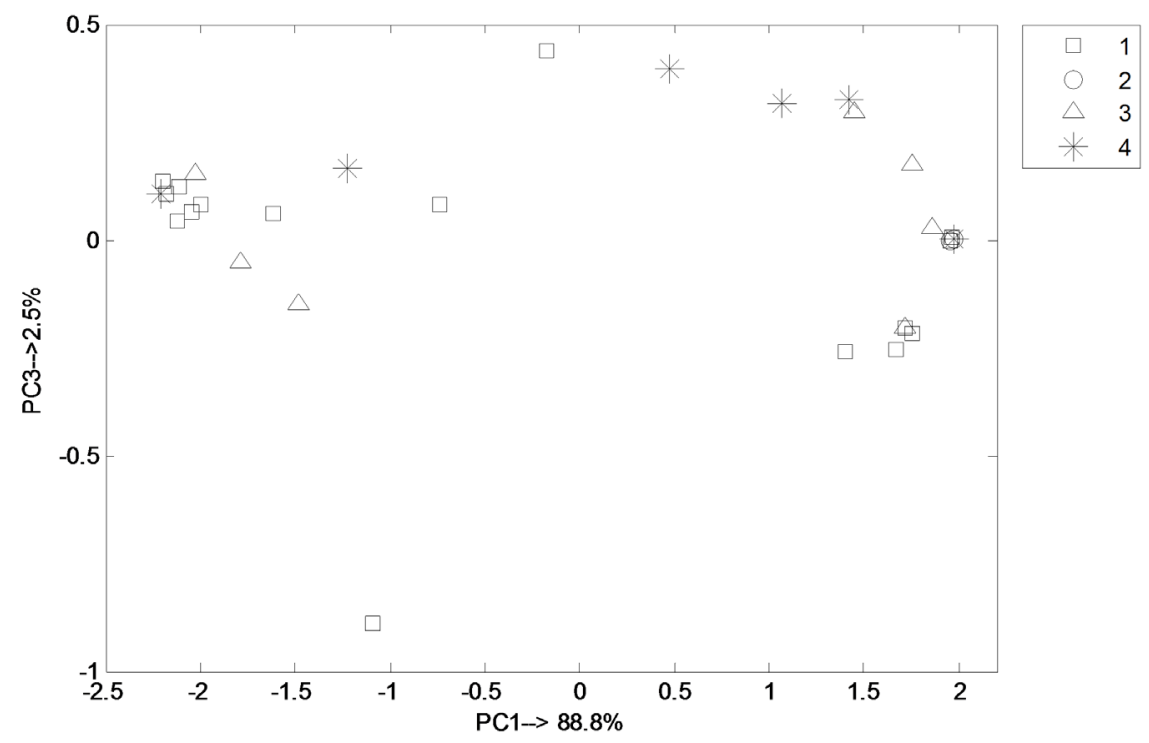

Figure S5.1b External factor: season (1=spring, 2=autumn, 3=winter, 4=summer) 


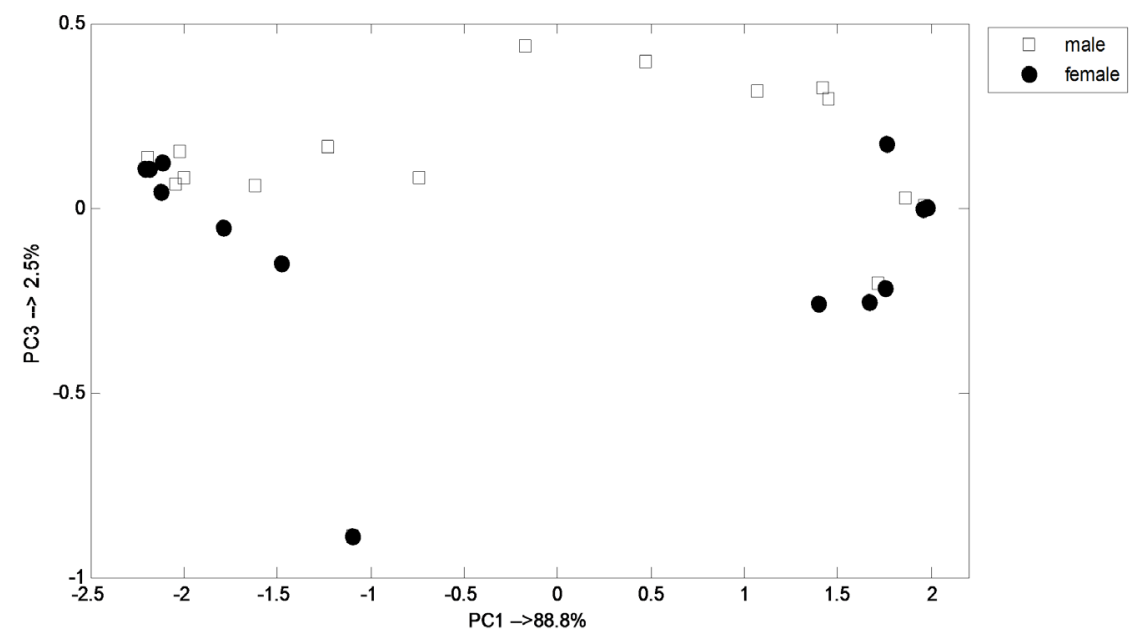

Figure S5.1c External factor: sex

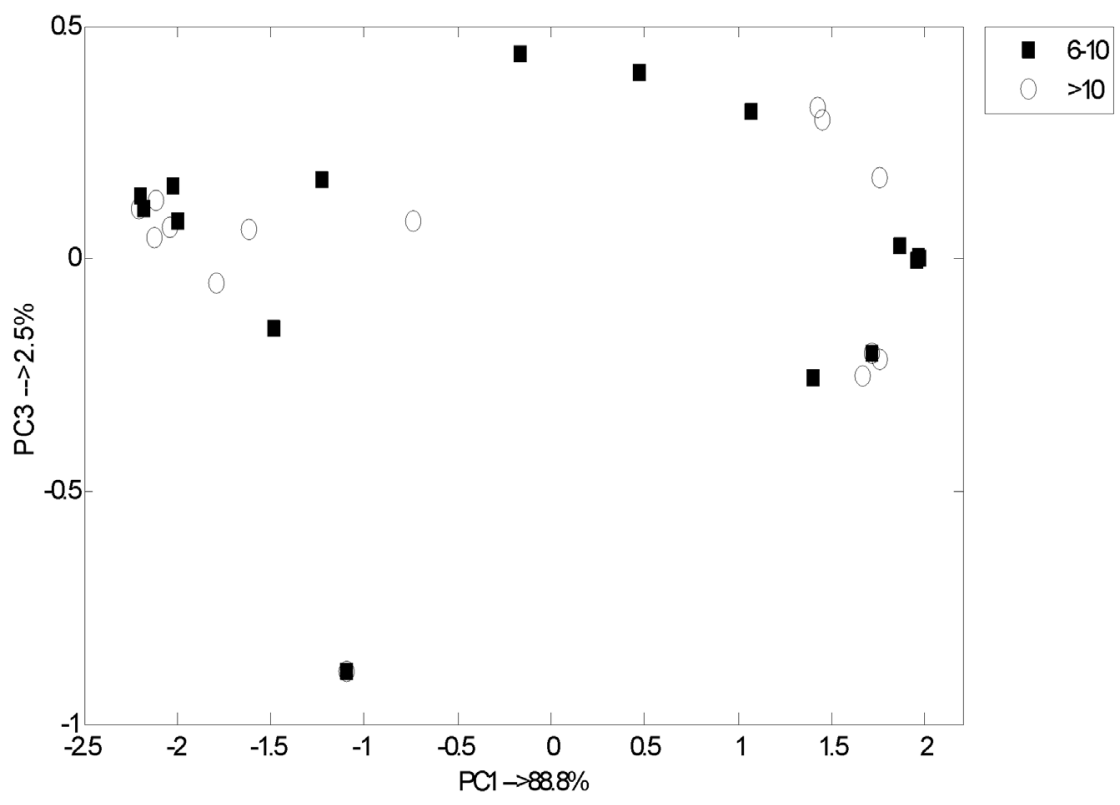

Figure S5.1d External factor: age 


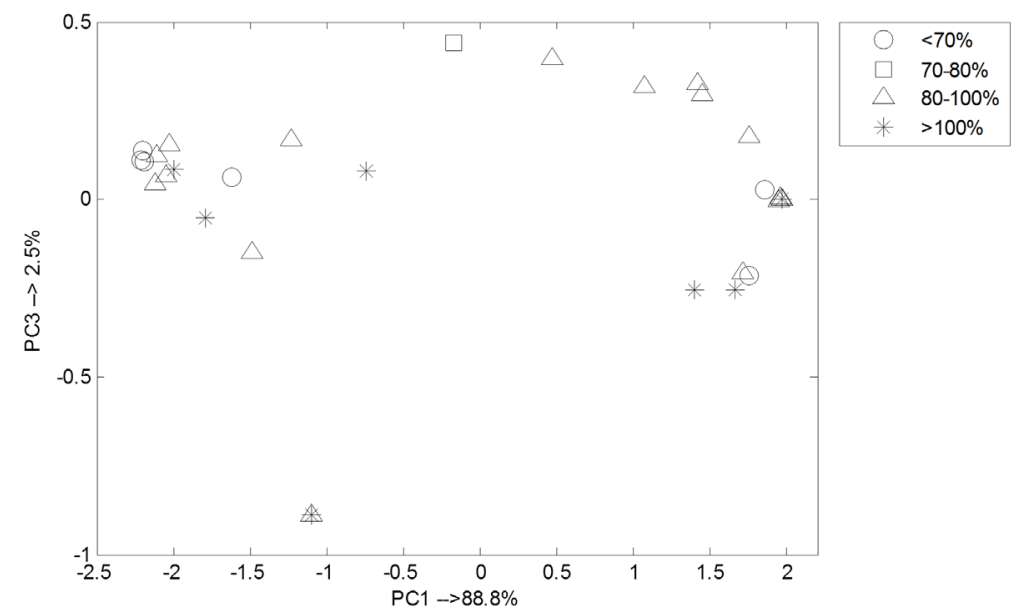

Figure S5.1e External factor: forced expiratory volume in 1 second as \% of predicted value

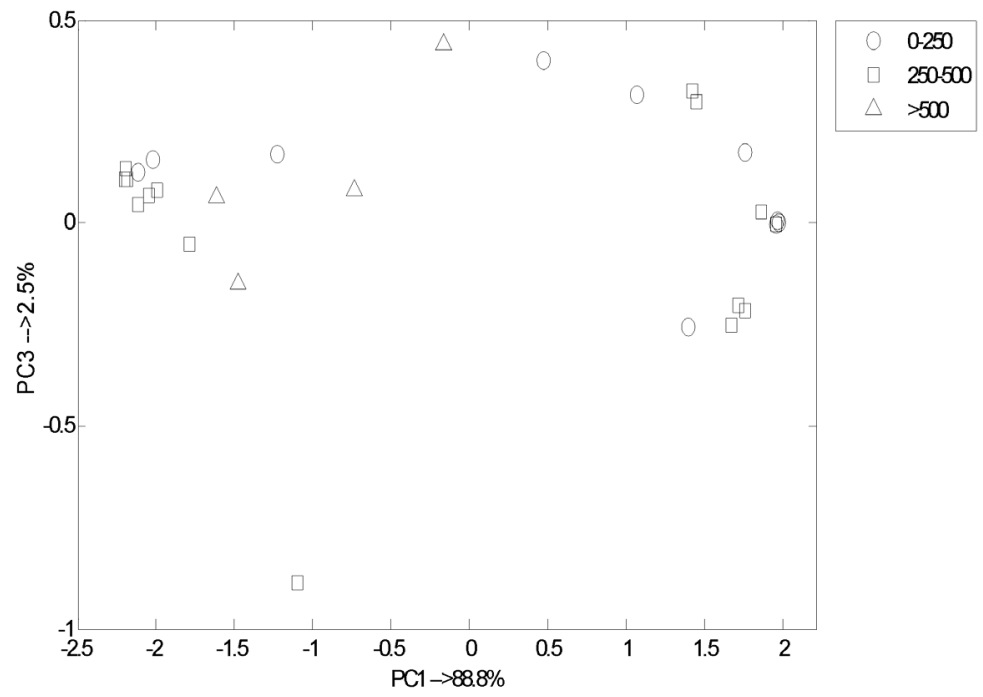

Figure S5.1f External factor: daily dose of inhaled corticosteroids 


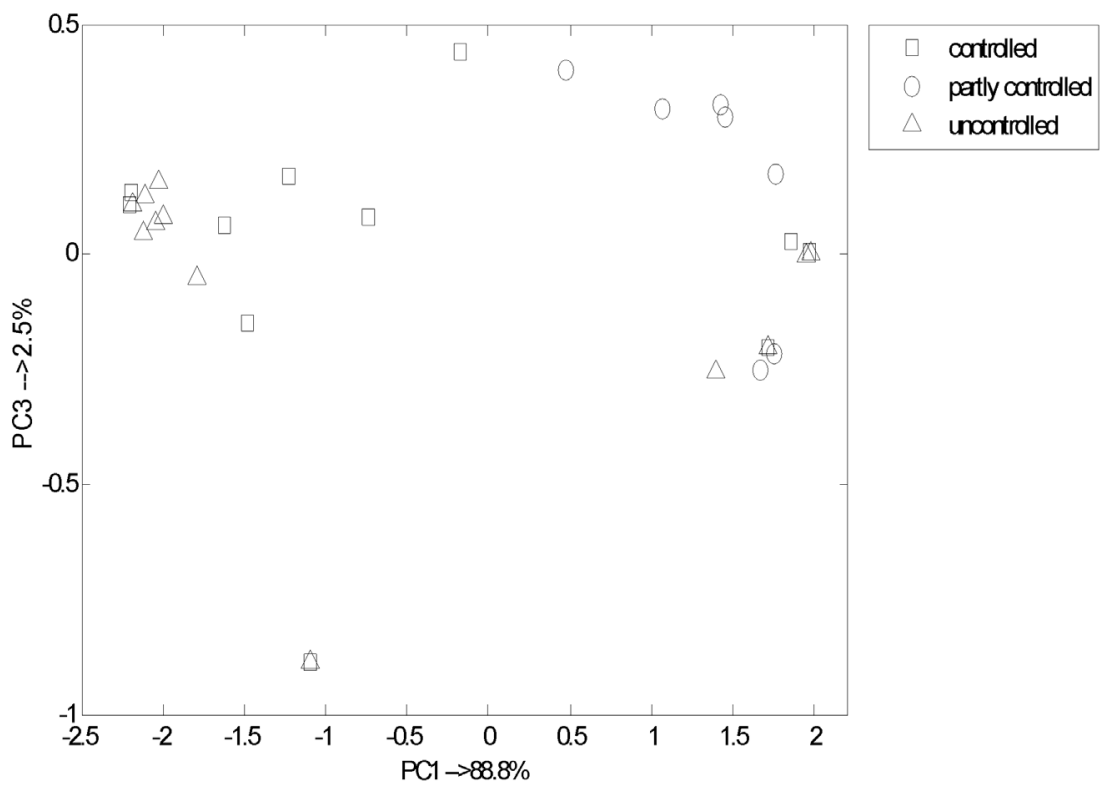

Figure S5.1g External factor: asthma level of control based on the asthma control questionnaire

Figure S5.1 Distribution of different external factors in the PCA score plot of the final classification model for prediction of asthma exacerbations 14 days after clinical visit: separation of stable children $(n=16)$ and children with an exacerbation 14 days after sampling*

* (for PCA-plot separation of stable children and children with an exacerbation 14 days after sampling see figure 5.2) 


\section{References}

1. Fact sheet $N^{\circ} 307$. World Health Organization Nov 2013 [cited; Available from: http://www.who.int/ mediacentre/factsheets/fs307/en/index.html

2. Gustafsson PM, Watson L, Davis KJ, Rabe KF. Poor asthma control in children: evidence from epidemiological surveys and implications for clinical practice. Int J Clin Pract 2006: 60(3): 321-334.

3. Rabe KF, Adachi M, Lai CK, Soriano JB, Vermeire PA, Weiss KB, Weiss ST. Worldwide severity and control of asthma in children and adults: the global asthma insights and reality surveys. The Journal of allergy and clinical immunology 2004: 114(1): 40-47.

4. Jang J, Gary Chan KC, Huang H, Sullivan SD. Trends in cost and outcomes among adult and pediatric patients with asthma: 2000-2009. Annals of allergy, asthma \& immunology : official publication of the American College of Allergy, Asthma, \& Immunology 2013: 111(6): 516-522.

5. Global strategy for asthma management and prevention. Global Initiative for Asthma (GINA) 2012 [cited; Available from: ginasthma.org/local/uploads/files/GINA_Report_March13.pdf

6. de Jongste JC. Astma bij kinderen; herziene richtlijnen van de sectie kinderlongziekten van de NVK [Asthma in children; revised guidelines of the paediatric department of the Dutch Paediatric Society], Amsterdam, 2007.

7. National Heart Lung and Blood Instutute NAEaPP. Expert panel Report 3: Guidelines for the diagnosis and management of asthma. 2007.

8. de Jongste JC, Carraro S, Hop WC, Group CS, Baraldi E. Daily telemonitoring of exhaled nitric oxide and symptoms in the treatment of childhood asthma. American journal of respiratory and critical care medicine 2009: 179(2): 93-97.

9. Petsky HL, Cates CJ, Lasserson TJ, Li AM, Turner C, Kynaston JA, Chang AB. A systematic review and meta-analysis: tailoring asthma treatment on eosinophilic markers (exhaled nitric oxide or sputum eosinophils). Thorax 2012: 67(3): 199-208.

10. Petsky HL, Li AM, Au CT, Kynaston JA, Turner C, Chang AB. Management based on exhaled nitric oxide levels adjusted for atopy reduces asthma exacerbations in children: A dual centre randomized controlled trial. Pediatric pulmonology 2014: [Epub ahead of print].

11. Barnes PJ. Reactive oxygen species and airway inflammation. Free radical biology \& medicine 1990: 9(3): 235-243.

12. Boots AW, van Berkel JJ, Dallinga JW, Smolinska A, Wouters EF, van Schooten FJ. The versatile use of exhaled volatile organic compounds in human health and disease. Journal of breath research 2012: 6(2): 027108.

13. Dallinga JW, Robroeks CM, van Berkel JJ, Moonen EJ, Godschalk RW, Jobsis Q, Dompeling E, Wouters EF, van Schooten FJ. Volatile organic compounds in exhaled breath as a diagnostic tool for asthma in children. Clinical and experimental allergy : journal of the British Society for Allergy and Clinical Immunology 2010: 40(1): 68-76.

14. Ibrahim B, Basanta M, Cadden P, Singh D, Douce D, Woodcock A, Fowler SJ. Non-invasive phenotyping using exhaled volatile organic compounds in asthma. Thorax 2011: 66(9): 804-809.

15. Olopade CO, Zakkar M, Swedler WI, Rubinstein I. Exhaled pentane levels in acute asthma. Chest 1997: 111(4): 862-865.

16. Robroeks CM, van Berkel JJ, Jobsis Q, van Schooten FJ, Dallinga JW, Wouters EF, Dompeling E. Exhaled volatile organic compounds predict exacerbations of childhood asthma in a 1-year prospective study. The European respiratory journal 2013: 42(1): 98-106.

17. Caldeira M, Barros AS, Bilelo MJ, Parada A, Camara JS, Rocha SM. Profiling allergic asthma volatile metabolic patterns using a headspace-solid phase microextraction/gas chromatography based methodology. Journal of chromatography A 2011: 1218(24): 3771-3780.

18. Caldeira M, Perestrelo R, Barros AS, Bilelo MJ, Morete A, Camara JS, Rocha SM. Allergic asthma exhaled breath metabolome: a challenge for comprehensive two-dimensional gas chromatography. Journal of chromatography A 2012: 1254: 87-97.

19. Gahleitner F, Guallar-Hoyas C, Beardsmore CS, Pandya HC, Thomas CP. Metabolomics pilot study to identify volatile organic compound markers of childhood asthma in exhaled breath. Bioanalysis 2013: 5(18): 2239-2247.

20. Meyer N, Dallinga JW, Nuss S, Moonen E, van Berkel J, Akdis C, van Schooten F, Menz G. Defining 
adult asthma endotypes by clinical features and patterns of volatile organic compounds in exhaled air. Respiratory research 2014: 15(1): 136.

21. van Vliet D, van Horck M, van de Kant K, Vaassen S, Gulikers S, Winkens B, Rosias P, Heynens J, Muris J, Essers B, Jobsis Q, Dompeling E. Electronic monitoring of symptoms and lung function to assess asthma control in children. Annals of allergy, asthma \& immunology : official publication of the American College of Allergy, Asthma, \& Immunology 2014: 113(3): 257-262 e251.

22. Dales RE, Spitzer WO, Tousignant P, Schechter M, Suissa S. Clinical interpretation of airway response to a bronchodilator. Epidemiologic considerations. Am Rev Respir Dis 1988: 138(2): 317320.

23. Robroeks CM, van Vliet D, Jobsis Q, Braekers R, Rijkers GT, Wodzig WK, Bast A, Zimmermann LJ, Dompeling E. Prediction of asthma exacerbations in children: results of a one-year prospective study. Clinical and experimental allergy : journal of the British Society for Allergy and Clinical Immunology 2012: 42(5): 792-798.

24. Juniper EF, Gruffydd-Jones K, Ward S, Svensson K. Asthma Control Questionnaire in children: validation, measurement properties, interpretation. The European respiratory journal 2010: 36(6): 1410-1416.

25. American Thoracic S, European Respiratory S. ATS/ERS recommendations for standardized procedures for the online and offline measurement of exhaled lower respiratory nitric oxide and nasal nitric oxide, 2005. American journal of respiratory and critical care medicine 2005: 171(8): 912-930.

26. Dallinga JW, Smolinska A, van Schooten FJ. Analysis of volatile organic compounds in exhaled breath by gas chromatography-mass spectrometry combined with chemometric analysis. Methods in molecular biology 2014: 1198: 251-263.

27. Amann A, de Lacy Costello B, Miekisch W, Schubert J, Buszewski B, Pleil J, Ratcliffe N, Risby T. The human volatilome: volatile organic compounds (VOCs) in exhaled breath, skin emanations, urine, feces and saliva. Journal of breath research 2014: 8(3): 034001.

28. Fens N, van der Schee MP, Brinkman P, Sterk PJ. Exhaled breath analysis by electronic nose in airways disease. Established issues and key questions. Clinical and experimental allergy : journal of the British Society for Allergy and Clinical Immunology 2013: 43(7): 705-715.

29. Sterk PJ, Fabbri LM, Quanjer PH, Cockcroft DW, O’Byrne PM, Anderson SD, Juniper EF, Malo JL. Airway responsiveness. Standardized challenge testing with pharmacological, physical and sensitizing stimuli in adults. Report Working Party Standardization of Lung Function Tests, European Community for Steel and Coal. Official Statement of the European Respiratory Society. The European respiratory journal Supplement 1993: 16: 53-83.

30. Reddel HK, Taylor DR, Bateman ED, Boulet LP, Boushey HA, Busse WW, Casale TB, Chanez P, Enright PL, Gibson PG, de Jongste JC, Kerstjens HA, Lazarus SC, Levy ML, O'Byrne PM, Partridge MR, Pavord ID, Sears MR, Sterk PJ, Stoloff SW, Sullivan SD, Szefler SJ, Thomas MD, Wenzel SE, American Thoracic Society/European Respiratory Society Task Force on Asthma C, Exacerbations. An official American Thoracic Society/European Respiratory Society statement: asthma control and exacerbations: standardizing endpoints for clinical asthma trials and clinical practice. American journal of respiratory and critical care medicine 2009: 180(1): 59-99.

31. Smolinska A, Hauschild AC, Fijten RR, Dallinga JW, Baumbach J, van Schooten FJ. Current breathomics-a review on data pre-processing techniques and machine learning in metabolomics breath analysis. Journal of breath research 2014: 8(2): 027105.

32. Buszewski B, Kesy M, Ligor T, Amann A. Human exhaled air analytics: biomarkers of diseases. Biomedical chromatography : BMC 2007: 21(6): 553-566.

33. Spanel P, Smith D. Volatile compounds in health and disease. Current opinion in clinical nutrition and metabolic care 2011: 14(5): 455-460.

34. Bateman ED, Reddel HK, Eriksson G, Peterson S, Ostlund O, Sears MR, Jenkins C, Humbert M, Buhl R, Harrison TW, Quirce S, O'Byrne PM. Overall asthma control: the relationship between current control and future risk. The Journal of allergy and clinical immunology 2010: 125(3): 600608, 608 e601-608 e606.

35. Corradi M, Folesani G, Andreoli R, Manini P, Bodini A, Piacentini G, Carraro S, Zanconato S, Baraldi $\mathrm{E}$. Aldehydes and glutathione in exhaled breath condensate of children with asthma exacerbation. American journal of respiratory and critical care medicine 2003: 167(3): 395-399. 
36. Pryor WA, Godber SS. Noninvasive measures of oxidative stress status in humans. Free radical biology \& medicine 1991: 10(3-4): 177-184.

37. van Berkel JJ, Dallinga JW, Moller GM, Godschalk RW, Moonen E, Wouters EF, van Schooten FJ. Development of accurate classification method based on the analysis of volatile organic compounds from human exhaled air. Journal of chromatography B, Analytical technologies in the biomedical and life sciences 2008: 861(1): 101-107. 



\title{
Chapter 6
}

\section{Prediction of asthma exacerbations in children} by innovative exhaled inflammatory markers: results of a longitudinal study

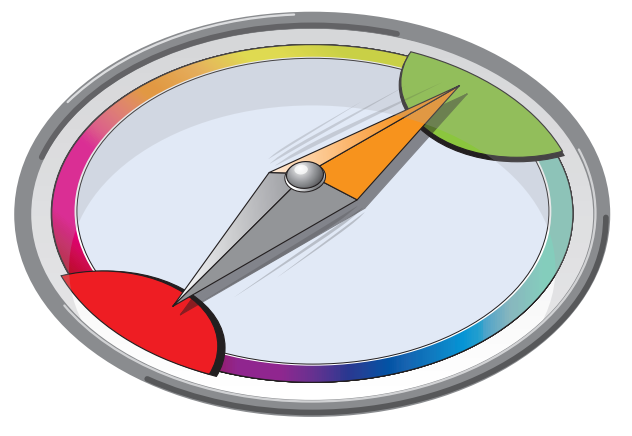

\author{
Van Vliet D \\ Alonso A \\ Rijkers GT \\ Heynens JW \\ Rosias PPR \\ Muris JWM \\ Jöbsis $Q$ \\ Dompeling $\mathrm{E}$
}




\section{Abstract}

\section{Background}

In asthma management guidelines the primary goal of treatment is asthma control. To date, asthma control, guided by symptoms and lung function, is not optimal in many children and adults. Direct monitoring of airway inflammation in exhaled breath may improve asthma control and reduce the number of exacerbations.

\section{Objectives}

1. To study the use of fractional exhaled nitric oxide (FeNO) and inflammatory markers in exhaled breath condensate (EBC), in the prediction of asthma exacerbations in a paediatric population.

2. To study the predictive power of these exhaled inflammatory markers combined with clinical parameters.

\section{Methods}

96 asthmatic children were included in this one-year prospective observational study, with clinical visits every 2 months. Between visits, daily symptom scores and lung function were recorded using a home monitor. During clinical visits, asthma control and FeNO were assessed. Furthermore, lung function measurements were performed and EBC was collected. Statistical analysis was performed using a test dataset and validation dataset for 1) conditionally specified models, receiver operating characteristic-curves (ROC-curves); 2) $k$-nearest neighbors algorithm.

\section{Results}

Three conditionally specified predictive models were constructed. Model 1 included inflammatory markers in EBC alone, model 2 included FeNO plus clinical characteristics and the ACQ score, and model 3 included all the predictors used in model 1 and 2 . The area under the ROC-curves was estimated as $47 \%, 54 \%$ and $59 \%$ for models 1,2 and 3 respectively. The $k$-nearest neighbors predictive algorithm, using the information of all the variables in model 3 , produced correct predictions for $52 \%$ of the exacerbations in the validation dataset.

\section{Conclusion}

The predictive power of FeNO and inflammatory markers in EBC for prediction of an asthma exacerbation was low, even when combined with clinical characteristics and symptoms. Qualitative improvement of the chemical analysis of EBC may lead to a better non-invasive prediction of asthma exacerbations. 


\section{Introduction}

Asthma is the most common chronic inflammatory disorder in children. ${ }^{1}$ Worldwide epidemiological studies show that asthma is still not optimally controlled in many children and adults, despite proper pharmacotherapy and emphasis on asthma control in international asthma management guidelines. ${ }^{2-6}$ Asthma control is determined by clinical symptoms, lung function, and occurrence of asthma exacerbations..$^{2-4}$ Exacerbations are accompanied by loss of quality of life, higher costs due to extra clinical visits and absence from school and work. ${ }^{7}$

Currently, management of asthma and titration of treatment is based on the level of asthma control determined by symptoms and lung function. ${ }^{2-4}$ However, these measures of asthma control do not give direct insight into the underlying inflammatory process. Measures of airway inflammation such as fractional exhaled nitric oxide (FeNO) and biomarkers in exhaled breath condensate $(E B C)$ reflect airway inflammation in a non-invasive manner. This is in contrast with an invasive procedure such as bronchoscopy with assessment of inflammatory markers in bronchial alveolar lavage or biopsies. ${ }^{8}$ These procedures are too invasive for routine and repeated use (in children). It is hypothesized that the management of asthma may improve by monitoring of airway inflammation and by titration of treatment on the basis of inflammatory parameters in exhaled breath..$^{9,10}$

In a previous longitudinal study in 40 children with asthma, exacerbations were predicted by Interleukin 5 (IL-5) in EBC and acidity of EBC (Inflammation Asthma Monitoring, FLAMEstudy). ${ }^{9}$ FeNO is an exhaled marker of inflammation, which reflects eosinophilic airway inflammation. ${ }^{11}$ So far, titration of medication based on FeNO has not been associated with significant decrease in the number of exacerbations. ${ }^{11-13}$ However, 1 study was underpowered, which may have contributed to this finding. Moreover, the predictive value of FeNO for an asthma exacerbation may improve, when combined with clinical characteristics and other exhaled markers of inflammation.

Before this concept of treating asthmatic children based on these exhaled markers of inflammation can be tested in a clinical randomized controlled trial (RCT), the accuracy of this method should be confirmed in a new population. Therefore, the aims of this study are:

1. To assess the predictive power of FeNO and inflammatory markers in EBC, and their combination for asthma exacerbations in a paediatric population.

2. To assess the predictive power for asthma exacerbations of exhaled markers of inflammation combined with clinical characteristics such as atopy, bronchial hyperresponsiveness, reversibility to a bronchodilator, asthma control, and daily dosage of inhaled corticosteroids (ICS). 


\section{Methods}

\section{Study design and patients}

Children between 6 and 18 years old with doctor-diagnosed asthma were recruited for this one-year observational cohort study (clinicaltrial.gov NCT 01239238). All children had been treated for asthma at the outpatient clinic of 2 specialized paediatric pulmonology centres for at least 6 months and used inhaled corticosteroids during the year preceding the study. Asthma was defined by the criteria of the Global Initiative for Asthma (GINA) and the guidelines of the Dutch Society of Paediatrics as: 1) presence of asthma symptoms and use of ICS during the year preceding the study ${ }^{2,4}$; 2) reversibility to a $\beta_{2-}$ agonist defined as an increase in $\mathrm{FEV}_{1}$ of $\geq 9 \%$ of predicted value ${ }^{4,14}$, as described before ${ }^{9}$; and/or 3 ) presence of bronchial hyperresponsiveness (defined as a $>20 \%$ drop in $\mathrm{FEV}_{1}$ after the inhalation of histamine with a concentration $\leq 8 \mathrm{mg} / \mathrm{ml}) .{ }^{4}$ Exclusion criteria were: 1 ) technical unsatisfactory performance of lung function measurements, 2) presence of cardiac abnormalities, 3) mental retardation, 4) congenital abnormalities or existence of a syndrome, 5) active smoking, or 6) treatment with immunotherapy during the study.

During the study, the investigators were blinded for the study results. The parents received financial compensation for transportation costs to the clinic. The recruitment of patients started in November 2010 and the follow-up ended March 2013.

The Medical Ethical Committee of the Maastricht University Medical Centre approved this study. Informed consent was signed by all parents and by children aged 12 years and older.

\section{Study parameters and procedures}

The primary outcome measure was the occurrence of an exacerbation. Regular clinical visits took place every 2 months. During each clinical visit, the same measurements and sequence of procedures took place. All measurements were performed by 3 trained research nurses. First, children completed the Asthma Control Questionnaires (ACQ). FeNO assessment, EBC collection, and dynamic spirometry were then performed (table 6.1). Between clinical visits, daily home monitor assessments were performed by the children and electronic questionnaires were completed by the parents. 
Table 6.1 Overview of study parameters

\begin{tabular}{|c|c|c|c|c|c|c|c|}
\hline$\overline{\text { Visit }}$ & 0 & 2 & 4 & 6 & 8 & 10 & 12 \\
\hline & months & months & months & months & months & months & months \\
\hline$\overline{\mathrm{ACQ}}$ & $\bullet$ & $\bullet$ & $\bullet$ & $\bullet$ & $\bullet$ & • & $\bullet$ \\
\hline GINA symptom score* & - & - & - & • & • & • & • \\
\hline FeNO & - & • & • & • & • & • & • \\
\hline EBC collection & $\cdot$ & • & • & • & • & • & • \\
\hline Dynamic spirometry & - & • & • & • & • & • & • \\
\hline $\mathrm{PC}_{20}$ test & \multicolumn{7}{|c|}{ At the start of the study } \\
\hline Registration of exacerbations & \multicolumn{7}{|c|}{ During the entire study } \\
\hline Home monitoring ${ }^{\dagger}$ & \multicolumn{7}{|c|}{ During the entire study } \\
\hline
\end{tabular}

ACQ, Asthma Control Questionnaire; EBC, exhaled breath condensate; FeNO, Fractional exhaled Nitric Oxide; GINA, Global Initiative for Asthma; $\mathrm{PC}_{20}$, histamine bronchial hyperresponsiveness test.

* Symptom score based on the GINA criteria was collected during 2 weeks preceding the clinical visit. This score was combined with $\mathrm{FEV}_{1}$, to assess asthma control as defined by GINA.

† Home monitoring consisted of daily symptom score plus FEV ${ }_{1}$ measurements.

\section{Questionnaires}

The ACQ was used to assess asthma control at the clinical visits. ${ }^{15}$ The cut-off points used for level of asthma control were: $A C Q \leq 0.75$ (controlled asthma); $0.75<A C Q \leq 1.5$ (partly controlled); and $A C Q>1.5$ (uncontrolled asthma). The ACQ results were not used in the treatment protocol. Treatment (step-up/step-down) was based on asthma control using the GINA-criteria. ${ }^{2}$ For this purpose, the GINA-respiratory symptoms during the 2 weeks preceding clinical visits and lung function parameters during clinical visits were used.

\section{FeNO assessment}

FeNO was measured online using a NIOX analyser (Aerocrine, Solna, Sweden) according to American Thoracic Society/European Respiratory Society (ATS/ERS) criteria. ${ }^{16}$ The animation as provided by the manufacturer was used to support children to establish a stable airflow during the manoeuvre. A standard flow rate of $50 \pm 5 \mathrm{ml} / \mathrm{sec}$ was required for a correct manoeuvre.

\section{$E B C$ collection, storage and chemical analysis}

EBC was collected by means of an optimized borosilicate glass tube, cooled by circulating water of 0.7 degrees Celsius, as reported previously. ${ }^{17}$ Children breathed for 10 minutes into the tube, through a mouthpiece connected to a two way non-rebreathing (series 1420; Hans Rudolph Inc, Kansas City, USA) valve, which also served as a saliva trap. The child used a nose-clip, breathed tidally and was entertained by a movie or game. Acidity of the condensate was measured without de-aeration, immediately after collection (handheld $\mathrm{pH}$-meter, typePH1000H, and mic-micro-S7 pH sensor, VWR International B.V., NL, Germany). The 
EBC-samples were separated into aliquots and immediately frozen using dry ice and stored at -80 degrees Celsius. From collection to chemical analysis freeze-thaw cycles were avoided. ${ }^{18}$ For chemical analysis 1 sample of at least $60 \mu \mathrm{L}$ was thawed. The levels of interleukin (IL) 1a, IL-5, IL-6, IL-8, IL-13, IL-17 and tumor necrosis factor (TNF) a were determined using a commercially available high sensitivity bead-based flow immunoassays and concentrations were calculated using BioPlex software version 5.1 (Millipore, St Charles, MO, USA). The calibration line consisted of the calibration fluids that were added to the plate according to the manufacturer's protocol plus 2 sequential dilutions to decrease the lower limit of quantification (LLoQ) of the assay. The median LLoQ's assessed during analysis of the EBC samples were for IL-1a: 636 fg/ml, IL-5: 13 fg/ml, IL-6: 112 fg/ml, IL-8: 25 fg/ml, IL-13: 30 fg/ml, IL-17: 575 fg/ $\mathrm{ml}$ and TNFa: $23 \mathrm{fg} / \mathrm{ml}$.

Concentrations of samples were calculated by extrapolation when fluorescence indices were below the LLoQ, yet above background. If outcomes could not be extrapolated, a concentration of $50 \%$ of the lowest measured concentration for the specific marker was imputed like described previously. ${ }^{17}$

\section{Dynamic spirometry}

Dynamic spirometry was performed by means of the ZAN 100 spirometer, according to ATS/ERS standards (nSpire Health $\mathrm{GmbH}$, Oberthulba, Germany). ${ }^{19}$ The highest value of 3 correctly performed manoeuvres was used for analysis. Recorded parameters included: $\mathrm{FEV}_{1}$, forced vital capacity (FVC) and maximum expiratory flow at $50 \%$ of FVC $\left(\mathrm{MEF}_{50}\right)$, all expressed as a percentage of the predicted value. Subsequently, the patient inhaled $400 \mu \mathrm{g}$ salbutamol by means of a spacer. After 15 minutes, a second lung function test was performed in order to assess the reversibility to a $\beta_{2}$-agonist. Patients were instructed to stop short-acting bronchodilators at least 8 hours and long-acting bronchodilators at least 48 hours before testing.

\section{Bronchial hyperresponsiveness}

Bronchial hyperresponsiveness was evaluated at the start of the study by a bronchial histamine challenge test. ${ }^{20}$ At first, an aerosol of buffered saline was inhaled, followed by aerosols of histamine solutions with doubling concentrations from $0.03 \mathrm{mg} / \mathrm{mL}$ to $16 \mathrm{mg} / \mathrm{mL}$, at intervals of 5 minutes. After complete inhalation of a solution, the $\mathrm{FEV}_{1}$ was measured at 30,90 and 120 seconds. The percentage decline in $\mathrm{FEV}_{1}$ was calculated and the test was stopped when a drop of $20 \%$ or more in $\mathrm{FEV}_{1}$ occurred, or the highest concentration of $16 \mathrm{mg} / \mathrm{mL}$ histamine was administered. The $\mathrm{PC}_{20}$ was calculated from a log concentration versus dose response curve. After reaching the threshold, children inhaled 800 microgram salbutamol, followed by 3 maximal expiratory flow volume manoeuvres. $16 \%$ of the $\mathrm{PC}_{20}$ tests were missing, because of recurrent active airway infections, inability to stop antihistamines or bronchodilators, or calibration errors of the histamine nebulizer. 


\section{Atopy}

Atopy was defined by either a positive Phadiatop (Phadia, Uppsala, Sweden) or RAST (Pharmacia, Uppsala, Sweden) or Allergen Skin test. In 3\% of the children allergy tests were missing.

\section{Home monitoring}

Daily home monitoring was performed using an AM2+ home monitor (Jaeger, CareFusion, Houten, The Netherlands). Participants were asked to use the home monitor on a daily basis at approximately the same time of the day and were carefully and repeatedly instructed. The AM2+ home monitor is a hand held monitor that can store respiratory symptom scores and lung function measurements. The respiratory symptom score consisted of a short questionnaire including asthma symptoms based on the GINA-criteria for asthma control. The lung function measurements consisted of 3 manoeuvres with maximal effort to achieve $F_{E V}$. The highest FEV 1 value of each day was selected for each patient. The data were transferred into a secured portal twice a week.

\section{Definition of asthma exacerbations}

Moderate or severe asthma exacerbations were defined according to the latest ATS/ERS criteria. $^{21}$

\section{Asthma treatment protocol during study}

Asthma medication was titrated based on the GINA asthma level of control, according to the GINA guidelines and the guidelines of the Paediatric Pulmonology section of the Dutch Society of Paediatrics. ${ }^{2,4}$ In the adjustment of treatment, FeNO values, markers in EBC or home monitor results were not taken into account.

\section{Sample size calculation}

The criterion for sample size calculation was reliable estimation of sensitivity and specificity of the predictive model. We considered a maximum estimation error of sensitivity or specificity of 0.15 . The corresponding standard error is 0.075 (Maximal SE $=2 * S E ;$ Max $S E=0.15 / 2=0.075$ ). We expected a true risk of exacerbation of $45 \%$, based on the previous FLAME-study. ${ }^{9}$ This resulted in inclusion of at least 91 children $\left(S E=\right.$ sqrt $\left(p^{*}(1-p) / N\right)$, where $p=$ true sensitivity or specificity, $\mathrm{N}=$ sample size for that group). We assumed a dropout rate of $10 \%$ during 1 year follow-up, so we aimed to include at least 100 children.

\section{Statistical data analysis}

All the statistical analyses were carried out using the SAS software package version 9.2. In the explanatory analysis of the data numerical variables were summarized using means and standard deviations (SD), or medians and inter quartile ranges (IQR, i.e. $25^{\text {th }}-75^{\text {th }}$ percentile). 
Furthermore, categorical variables were summarized using frequency tables and percentages. Due to the longitudinal nature of the study, responses from the same patient are naturally correlated. To account for this correlation conditional models were used. Conditional models describe the current outcome of a patient, in a sequence of longitudinal measurements, conditional upon (subsets of) the previous outcomes and covariates. ${ }^{22}$ In the present study the probability of an asthma exacerbation between the current and next visit was modelled using 3 conditional models. The first model used the 8 cytokines in EBC (IL-1a, IL-5, IL-6, IL8, IL-13, IL-17, TNF $\alpha$ ), sex, age, trial centre and the occurrence (or not) of an exacerbation in the period between the previous and current visit, as covariates. In the second model, FeNO, reversibility to a bronchodilator as increase in $\mathrm{FEV}_{1} \%$ of predicted value, $\mathrm{PC}_{20}$, daily dosage of ICS, atopy, ACQ score, sex, age and trial centre and the occurrence (or not) of an exacerbation in the period between the previous and current visit were used as covariates. In the third model, the covariates from the first and second model were combined. The models were fitted using the procedure GENMOD in SAS.

For the analysis 11 randomly selected patients (76 measurements) were used to create a validation dataset and measurements $(n=543)$ of all the remaining patients were included in a training dataset. All predictive models were estimated using the information in the training dataset. Posteriorly the predictive capability of inflammation markers was assessed using the information in the validation dataset. The predictive capability of the models was primarily evaluated using the area under the corresponding ROC-curves. Additionally, the percentage of correct predictions was also assessed using the validation data.

Alternatively, the $k$-nearest neighbors algorithm (KNN) was also used to evaluate the predictive performance of the exhaled markers of inflammation. ${ }^{23} \mathrm{KNN}$ is a non parametric lazy learning algorithm that uses vectors of predictors or covariates as training samples, each with a class label. The training phase of the algorithm consists only of storing the feature vectors and class labels of the patients in the training dataset. The KNN algorithm was implemented using the SAS procedure DISCRIM.

\section{Results}

\section{Patients}

In the 2 participating hospitals, 331 children with doctor-diagnosed asthma were asked to participate in the study. Of these children, 102 children and parents were willing to participate (figure 6.1). These children were assessed for eligibility based on inclusion criteria. Six of these children were excluded, because they could not perform dynamic spirometry manoeuvres correctly $(n=1)$, did not meet the asthma criteria $(n=4)$ or had comorbidity with difficulty in distinction of symptoms between the diseases $(n=1)$.

Figure 6.1 Consort flow diagram of the study 


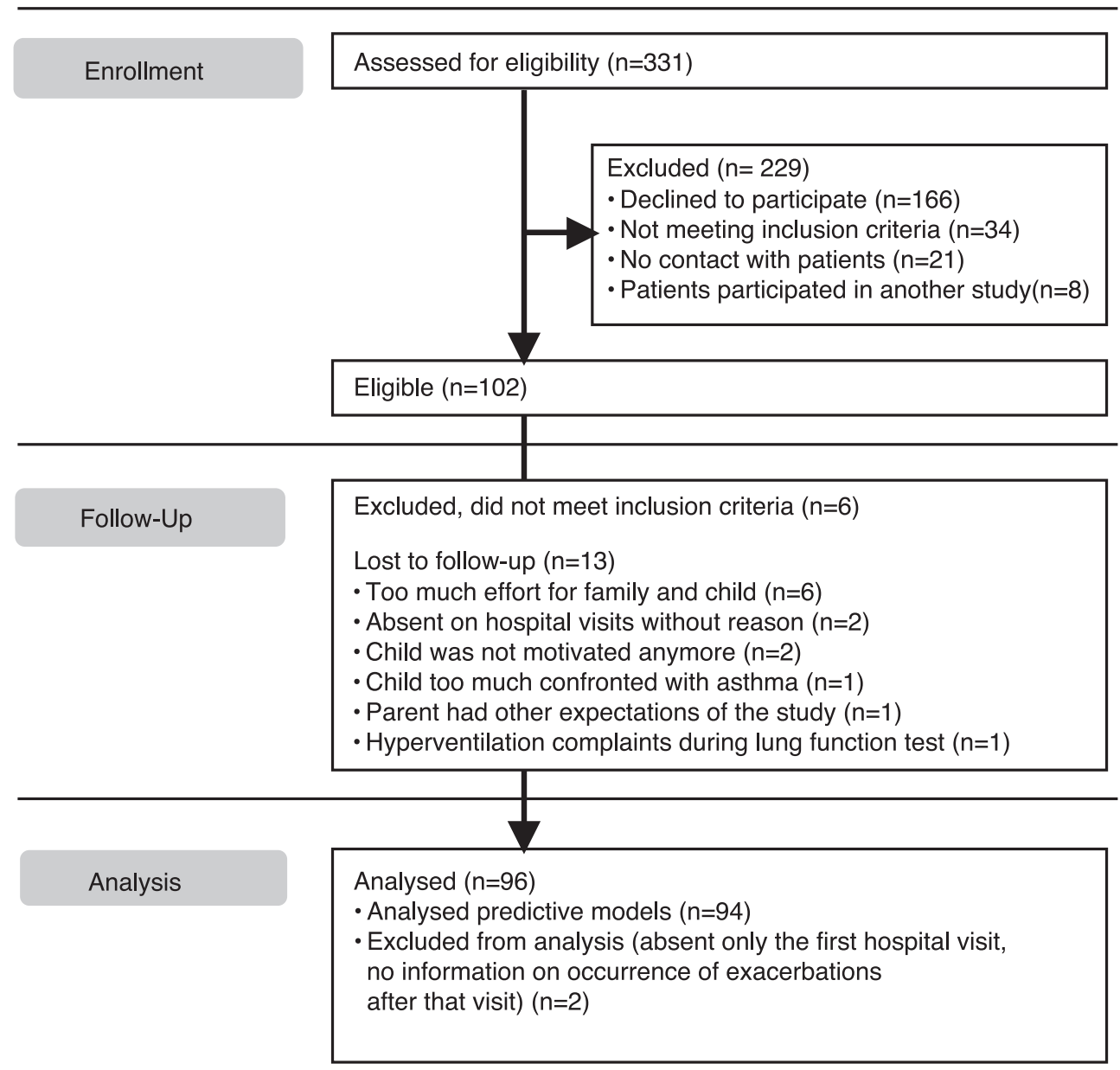

96 children with asthma started the study. The majority of subjects were atopic and had severe bronchial hyperresponsiveness despite a moderate daily dose of fluticasone (or equivalent) (table 6.2). There were no clinically relevant differences in baseline characteristics between the centres. During the study 13 children dropped out. Of these children, 2 were excluded from the statistical models because these children were only present during the first clinical visit and it was unknown whether they experienced an exacerbation in the following 2 months ('intention to treat analysis'). No protocol deviations occurred. 
Table 6.2 Patient characteristics at baseline

\begin{tabular}{|c|c|c|c|}
\hline & Total $n=96$ & Centre $A n=51$ & Centre $B \mathrm{n}=45$ \\
\hline Sex male, n (\%) & $50(52)$ & $27(53)$ & $23(51)$ \\
\hline Mean age [range] in years & $10[6-17]$ & $9[6-17]$ & $10[7-15]$ \\
\hline $\mathrm{FEV}_{1} \%$ predicted value, mean $\pm \mathrm{SD}$ & $96.8 \pm 14.2$ & $95.4 \pm 15.5$ & $98.4 \pm 12.7$ \\
\hline $\begin{array}{l}\text { Bronchodilator response, delta } \mathrm{FEV}_{1} \\
\% \text { predicted value: mean } \pm \mathrm{SD}\end{array}$ & $6.6 \pm 8.5$ & $6.7 \pm 9.8$ & $6.5 \pm 7.0$ \\
\hline ICS use, $\%$ & 94 & 90 & 98 \\
\hline $\begin{array}{l}\text { ICS Fluticasone daily dosage or } \\
\text { equivalent, mean } \pm S D^{*}\end{array}$ & $269 \pm 175$ & $295 \pm 202$ & $240 \pm 134$ \\
\hline$A C Q$, median [IQR] & $0.6[0.3-1]$ & $0.5[0.3-1.0]$ & $0.6[0.1-1.1]$ \\
\hline FeNO, ppb: median [IQR] & $12.5[8.0-31.0]$ & $13.0[8.0-35.0]$ & $12.0[8.0-27.0]$ \\
\hline $\mathrm{PC}_{20}, \mathrm{mg} / \mathrm{mL}:$ median $[\mathrm{IQR}]^{\dagger}$ & $1.2[0.3-2.9]$ & $1.0[0.3-2.3]$ & $1.4[0.4-3.2]$ \\
\hline Atopic, $\%^{\ddagger}$ & 76 & 77 & 76 \\
\hline
\end{tabular}

Centre A: Maastricht; Centre B: Sittard.

$A C Q$, Asthma Control Questionnaire; FeNO, Fractional exhaled Nitric Oxide; FEV ${ }_{1}$, forced expiratory volume in 1 second; ICS, Inhaled Corticosteroids; IQR, Inter Quartile Range; SD, Standard Deviation.

* Six children did not use ICS at baseline.

${ }^{\dagger} \mathrm{PC}_{20}$ : concentration of histamine inducing a $20 \%$ drop in $\mathrm{FEV}_{1}$.

${ }^{\ddagger}$ Atopy is defined as a positive Phadiatop (Phadia, Uppsala, Sweden), or RAST, or a positive allergen skin test.

\section{Frequency of exacerbations}

$48 \%$ of all 94 children experienced 1or more exacerbations during the study. Of all exacerbations 5 were severe in 5 children and 72 exacerbations were moderate.

\section{Description of exhaled markers of inflammation}

The mean time between collection of EBC and occurrence of an asthma exacerbation was 33 days (standard deviation 17 days). In table 6.3, the distribution of concentrations of FeNO, acidity of EBC and EBC inflammatory markers is given. The inflammatory markers in EBC and FeNO exhibited a large variability in concentrations as reflected by the wide ranges and IQR. 
Table 6.3 Concentrations of inflammatory markers in EBC and FeNO

\begin{tabular}{llllll}
\hline Inflammatory markers & $\mathrm{n}$ & Minimum & Maximum & Median & IQR \\
\hline $\mathrm{pH}$ & 611 & 3.31 & 8.80 & 5.80 & $5.52,6.20$ \\
$\mathrm{IL}-1 \mathrm{\alpha}, \mathrm{fg} / \mathrm{ml}$ & 619 & 0.30 & 23482.80 & 98.00 & $0.30,483.20$ \\
$\mathrm{IL}-5, \mathrm{fg} / \mathrm{ml}$ & 619 & 0.05 & 169.20 & 2.75 & $0.05,19.33$ \\
$\mathrm{IL}-6, \mathrm{fg} / \mathrm{ml}$ & 619 & 0.10 & 207.10 & 1.45 & $0.10,21.20$ \\
$\mathrm{IL}-8, \mathrm{fg} / \mathrm{ml}$ & 619 & 0.01 & 4508.51 & 0.01 & $0.01,2.30$ \\
$\mathrm{IL}-13, \mathrm{fg} / \mathrm{ml}$ & 619 & 0.05 & 393.80 & 4.43 & $0.05,31.30$ \\
$\mathrm{IL}-17, \mathrm{fg} / \mathrm{ml}$ & 619 & 0.15 & 1977.10 & 11.08 & $0.15,184.53$ \\
$\mathrm{TNF}, \mathrm{fg} / \mathrm{ml}$ & 619 & 0.01 & 352.10 & 0.63 & $0.01,11.45$ \\
FeNO, ppb & 612 & 5.00 & 196.00 & 15.00 & $9.00,27.00$ \\
\hline
\end{tabular}

EBC, Exhaled Breath Condensate; FeNO, Fractional exhaled Nitric Oxide; IL, interleukin; TNF, tumor necrosis factor.

\section{Predictive power of exhaled marker of inflammation}

The results obtained from model 1 clearly illustrate that information on acidity of EBC and inflammatory markers in EBC alone are not suffice to carry out accurate predictions (figure 6.2). The estimated parameters for this model are provided in table 6.4. Notice that, although interesting in an explanatory context, the point estimates and $p$-values are rather irrelevant in a prediction context. More relevant in a prediction scenario is the area under the ROC-curve and for model 1 it was estimated as $47 \%$ (figure 6.2). The area under the ROC-curve of model 2, consisting of FeNO and clinical characteristics was estimated as 54\% (figure 6.2).

As expected, adding more predictors further improved the predictive performance of the model. For instance, for the most complex model 3 the area under the curve equalled $59 \%$ (figure 6.2). Nonetheless, the performance of all models was rather poor and the confidence interval for the area under the curve contained the random guessing value $50 \%$ for all the models. 


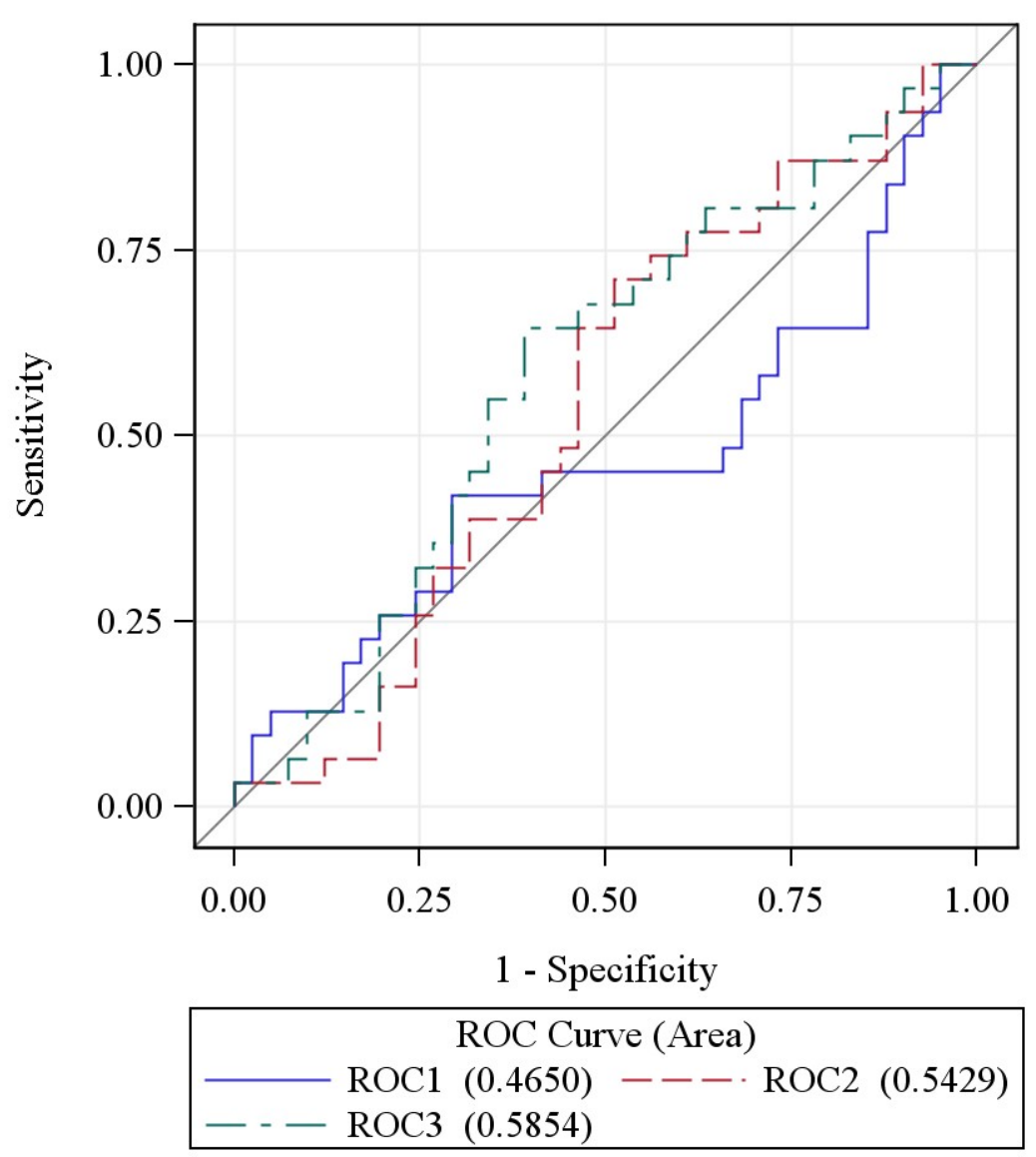

Figure 6.2 Overview of ROC-curves of 3 predictive models for asthma exacerbations*

* ROC1: exacerbation prediction model on the basis of the acidity of EBC and inflammatory markers in EBC alone; ROC2: model on the basis of FeNO, reversibility to a bronchodilator as increase in FEV1 \% of predicted value, $\mathrm{PC}_{20}$, daily dosage of ICS; ROC3: model all variables of model 1 and 2 . 
Table 6.4 Performance of acidity of EBC, inflammatory markers in EBC, FeNO, and asthma clinical characteristics in prediction of asthma exacerbation

\begin{tabular}{llll}
\hline Inflammatory markers & estimate & $95 \% \mathrm{Cl}$ & $\mathrm{p}$-value \\
\hline $\mathrm{pH}$ & 0.345 & $-0.029,0.718$ & 0.071 \\
$\mathrm{IL}-1 \alpha$ & -0.0004 & $-0.001,0.0001$ & 0.100 \\
IL-5 & 0.014 & $-0.019,0.047$ & 0.394 \\
IL-6 & 0.002 & $-0.015,0.020$ & 0.798 \\
IL-8 & -0.004 & $-0.012,0.003$ & 0.260 \\
IL-13 & -0.005 & $-0.018,0.009$ & 0.488 \\
IL-17 & -0.001 & $-0.002,0.001$ & 0.359 \\
TNFa & -0.001 & $-0.053,0.051$ & 0.960 \\
FeNO & -0.011 & $-0.029,0.007$ & 0.228 \\
Atopy & -0.182 & $-0.985,0.620$ & 0.656 \\
PC ${ }_{20}$ & -0.129 & $-0.347,0.090$ & 0.248 \\
Bronchodilator response, delta FEV ${ }_{1}$ \% predicted value & -0.047 & $-0.104,0.011$ & 0.111 \\
daily dosage of ICS & -0.001 & $-0.003,0.001$ & 0.308 \\
ACQ score & 0.082 & $-0.424,0.589$ & 0.751 \\
\hline
\end{tabular}

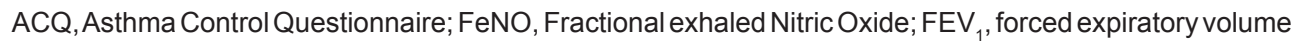
in 1 second; ICS, Inhaled Corticosteroids; IL, interleukin; $\mathrm{PC}_{20}$, histamine bronchial hyperresponsiveness test; TNF, tumor necrosis factor.

Similar results were obtained when the KNN algorithm was used. Similar to ROC-curves, the most complex model 3 delivered the best prediction when using the KNN algorithm. In fact, model 3 showed an overall correct prediction of $52 \%$ in the validation dataset (table 6.5).

Table 6.5 KNN- prediction of asthma exacerbation based on acidity of EBC, inflammatory markers in EBC, FeNO, and asthma clinical characteristics *

\begin{tabular}{|c|c|c|c|}
\hline \multicolumn{4}{|c|}{ Prediction } \\
\hline Exacerbation & No n(\%) & Yes $n(\%)$ & Total $\mathrm{n}(\%)$ \\
\hline No $n(\%)$ & $24(33)$ & $17(24)$ & $41(57)$ \\
\hline Yes n(\%) & $17(24)$ & $14(19)$ & $31(43)$ \\
\hline Total n(\%) & $41(57)$ & $31(43)$ & $72(100)$ \\
\hline
\end{tabular}

${ }^{*} \mathrm{KNN}$ algorithm is performed as statistical technique. 


\section{Discussion}

In this study we investigated the prediction of asthma exacerbations in children by means of exhaled inflammatory markers (acidity of EBC, inflammatory markers in EBC, FeNO) and clinical asthma characteristics. Collection of EBC was successful in all children. The ability of a combination of acidity of EBC and inflammatory markers in EBC and FeNO to predict asthma exacerbations in children was poor. The prediction improved by the combination of exhaled inflammatory markers and clinical characteristics (reversibility to a bronchodilator, $\mathrm{PC}_{20}$, daily dosage of ICS). However, FeNO and clinical characteristics had no additional value on the predictive power of inflammatory markers in EBC. The AUC for the model with all the variables was $59 \%$, which was close to the level of $50 \%$ of random guessing. Thus, FeNO and inflammatory markers in EBC assessments every 2 months, were not useful for the prediction of exacerbations in this study.

Neither acidity of EBC, inflammatory markers in EBC, FeNO, nor the combination of these biomarkers was able to predict asthma exacerbations in children. Few studies have focused on the ability of cytokines or chemokines in EBC to predict asthma exacerbations. Therefore, we have compared our results with studies assessing related and/or distinct inflammatory markers in $\mathrm{EBC}$, or cytokines in BAL or sputum of children with asthma exacerbations.

First, we reviewed the studies which assessed the same EBC markers in exacerbations of childhood asthma. Our finding of poor predictive capabilities of cytokines/chemokines in EBC in this study is in contrast to findings of an earlier study. ${ }^{9}$ Robroeks et al. reported that IL-5 in and the $\mathrm{pH}$ of $\mathrm{EBC}$ were predictors for exacerbations in 40 children with asthma in the FLAMEstudy. ${ }^{9}$ There is considerable overlap between the FLAME-study and our study regarding design, measurements and inclusion criteria. However, we were obliged to change the chemical analysis of EBC and have applied another statistical method to build the predictive model, which will be both discussed below. Second, we looked for published data regarding markers of inflammation in EBC and exacerbations in asthma. Baraldi et al. compared cysteinyl leukotrienes (CysLTs) concentrations in EBC at the start of an asthma exacerbation in asthmatic children, before and 5 days after prednisone treatment. ${ }^{24}$ Equal to the cytokines in our study, CysLTs are synthesized in the early-phase and late-phase asthmatic reaction. These investigators reported a significant decrease of CysLTs after treatment with prednisone. Debley et al. measured CysLTs in EBC in children during acute asthma exacerbations and 1, 2 and 4 weeks after hospital discharge. ${ }^{25}$ As the EBC CysLT concentrations changed little during 1 month follow-up period, their findings suggest that EBC CysLT concentrations do not discriminate between a stable period and an acute exacerbation. ${ }^{25}$ In line with CysLTs, hydrogen peroxide, a marker for oxidative stress, was not significantly changed after treatment with bronchodilators or oral steroids compared to during asthma exacerbation. ${ }^{26}$

Third, regarding cytokine biomarkers in sputum samples, IL-8 and IL-5 concentrations were 
assessed in (induced) sputum samples of asthmatic children during and 2 weeks after recovery of an acute asthma exacerbation. ${ }^{27}$ In this study IL-5 was only detectable in $29 \%$ of the sputum samples collected during asthma exacerbation and no significant change in IL-5 during the course of asthma exacerbation was found. ${ }^{27}$ The low detection rate of IL-5 corresponds to our finding that IL-5 has limited power to predict an asthma exacerbation. In contrast, IL-8 concentration was significantly reduced in sputum after recovery of the asthma exacerbation, which was not reflected in our EBC analysis. ${ }^{27}$

Fourth, our finding that FeNO could not predict an asthma exacerbation is in line with findings of De Jongste et al. and by a meta-analysis by Petsky et al. ${ }^{13,28}$ In the study of De Jongste et al. in atopic asthmatics, daily FeNO measurements took place, which limited the time span between FeNO measurements as much as possible. ${ }^{13}$ However, even in this case FeNO could not sufficiently predict an asthma exacerbation. In a recently performed RCT, management based on FeNO levels had a positive effect on asthma outcome. ${ }^{29}$ Although these researchers found that significantly fewer children in the FeNO group had $\geq 1$ exacerbation(s) compared to the control group, no statistically significant difference in exacerbation rate was detected between the groups. ${ }^{29}$ Therefore, our data and those of others suggest that FeNO is not an useful predictor for asthma exacerbations in children.

A strength of this study was the focus on a combination of noninvasive inflammatory markers (inflammatory markers in EBC in combination with FeNO) along with clinical parameters to predict asthma exacerbation in children using longitudinal assessments. Another strength was the use of a home monitor for collection of daily symptom scores and lung function $\left(F E V_{1}\right)$, in order to increase the chance to detect all exacerbations. Although we tried to keep the design and methods in the FLAME-study and the current study comparable, 2 important changes had to be made. First, the assay originally used to assess cytokines in EBC was no longer available. Therefore, we switched to a commercially available kit. Even though the original assay was reliable, switching also implicated that our method could be more easily transferred to other laboratories. Despite being sensitive, we were unable to reproduce the basic findings of the FLAME-study with the commercially available kit. ${ }^{9}$ This may indicate that this kit is not suitable for the EBC matrix and more effort has to be made to design assays suitable for EBC. Second, we switched to another statistical method, namely conditionally specified models, which is an advantage of the current study. ${ }^{22}$ This type of model has progressed the past years and takes into account the interdependency between repeated measurements within 1 child. In addition, 2 datasets were used for statistical analysis in the current study, namely a training dataset (543 measurements) and a validation dataset (76 measurements), whereas in the former FLAME-study only 1 dataset was analysed with Cox regression. It is not likely that switching models has affected the results of the current study.

We cannot exclude that we may have found different results if we had implemented shorter time periods between regular visits. The time frame of 2 months was based on the design of the 
FLAME-study in which we found significant results with 2-monthy intervals. With the observed discrepancies between the studies, these time frames remain a matter of further investigation. In a post hoc analysis based on results of daily FeNO measurements to predict an asthma exacerbation in children, at least 3 to 5 FeNO measurements in the 3 weeks preceding the exacerbation were needed to predict an exacerbation. ${ }^{30}$ One single measurement was not sufficient for prediction of an exacerbation. Overall, more work has to be done to determine the optimal time frame between an asthma exacerbation, and increase in parameters of airway inflammation. Therefore, choosing a shorter time between visits may be more successful, but may not be manageable for patients. Even in this study, patients dropped out because clinical visits every 2 months proved too cumbersome.

There are several explanations for the low predictive capabilities of inflammatory markers in EBC in this study. First, as mentioned, we have used commercially available hypersensitive kits to analyse the EBC samples. Despite being sensitive, the detection of cytokines in EBC did not meet expectations, which contributed to the poor predictive properties of the mediators. Second, the exhaled markers of inflammation behaved similarly in a period without exacerbations versus a period before and during an exacerbation. This may be the consequence of the large variability in concentrations of inflammatory markers in EBC. The variability could be influenced by: a) lack of sensitivity of antibodies of the assays used for chemical analysis, or b) lack of assays adjusted for use with EBC as matrix. The ICS daily dosage could not mask possible predictive properties of the inflammatory markers, because this clinical parameter was included in all predictive models.

So far neither assessment of biomarkers in EBC nor FeNO measurements, should be implemented in clinical care to predict an asthma exacerbation. Despite our findings, the non-invasive character of the inflammatory markers and direct measurement of airway inflammation keeps this approach attractive. More (methodological) research is needed 1) to develop EBC adjusted assays; 2) to develop appropriate storage techniques for EBC to avoid negative effects of the EBC matrix on the stability of cytokines (such as low pH). Similar to the dried blood spot storage method, an alternative option may be to absorb and store EBC onto filter paper and avoid negative effects of, for instance proteases. ${ }^{31}$ To establish these goals, more collaboration between researchers and industry is necessary and should be stimulated. Beside improvement of assays for inflammatory marker detection in EBC, new information regarding the metabolomics approach of EBC is promising. Metabolomic profiles demonstrated to be specific for severe asthma and to allow adequate discrimination from nonasthma patients. ${ }^{32,33}$

In conclusion, the power of FeNO and inflammatory markers in EBC separately or combined, for prediction of an asthma exacerbation with the current methodology was low. The results 
from the former FLAME-study could not be reproduced in this external validation study. This may be due to methodological problems associated with storage and analysis of EBC. There is an urgent need for improvement in the chemical analysis of inflammatory markers in EBC. 


\section{References}

1. Fact sheet No307. World Health Organization Nov 2013 [cited; Available from: http://www.who.int/ mediacentre/factsheets/fs307/en/index.html

2. Global strategy for asthma management and prevention. Global Initiative for Asthma (GINA) 2012 [cited; Available from: ginasthma.org/local/uploads/files/GINA_Report_March13.pdf

3. National Heart Lung and Blood Instutute NAEaPP. Expert panel Report 3: Guidelines for the diagnosis and management of asthma. 2007.

4. de Jongste JC. Astma bij kinderen; herziene richtlijnen van de sectie kinderlongziekten van de NVK [Asthma in children; revised guidelines of the paediatric department of the Dutch Paediatric Society], Amsterdam, 2007.

5. Gustafsson PM, Watson L, Davis KJ, Rabe KF. Poor asthma control in children: evidence from epidemiological surveys and implications for clinical practice. Int J Clin Pract 2006: 60(3): 321-334.

6. Rabe KF, Adachi M, Lai CK, Soriano JB, Vermeire PA, Weiss KB, Weiss ST. Worldwide severity and control of asthma in children and adults: the global asthma insights and reality surveys. The Journal of allergy and clinical immunology 2004: 114(1): 40-47.

7. Jang J, Gary Chan KC, Huang H, Sullivan SD. Trends in cost and outcomes among adult and pediatric patients with asthma: 2000-2009. Annals of allergy, asthma \& immunology : official publication of the American College of Allergy, Asthma, \& Immunology 2013: 111(6): 516-522.

8. Jackson AS, Sandrini A, Campbell C, Chow S, Thomas PS, Yates DH. Comparison of biomarkers in exhaled breath condensate and bronchoalveolar lavage. American journal of respiratory and critical care medicine 2007: 175(3): 222-227.

9. Robroeks CM, van Vliet D, Jobsis Q, Braekers R, Rijkers GT, Wodzig WK, Bast A, Zimmermann LJ, Dompeling E. Prediction of asthma exacerbations in children: results of a one-year prospective study. Clinical and experimental allergy : journal of the British Society for Allergy and Clinical Immunology 2012: 42(5): 792-798.

10. Thomas PS, Lowe AJ, Samarasinghe P, Lodge CJ, Huang Y, Abramson MJ, Dharmage SC, Jaffe A. Exhaled breath condensate in pediatric asthma: promising new advance or pouring cold water on a lot of hot air? a systematic review. Pediatric pulmonology 2013: 48(5): 419-442.

11. Petsky HL, Cates CJ, Li A, Kynaston JA, Turner C, Chang AB. Tailored interventions based on exhaled nitric oxide versus clinical symptoms for asthma in children and adults. Cochrane Database Syst Rev 2009(4): CD006340.

12. Pijnenburg MW, Bakker EM, Hop WC, de Jongste JC. Titrating steroids on exhaled nitric oxide in children with asthma: a randomized controlled trial. American journal of respiratory and critical care medicine 2005: 172(7): 831-836.

13. de Jongste JC, Carraro S, Hop WC, Group CS, Baraldi E. Daily telemonitoring of exhaled nitric oxide and symptoms in the treatment of childhood asthma. American journal of respiratory and critical care medicine 2009: 179(2): 93-97.

14. Dales RE, Spitzer WO, Tousignant P, Schechter M, Suissa S. Clinical interpretation of airway response to a bronchodilator. Epidemiologic considerations. Am Rev Respir Dis 1988: 138(2): 317320.

15. Juniper EF, Gruffydd-Jones K, Ward S, Svensson K. Asthma Control Questionnaire in children: validation, measurement properties, interpretation. The European respiratory journal 2010: 36(6): 1410-1416.

16. American Thoracic S, European Respiratory S. ATS/ERS recommendations for standardized procedures for the online and offline measurement of exhaled lower respiratory nitric oxide and nasal nitric oxide, 2005. American journal of respiratory and critical care medicine 2005: 171(8): 912-930.

17. Rosias PP, Robroeks CM, Kester A, den Hartog GJ, Wodzig WK, Rijkers GT, Zimmermann LJ, van Schayck $C P$, Jobsis $Q$, Dompeling E. Biomarker reproducibility in exhaled breath condensate collected with different condensers. The European respiratory journal 2008: 31(5): 934-942.

18. Horvath I, Hunt J, Barnes PJ, Alving K, Antczak A, Baraldi E, Becher G, van Beurden WJ, Corradi M, Dekhuijzen R, Dweik RA, Dwyer T, Effros R, Erzurum S, Gaston B, Gessner C, Greening A, Ho LP, Hohlfeld J, Jobsis Q, Laskowski D, Loukides S, Marlin D, Montuschi P, Olin AC, Redington 
AE, Reinhold P, van Rensen EL, Rubinstein I, Silkoff P, Toren K, Vass G, Vogelberg C, Wirtz H, Condensate AETFoEB. Exhaled breath condensate: methodological recommendations and unresolved questions. The European respiratory journal 2005: 26(3): 523-548.

19. Miller MR, Hankinson J, Brusasco V, Burgos F, Casaburi R, Coates A, Crapo R, Enright P, van der Grinten CP, Gustafsson P, Jensen R, Johnson DC, Maclntyre N, McKay R, Navajas D, Pedersen OF, Pellegrino R, Viegi G, Wanger J, Force AET. Standardisation of spirometry. The European respiratory journal 2005: 26(2): 319-338.

20. Sterk PJ, Fabbri LM, Quanjer PH, Cockcroft DW, O'Byrne PM, Anderson SD, Juniper EF, Malo JL. Airway responsiveness. Standardized challenge testing with pharmacological, physical and sensitizing stimuli in adults. Report Working Party Standardization of Lung Function Tests, European Community for Steel and Coal. Official Statement of the European Respiratory Society. The European respiratory journal Supplement 1993: 16: 53-83.

21. Reddel HK, Taylor DR, Bateman ED, Boulet LP, Boushey HA, Busse WW, Casale TB, Chanez P, Enright PL, Gibson PG, de Jongste JC, Kerstjens HA, Lazarus SC, Levy ML, O'Byrne PM, Partridge MR, Pavord ID, Sears MR, Sterk PJ, Stoloff SW, Sullivan SD, Szefler SJ, Thomas MD, Wenzel SE, American Thoracic Society/European Respiratory Society Task Force on Asthma C, Exacerbations. An official American Thoracic Society/European Respiratory Society statement: asthma control and exacerbations: standardizing endpoints for clinical asthma trials and clinical practice. American journal of respiratory and critical care medicine 2009: 180(1): 59-99.

22. Molenberghs G, Verbeke G. Models for Discrete Longitudinal Data. Springer, New York, 2005.

23. Hastie T, Tibshirani R, Friedman JH. The Elements of Statistical Learning. corrected edition, July 2003 ed. Springer, New York, 2003.

24. Baraldi E, Carraro S, Alinovi R, Pesci A, Ghiro L, Bodini A, Piacentini G, Zacchello F, Zanconato S. Cysteinyl leukotrienes and 8-isoprostane in exhaled breath condensate of children with asthma exacerbations. Thorax 2003: 58(6): 505-509.

25. Debley JS, Cochrane ES, Redding GJ, Carter ER. Lung function and biomarkers of airway inflammation during and after hospitalization for acute exacerbations of childhood asthma associated with viral respiratory symptoms. Annals of allergy, asthma \& immunology : official publication of the American College of Allergy, Asthma, \& Immunology 2012: 109(2): 114-120.

26. Caffarelli C, Calcinai E, Rinaldi L, Povesi Dascola C, Terracciano L, Corradi M. Hydrogen peroxide in exhaled breath condensate in asthmatic children during acute exacerbation and after treatment. Respiration 2012: 84(4): 291-298.

27. Norzila MZ, Fakes K, Henry RL, Simpson J, Gibson PG. Interleukin-8 secretion and neutrophil recruitment accompanies induced sputum eosinophil activation in children with acute asthma. American journal of respiratory and critical care medicine 2000: 161(3 Pt 1): 769-774.

28. Petsky HL, Cates CJ, Lasserson TJ, Li AM, Turner C, Kynaston JA, Chang AB. A systematic review and meta-analysis: tailoring asthma treatment on eosinophilic markers (exhaled nitric oxide or sputum eosinophils). Thorax 2012: 67(3): 199-208.

29. Petsky HL, Li AM, Au CT, Kynaston JA, Turner C, Chang AB. Management based on exhaled nitric oxide levels adjusted for atopy reduces asthma exacerbations in children: A dual centre randomized controlled trial. Pediatric pulmonology 2014: [Epub ahead of print].

30. van der Valk RJ, Baraldi E, Stern G, Frey U, de Jongste JC. Daily exhaled nitric oxide measurements and asthma exacerbations in children. Allergy 2012: 67(2): 265-271.

31. Keustermans GC, Hoeks SB, Meerding JM, Prakken BJ, de Jager W. Cytokine assays: an assessment of the preparation and treatment of blood and tissue samples. Methods 2013: 61(1): 10-17.

32. Carraro S, Giordano G, Reniero F, Carpi D, Stocchero M, Sterk PJ, Baraldi E. Asthma severity in childhood and metabolomic profiling of breath condensate. Allergy 2013: 68(1): 110-117.

33. Ibrahim B, Marsden P, Smith JA, Custovic A, Nilsson M, Fowler SJ. Breath metabolomic profiling by nuclear magnetic resonance spectroscopy in asthma. Allergy 2013: 68(8): 1050-1056. 



\section{Chapter 7}

General discussion

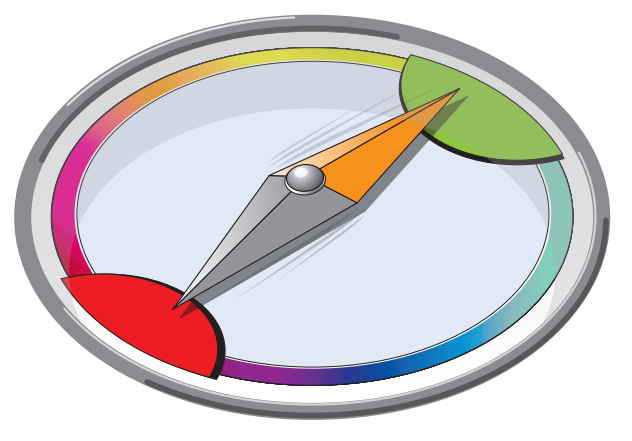


Asthma control is a central goal in evidence based guidelines concerning the management of asthma in children. ${ }^{1-5}$ Currently, asthma medication is titrated based on the level of asthma control, which is evaluated by a general practitioner or a paediatrician on a regular basis $1,2,4$ The level of asthma control is determined by the presence or absence of respiratory symptoms, limitation of activities of daily life, and use of rescue medication, according to the Global Initiative for Asthma (GINA) - Asthma management guidelines. ${ }^{1}$ Validated questionnaires to assess asthma control such as the Asthma Control Questionnaire (ACQ $)^{6,7}$ or the Asthma Control Test (ACT) are available. ${ }^{8}$

Despite these evidence based guidelines, asthma is not controlled well in many children and adults worldwide. ${ }^{8-10}$ An important question is how this can be explained. It is questionable whether doctors have a realistic and complete view of the health status of asthmatic patients. The validated questionnaires have the benefit of being standardized, which is important to compare asthma control within and between patients. ${ }^{11}$ However, a pitfall of these asthma control questionnaires is the risk for recall bias. ${ }^{12}$ Although asthma is a respiratory inflammatory disease,$^{13}$ medication titration is based on symptoms and lung function, but not on measures of the underlying airway inflammation. Increase of airway inflammation may result in decrease of asthma control or even worse, in an asthma exacerbation. Information about airway inflammation may help doctors to assess loss of asthma control or even to predict an asthma exacerbation. In addition, beside asthma control, asthma-specific quality of life (QoL) is considered as an outcome parameter of asthma both in clinical care and in clinical trials. ${ }^{1,2,4}$ However, in daily clinical care of asthma patients, doctors may not assess asthmaspecific QoL at regular intervals and in a standardised way.

The general purpose of the research in this thesis was to explore strategies to improve monitoring and asthma control in children. The specific aims of this thesis were:

1. To compare 2 strategies to assess asthma control, namely prospective home monitoring of symptoms and forced expiratory volume in 1 second $\left(F E V_{1}\right)$ with retrospective assessment by means of the ACQ and lung function during a clinical visit.

2. To determine the longitudinal association between asthma control, clinical characteristics and asthma-specific QoL in children.

3. To explore the association between asthma control and exhaled inflammatory markers (volatile organic compounds (VOCs), fractional exhaled nitric oxide (FeNO) and biomarkers in exhaled breath condensate (EBC)), and to assess the potential of these exhaled inflammation markers to discriminate between subgroups of children with persistently uncontrolled asthma or persistently controlled asthma.

4. To study the power to predict asthma exacerbations in children by various non-invasive techniques (VOCs, FeNO and biomarkers in EBC). 
In the current chapter, we will give a brief overview of the study. Thereafter, we will discuss each studied monitoring strategy: a) the main findings of our study, b) a brief comparison to literature and c) speculations about clinical implications. The strengths and limitations of the study will be discussed. Finally, a conclusion of the thesis will be followed by suggestions for future research regarding the monitoring strategies of asthma in children.

\section{Brief study overview}

A prospective observational study over a period of 1 year was performed in 96 asthmatic children, with clinical visits every 2 months. The majority of subjects were atopic and had bronchial hyperresponsiveness despite a moderate daily dose of fluticasone (or equivalent). During the study 13 children dropped out.

During clinical visits, asthma control (based on the ACQ and the GINA-criteria), asthmaspecific QoL and FeNO were assessed. Furthermore, lung function measurements were performed and EBC was collected, whereas exhaled breath was also analysed for FeNO and VOCs. Once during the study, bronchial hyperresponsiveness was evaluated by a bronchial histamine challenge test and atopy was recorded based on the Phadiatop (Phadia, Uppsala, Sweden) or RAST (Pharmacia, Uppsala, Sweden) or Allergen Skin test. Between visits, daily symptom scores and lung function were recorded using a home monitor. Via electronic questionnaires parents completed an International Study of Asthma and Allergies in Children questionnaire and a Medication Adherence Report Scale. During the study, asthma medication was titrated based on the asthma level of control according to the GINA guidelines and the guidelines of the Paediatric Pulmonology section of the Dutch Society of Paediatrics..$^{1,4}$ In the adjustment of treatment, FeNO values, markers in EBC, exhaled VOCs or home monitor results were not taken into account.

\section{Prospective monitoring of asthma at home}

Two methods to assess asthma control were compared: 1) prospective daily home assessments of $\mathrm{FEV}_{1}$ plus electronic symptom scores for 7 days based on the GINA criteria, and 2) retrospective clinical evaluation of asthma control in the past 7 days by means of the ACQ. ${ }^{6,7}$ In $37 \%$ of the children, asthma control was classified 1 or 2 levels lower in case of prospective home monitoring compared to retrospective assessment of asthma control by the ACQ. This was supported by significantly lower lung function values $\left(F E V_{1}\right.$ and $F E V_{1} /$ VC) in these children compared to the children with controlled/partly controlled asthma and children who were classified the same by both methods. However, the adherence to home monitor use was not optimal (median completed home monitor data of all children $69 \% ; I Q R$, $53 \%-89 \%$ ). This low adherence could be interpreted in different ways. On the one hand, technical problems during the use of home monitors could have demotivated children/parents 
to use them. On the other hand, the 'actual' compliance to home monitor use in the asthmatic paediatric population may also be lower, because the patients in this study were relatively motivated to use a home monitor. We could not find differences in clinical characteristics that could explain the lack of adherence to home monitor use in our study.

The difference in asthma control based on the GINA criteria versus the ACQ that we found is in line with other studies assessing asthma control on the basis of retrospective assessment of the GINA criteria versus ACQ. ${ }^{14,15}$ Furthermore, in literature, there is controversy over whether home monitoring is effective in management of asthma in children or adults. ${ }^{16-24}$ Studies incorporated electronic or written symptom diaries and peak expiratory flow (PEF) or $\mathrm{FEV}_{1}$ as lung function parameter. ${ }^{17-20,22-24}$ There are randomised controlled trials (RCTs) in children showing that adjusting treatment based on daily electronic symptom diaries plus PEF was effective: a decrease in respiratory symptoms and number of emergency room visits was found. ${ }^{19,20}$ However, in some RCTs no positive effect of home monitoring was shown. ${ }^{17,18,22,23}$

Before home monitoring could be introduced in clinical practice, first more research into its effectiveness in improving asthma control and asthma-specific QoL, or decreasing health care costs is needed. Home monitoring could be used in healthcare programs of asthma in children, where medication is titrated based on monitor data by a physician (telehealthcare). In cases where asthma control is decreased, clinical visits could be scheduled. The next step could be to use the home monitor in self-management programs by asthmatic children and their parents. ${ }^{1}$

\section{Asthma-specific QoL versus asthma control}

The longitudinal association between asthma control and asthma-specific QoL, and the relationships between clinical asthma characteristics and asthma-specific QoL were determined. Deterioration of asthma control from controlled to uncontrolled was associated with a clinically relevant decrease in asthma-specific QoL during 1 year. In addition, an increased use of $\beta_{2}$-agonists, the occurrence of an exacerbation in the previous 2 months, and the occurrence of wheezing episodes in the preceding year were associated with a decrease in asthma-specific QoL. However, these longitudinal data also showed that asthma control and asthma-specific QoL outcomes are not mutually interchangeable: at a certain level of asthma control, there was considerable variation in QoL levels, especially in case of uncontrolled and partially controlled disease.

In the literature, the correlation between asthma control and asthma-specific QoL was mostly assessed in cross-sectional studies. ${ }^{25-33}$ However, a cross-sectional association does not give information about the correlation within patients in the course of time. This information 
can be obtained in longitudinal studies. It is questionable whether the asthma-specific QoL questionnaires that are available purely measure the asthma-specific QoL. ${ }^{34}$ Based on the National institute of Health $(\mathrm{NIH})$ recommendation to standardize measures of the impact of asthma on QoL, Wilson et al. described in their review, that perception of impact of impairments on asthma-specific QoL is not solely assessed by the symptom or activity domain, but is also dependent on the child's expectations, priorities and lifestyle. In this review, it was recommended that a key defining characteristic of any measurement of QOL is that "it should assess the degree to which impairment matters to the patient" ${ }^{34}$ The PAQLQ, which was used in our study also measures activity limitations and symptoms beside the emotional function domain. Probably of all domains of the PAQLQ, the emotional domain best reflects the degree to which impairments matter to the child. The association between asthma control and the emotional domain was weak, possibly because it depends more on for example the life-style, expectations, and priorities of the children as stated above by Wilson et al. ${ }^{34}$ Besides, there are studies that show associations between the presence of psychological characteristics of children and worsening of asthma control. ${ }^{35-38}$ These studies conclude that psychological problems and exposure to severely stressful events are associated with increased asthma severity over time. ${ }^{35-38}$ Doctors may miss a cornerstone when asthma-specific QoL is neglected in the doctor-patient consultation.

To date, asthma-specific QoL may not be assessed regularly in clinical care. Therefore a way forward would be to start with clinically asthma-specific QoL assessments, to obtain an impression of the possible clinical implications of its outcomes. Preferably, asthma-specific QoL could be measured in a more or less standardized way, because the performance of asthma-specific QoL assessment may depend on the time, motivation and skills of individual clinicians.

\section{Non-invasive measurement of airway inflammation}

\section{Exhaled VOCs}

In chapter 3, the association between exhaled VOCs and asthma control was analysed longitudinally. Exhaled VOCs were not longitudinally associated with levels of asthma control in children. However, exhaled VOCs showed potential to discriminate between 2 important subgroups of asthmatic children, namely those with persistently controlled versus uncontrolled asthma during all clinical visits. This suggests that exhaled VOCs may help clinicians to identify children with high risk for persistently uncontrolled or controlled asthma. In the first category of patients, physicians will be more inclined to increase treatment or change treatment and will look for causes of uncontrolled disease. In the latter category with persistently controlled disease, doctors will taper off maintenance treatment more rapidly and consistently. Another important aim was to identify the specific VOCs that were most predictive for an asthma 
exacerbation. Seven specific VOCs were able to predict an asthma exacerbation with reasonable accuracy. However, the predictive power was inversely related to the time from sample collection to exacerbation. The correct prediction of an exacerbation within 21 days after sample collection in children with asthma exacerbations was $62.5 \%$, which increased to $87.5 \%$ when the period between sampling and the onset of exacerbations was 14 days. Of the 7 selected VOCs, the chemical background of 6 substances was characterized, namely 3 aldehydes, 1 hydrocarbon, 1 ketone, and 1 aromatic substance.

In the literature, the role of single VOCs or VOC profiles in the diagnosis and monitoring of asthma was studied in several studies and 2 recent reviews. ${ }^{39-50}$ VOC profiles were able to discriminate between asthmatic patients and healthy controls in both children and adults. ${ }^{41-47,51}$ Ethane levels were significantly higher in adults with asthma not receiving steroid therapy compared to healthy controls or compared to patients receiving steroid therapy. ${ }^{49}$ In addition, elevated pentane levels were found in adults during an asthma exacerbation compared to healthy controls. ${ }^{48}$ Exhaled pentane levels decreased significantly when patients recovered from an acute exacerbation..$^{48}$ Concerning identification of subgroups of asthmatic patients, FeNO and lung function indices were useful to differentiate between children with severe and $\mathrm{mild} /$ moderate asthma based on symptoms. ${ }^{52}$ Furthermore, similar to findings in this thesis, a recent longitudinal observational study showed that a combination of exhaled VOCs had the potential to predict an asthma exacerbation in 40 children followed during 1 year (InFLammation Asthma Monitoring study, FLAME-study). ${ }^{50}$ However, the identified, most predictive VOCs for an asthma exacerbation differed between the FLAME-study and the current study. This finding shows that different sets of VOCs may be predictive for asthma exacerbations, depending on the population. Since asthma is a heterogeneous disease, different sets of predicting VOCs probably reflect different phenotypes of asthma. The VOCs most predictive for an exacerbation may vary with the trigger of an exacerbation (viral infection, allergen exposure, or non-specific trigger), or the severity of the asthma exacerbations. The number of exacerbations in the present study and the former FLAME-study were too few to perform a subgroup analysis to further investigate these aspects.

The findings in this thesis and of the FLAME-study showed that some exhaled VOCs have potential to predict an asthma exacerbation in children. Moreover, it appeared that exhaled VOCs are able to identify subgroups of children with persistently uncontrolled and controlled asthma during clinical visits, which can be helpful for specific management strategies in these patients. In our study we used the time-consuming and expensive GC-MS technique. Before exhaled VOCs can be introduced in clinical care, the instrument to assess VOCs should be simplified. Such an instrument must be small, portable and should provide fast results. Handheld devices are already available such as eNoses, sensors, and chips, which assess VOC profiles in real time. Part of these devices detect a profile of VOCs, which is not further 
chemically identified and is called a 'breath print'. Possibly this is a more suitable approach for the monitoring of asthma than the chemical identification of small sets of VOCs. However, in order to gain more insight into the pathogenesis of (exacerbations of) asthma in children, chemical identification of VOCs is preferable. Results in this thesis indicate that a standard sampling interval of 2 months in order to predict the asthma exacerbations in children is not adequate, but should be shortened. In order to make this feasible in clinical practice, home assessments may be necessary. An optimal sampling frequency should be subject of future studies.

\section{Markers in exhaled breath condensate}

In this thesis, cytokines/chemokines in EBC were not related to asthma control. Moreover, EBC markers were not able to discriminate between children with persistently controlled or uncontrolled asthma. Adding markers in EBC to a model with exhaled VOCs to discriminate between children with persistently controlled or uncontrolled asthma during clinical visits, the correct classification nearly increased (areas under the Receiver Operating Characteristic (ROC) curves of model: including only VOCs $86 \%$ - including VOCs, FeNO and markers in EBC $87 \%$ ). Furthermore, the ability of inflammatory markers in EBC alone or in combination with clinical parameters to predict asthma exacerbations in children was studied. Acidity of EBC, and the inflammatory markers interleukin (IL) 1 $\alpha$, IL-5, IL-6, IL-8, IL-13, IL-17, TNF $\alpha$ in EBC were analysed. Areas under the ROC-curves were $47 \%, 54 \%$ and $59 \%$ for prediction of asthma exacerbations by using 1) inflammatory markers in EBC alone, versus 2) FeNO plus clinical characteristics, versus 3) all exhaled markers of inflammation plus clinical characteristics, respectively. These areas under the ROC-curves were almost equal to random guessing, therefore these inflammatory markers were not suitable to predict an asthma exacerbation.

In a previous longitudinal study of 40 children with asthma, exacerbations were predicted by IL-5 in EBC and acidity of EBC (FLAME-study)..$^{53}$ These findings were not reproduced in the current study. In the FLAME-study we used in-house kits with home-made laboratory beads and specific antibodies, which were applied to EBC samples, and analysed by means of the liquid bead-based multiplexing xMap technology (Luminex Corporation, Austin, USA). ${ }^{53,54}$ The detection rates of this technique was almost $100 \%$ for most cytokines and chemokines, and demonstrated (on average) a good reproducibility. ${ }^{53,55}$ As the beads and antibodies of the inhouse kits were no longer available, we switched to new commercially available hypersensitive kits to analyse the EBC samples that are described in this thesis. We tried to assess the reasons for the lower concentrations and detections that were measured in the EBC samples by using the commercial kits. Therefore, we carried out several experiments with the aim to find a possibility to improve the analysis of our EBC samples by using the hypersensitive commercial kit. A short description of the experiments and conclusions are listed below.

- We tested whether photomultiplier (PMT) sensitivity settings could improve our 
cytokine detection in EBC samples. Higher PMT setting could result in more sensitive measurement of cytokines. In our experiment, the absolute fluorescence values of EBC samples measured with the high PMT setting were higher than fluorescence with the low PMT setting. However, the background fluorescence values were also higher. Therefore, high PMT settings did not result in improvement of detection of cytokines in EBC.

- We performed a spike experiment. In this experiment, we added a known concentration of a specific cytokine to an EBC sample (spike solution). We measured the concentration of the EBC sample, the spike solution and combination of EBC sample plus spike solution. The solution we used for this spike experiment had a concentration of $1250 \mathrm{fg} / \mathrm{ml}$ that was diluted in the EBC 1:5. After spiking the EBC samples with a known concentration of IL-6 and IL-8, we measured a lower concentration than expected (expected concentration = concentration of cytokine in EBC sample plus concentration cytokine in spike solution). We hypothesized that the detection of only $30-60 \%$ of the spike IL-6 and IL-8 after mixture with $\mathrm{EBC}$ of an asthmatic child could be caused by presence of an inhibiting substance in EBC, such as proteases.

- $\quad$ Therefore, we performed an experiment with protease inhibitor in 10 children. From each child we collected EBC with and without a protease inhibitor. The addition of protease inhibitor to the sample during collection of EBC did not result in higher absolute fluorescence values. Therefore, based on this experiment, we had no sign for presence of proteases in EBC that caused a decrease in detection of cytokines.

- We performed a second spike experiment, because of the contradictory result of the previous spike experiment and the protease experiment. Higher concentrations of cytokines were measured after addition of the spike solution to EBC-samples. Based on this experiment, presence of an inhibiting substance was unlikely, which corresponded with the protease inhibitor experiment.

- Moreover, we also analysed samples with another high sensitivity kit based on fluorescence intensity detection (Invitrogen, Carlsbad, CA) and a kit based on electrochemiluminescence (Meso Scale discovery, Gaithersburg, MD, USA). Both strategies did not improve the detection of cytokines in EBC.

From the experiments we learned that spiking of EBC samples may help to improve detection of low levels of cytokines in matrices such as EBC. However, more research is required to understand how components in the matrix may affect detection of cytokines; spiking may alleviate blocking effects and simply improve detection of the spiked cytokine. Apart from the experiments, we hypothesize that during storage of EBC, the EBC matrix has negative effects on the stability of cytokines. Similar to the dried blood spot storage method, an option may be to absorb and store EBC onto filter paper and avoid negative effects on cytokine stability. ${ }^{56}$ In addition, the matrix that is used in the kits may be not suitable for EBC, which has a very low concentration of proteins compared to blood. 
In conclusion, based on these results, cytokines/chemokines in EBC analysed by current methods, are not clinically useful in asthma management: the measured markers in EBC were not associated with asthma control, nor predictive for asthma exacerbations. The detection and measured concentration of cytokines and chemokines in EBC was low, which limits application and usefulness of this technique so far. It is evident that a breakthrough in the analysis of EBC is necessary. It is likely that nuclear magnetic resonance-spectroscopy or gene expression of inflammation/oxidative stress markers offers a better approach for the analysis of EBC. ${ }^{57}$

\section{FeNO}

The addition of FeNO to a statistical model to classify children with persistently controlled or uncontrolled asthma based on exhaled VOCs, did not let to a more accurate classification (areas under ROC-curve of model: including only VOCs $86 \%$ - including VOCs, FeNO and markers in EBC 87\%). Moreover, the ability of FeNO to predict asthma exacerbations in children was tested in a prediction model consisting of markers in EBC and the covariates sex, age, trial centre, atopy, bronchial hyperresponsiveness, reversibility to a bronchodilator, ACQ-score and daily dosage of inhaled corticosteroids (ICS). FeNO was not predictive for asthma exacerbations in the children of our study. Furthermore, FeNO had no additional value on the predictive power of inflammatory markers in EBC.

FeNO is an extensively investigated biomarker. The finding of poor association between FeNO and asthma control is in line with other studies. ${ }^{58,59}$ However, the evidence for the efficacy of FeNO to improve asthma management is conflicting and is rather more negative than positive. In 2012, Petsky et al. published a meta-analysis to evaluate the efficacy of tailoring asthma interventions based on FeNO compared to clinical symptoms only in adults and children. ${ }^{60}$ In this meta-analysis 4 randomized controlled trials that treated asthmatic children/adolescents in the intervention group based on daily or monthly FeNO measurements were included. ${ }^{60-64}$ This meta-analysis showed that the number of exacerbations did not differ significantly between intervention and control group, whereas the ICS doses at the end of the studies were significantly higher in the intervention group compared to the control group. ${ }^{60}$ Moreover, RCTs performed after this meta-analysis were also not consistent. ${ }^{65-67}$ Two RCTs showed no favourable effect of FeNO, whereas 1 RCT showed that significantly fewer children in the FeNO group had $\geq 1$ exacerbation(s) compared to the control group. However, on average, there was no statistically significant difference in exacerbation rate between the groups.

In clinical practice, FeNO can be easily measured in a non-invasive way, which makes FeNO an attractive inflammatory marker for asthma monitoring. However, although FeNO in human breath has been thoroughly studied from $1993^{68}$, there is no consensus that FeNO is effective and useful in management of asthma control. In our study, FeNO was not a predictor of 
asthma exacerbations. Therefore, we do not recommend using FeNO to predict exacerbations in children with asthma in daily clinical practice.

\section{Strengths and limitations of the study}

The strengths of this study are the longitudinal design during a period of one-year, the considerable group of children with asthma $(n=96)$, medication titration based on a strict protocol of the GINA criteria, the home monitor with assessments of symptoms and lung function and the simultaneous application of various non-invasive techniques to assess airway inflammation: FeNO, cytokines/chemokines in EBC, and exhaled VOCs. In this way, these non-invasive techniques could be compared with respect to the prediction of loss of asthma control/exacerbations. We used GC-MS to analyse VOCs in exhaled breath, which is considered the gold standard in recent reviews. ${ }^{39,40,69}$ The study design was appropriate to answer the research question aimed at prediction of asthma exacerbations.

Limitations of our study are the relatively high PAQLQ scores at baseline which may have limited the room for improvement and caused a kind of 'ceiling effect'. Consequently, factors related to this improvement may be missed. In addition, no demographic factors of the study population were taken into account, which is a limitation in the chapter on PAQLQ. Finally, it appeared that the two-month time interval for the regular measurements of airway inflammation is quite large, especially with respect to the exhaled VOCs.

\section{Conclusion}

First, there was low agreement between asthma control levels based on prospective home monitoring and retrospective ACQ assessment during clinical visits. Twice as many cases of partly controlled asthma were found by means of prospective assessment at home compared to retrospective measurement of asthma control during clinical visits. If this less optimistic assessment of asthma control by means of prospective monitoring were based on a more accurate measurement of asthma control prospectively, then home monitoring of asthma control may have a favourable influence on the management of asthma in children. Optimization of adherence to home monitor use is required for its possible applicability in clinical care.

Second, when focussing on asthma-specific QoL, there was a strong longitudinal association between asthma control and asthma-specific QoL in our study. However, we also found that asthma control and asthma-specific QoL were not mutually interchangeable. The asthma specific QoL was lower in children with increased use of $\beta_{2}$-agonists, more wheezing episodes in the year before the study, an asthma exacerbation in the 2 months prior to clinical visit, and a lower lung function. 
Third, only exhaled VOCs were able to identify 2 subgroups of asthmatic children with persistently controlled versus uncontrolled asthma during clinical visits.

Fourth, of the non-invasive exhaled inflammation markers studied in this thesis, the exhaled VOCs showed the highest potential to predict asthma exacerbations. A set of 7 VOCs predicted asthma exacerbations within 14 days after sampling in $88 \%$ of the asthmatic children with exacerbations correctly. FeNO nor inflammation markers in EBC contributed to the prediction of asthma exacerbations in children. Moreover, clinical parameters such as asthma control, atopy, bronchial hyperresponsiveness, lung function or reversibility to ß-agonists, did not contribute to the correct prediction of asthma exacerbations. This may indicate that exhaled VOCs may be useful for the monitoring of asthma in children, but more research is necessary to confirm this and to assess optimal monitoring frequency, and most predictive VOCs.

\section{Future directions}

\section{Prospective monitoring of asthma at home}

To gain more insight in the effectiveness and cost-effectiveness of home monitoring by means of the combination of electronic symptom scores and $\mathrm{FEV}_{1}$, a randomised controlled trial should be executed. In the intervention group asthma control needs to be assessed prospectively by means of the home monitor, and titration of medication should be performed on the basis of these home data. In the control group, treatment will be based on retrospective assessments of symptoms and lung function during regular visits. Furthermore, studies are necessary to investigate the determinants for low adherence to home monitoring and how to improve this adherence. Moreover, it should be evaluated how frequent symptoms and lung function should by assessed at home to assess level of asthma control in a reliable way.

\section{Asthma-specific QoL versus asthma control}

More longitudinal data on asthma-specific QoL assessments are necessary in order to explore what the added value of monitoring QoL beside asthma control in clinical practice could be. In addition, more information could be gained about which factors contribute to a decrease in asthma-specific QoL. For this purpose, a more or less standardized method to assess asthma-specific QoL is necessary.

Concerning the present asthma-specific QoL instruments, studies are needed to explore a cut-off score for asthma-specific QoL questionnaires to make these tools useful in clinical practice, the interpretation of a score of an asthma-specific QoL questionnaire, and the optimal frequency to assess asthma-specific QoL clinically.

A qualitative study on the view of children, parents and physicians about pros and cons of asthma-specific QoL assessments in clinical care, on if/how assessment of asthmaspecific QoL influenced their burden caused by asthma symptoms, and how time consuming assessment of asthma-specific QoL was, is useful. 


\section{Non-invasive measurements of airway inflammation}

Currently, the lack of proper analytical techniques to measure markers in EBC is the major limitation hampering clinical application of this interesting non-invasive technique. Future studies in EBC should focus on new techniques to analyse markers in EBC. The possibilities to improve detection of markers by pre-concentration or by development of more specialized kits for EBC is appropriate. An approach different from the condensation of exhaled breath is the more direct collection of exhaled particles and inflammation markers, which may appear to be more successful than analysis of the condensate of exhaled breath. ${ }^{70,71}$

With respect to exhaled VOCs, it is important to determine whether/how VOCs predictive for asthma exacerbations are influenced by the cause of the exacerbation (viral infection, allergen exposure, nonspecific stimulus), and the severity of exacerbation. The optimal measurement frequency should be determined and smaller instruments/methods for assessments at home should be developed. There is still a lot of work to do on the standardisation of VOC measurements. Currently, there is no international guideline about optimal conditions for measurements available, although several international task forces are currently working on this topic.

In the future, it may be possible to construct an instrument which is able to record symptoms and assess lung function, and exhaled VOCs on a regular basis at home. 


\section{References}

1. Global strategy for asthma management and prevention. Global Initiative for Asthma (GINA) 2012 [cited; Available from: ginasthma.org/local/uploads/files/GINA_Report_March13.pdf

2. BTS. BTS/SIGN Guideline on the management of asthma: British Thoracic Society. 2012.

3. Long Alliantie Nederland. Zorgstandaard Astma Kinderen \& Jongeren. 2013.

4. de Jongste JC. Astma bij kinderen; herziene richtlijnen van de sectie kinderlongziekten van de NVK [Asthma in children; revised guidelines of the paediatric department of the Dutch Paediatric Society], Amsterdam, 2013.

5. Expert Panel Report 3 (EPR-3): Guidelines for the Diagnosis and Management of Asthma-Summary Report 2007. J Allergy Clin Immunol 2007;120 (5 Suppl): S94-138.

6. Juniper EF, Gruffydd-Jones K, Ward S, Svensson K. Asthma Control Questionnaire in children: validation, measurement properties, interpretation. The European respiratory journal 2010: 36(6): 1410-1416.

7. Nguyen JM, Holbrook JT, Wei CY, Gerald LB, Teague WG, Wise RA, American Lung Association Asthma Clinical Research C. Validation and psychometric properties of the Asthma Control Questionnaire among children. The Journal of allergy and clinical immunology 2014: 133(1): 91-97 e91-96.

8. Voorend-van Bergen S, Vaessen-Verberne AA, Landstra AM, Brackel HJ, van den Berg NJ, Caudri D, de Jongste JC, Merkus PJ, Pijnenburg MW. Monitoring childhood asthma: web-based diaries and the asthma control test. The Journal of allergy and clinical immunology 2014: 133(6): 1599-1605 e1592.

9. Gustafsson PM, Watson L, Davis KJ, Rabe KF. Poor asthma control in children: evidence from epidemiological surveys and implications for clinical practice. Int J Clin Pract 2006: 60(3): 321-334.

10. Rabe KF, Adachi M, Lai CK, Soriano JB, Vermeire PA, Weiss KB, Weiss ST. Worldwide severity and control of asthma in children and adults: the global asthma insights and reality surveys. The Journal of allergy and clinical immunology 2004: 114(1): 40-47.

11. Nuijsink M, de Jongste JC, Pijnenburg MW. Will symptom-based therapy be effective for treating asthma in children? Current allergy and asthma reports 2013: 13(5): 421-426.

12. van den Brink M, Bandell-Hoekstra EN, Abu-Saad HH. The occurrence of recall bias in pediatric headache: a comparison of questionnaire and diary data. Headache 2001: 41(1): 11-20.

13. Busse WW, Lemanske RF, Jr. Asthma. The New England journal of medicine 2001: 344(5): 350362.

14. Korn S, Both J, Jung M, Hubner M, Taube C, Buhl R. Prospective evaluation of current asthma control using ACQ and ACT compared with GINA criteria. Annals of allergy, asthma \& immunology : official publication of the American College of Allergy, Asthma, \& Immunology 2011: 107(6): 474479.

15. Olaguibel JM, Quirce S, Julia B, Fernandez C, Fortuna AM, Molina J, Plaza V, Group MS. Measurement of asthma control according to Global Initiative for Asthma guidelines: a comparison with the Asthma Control Questionnaire. Respiratory research 2012: 13: 50.

16. McLean S, Chandler D, Nurmatov U, Liu J, Pagliari C, Car J, Sheikh A. Telehealthcare for asthma: a Cochrane review. CMAJ : Canadian Medical Association journal = journal de l'Association medicale canadienne 2011: 183(11): E733-742.

17. Chan DS, Callahan CW, Hatch-Pigott VB, Lawless A, Proffitt HL, Manning NE, Schweikert M, Malone FJ. Internet-based home monitoring and education of children with asthma is comparable to ideal office-based care: results of a 1-year asthma in-home monitoring trial. Pediatrics 2007: 119(3): 569-578.

18. Deschildre A, Beghin L, Salleron J, Iliescu C, Thumerelle C, Santos C, Hoorelbeke A, Scalbert M, Pouessel G, Gnansounou M, Edme JL, Matran R. Home telemonitoring (forced expiratory volume in $1 \mathrm{~s}$ ) in children with severe asthma does not reduce exacerbations. The European respiratory journal 2012: 39(2): 290-296.

19. Guendelman S, Meade K, Benson M, Chen YQ, Samuels S. Improving asthma outcomes and selfmanagement behaviors of inner-city children: a randomized trial of the Health Buddy interactive device and an asthma diary. Archives of pediatrics \& adolescent medicine 2002: 156(2): 114-120. 
20. Jan RL, Wang JY, Huang MC, Tseng SM, Su HJ, Liu LF. An internet-based interactive telemonitoring system for improving childhood asthma outcomes in Taiwan. Telemedicine journal and e-health : the official journal of the American Telemedicine Association 2007: 13(3): 257-268.

21. Rikkers-Mutsaerts ER, Winters AE, Bakker MJ, van Stel HF, van der Meer V, de Jongste JC, Sont JK, Group SS. Internet-based self-management compared with usual care in adolescents with asthma: a randomized controlled trial. Pediatric pulmonology 2012: 47(12): 1170-1179.

22. Wensley D, Silverman M. Peak flow monitoring for guided self-management in childhood asthma: a randomized controlled trial. American journal of respiratory and critical care medicine 2004: 170(6): 606-612.

23. Willemsen G, van Beijsterveldt TC, van Baal CG, Postma D, Boomsma DI. Heritability of selfreported asthma and allergy: a study in adult Dutch twins, siblings and parents. Twin research and human genetics : the official journal of the International Society for Twin Studies 2008: 11(2): 132142.

24. van der Meer V, van Stel HF, Detmar SB, Otten W, Sterk PJ, Sont JK. Internet-based selfmanagement offers an opportunity to achieve better asthma control in adolescents. Chest 2007: 132(1): 112-119.

25. Annett RD, Bender BG, Skipper B, Allen C. Predicting moderate improvement and decline in pediatric asthma quality of life over 24 months. Qual Life Res 2010: 19(10): 1517-1527.

26. Burkhart PV, Svavarsdottir EK, Rayens MK, Oakley MG, Orlygsdottir B. Adolescents with asthma: predictors of quality of life. J Adv Nurs 2009: 65(4): 860-866.

27. Dean BB, Calimlim BC, Sacco P, Aguilar D, Maykut R, Tinkelman D. Uncontrolled asthma: assessing quality of life and productivity of children and their caregivers using a cross-sectional Internet-based survey. Health Qual Life Outcomes 2010: 8: 96.

28. Gandhi PK, Kenzik KM, Thompson LA, DeWalt DA, Revicki DA, Shenkman EA, Huang IC. Exploring factors influencing asthma control and asthma-specific health-related quality of life among children. Respiratory research 2013: 14: 26.

29. Juniper EF, Guyatt GH, Feeny DH, Ferrie PJ, Griffith LE, Townsend M. Measuring quality of life in the parents of children with asthma. Qual Life Res 1996: 5(1): 27-34.

30. Juniper EF, Wisniewski ME, Cox FM, Emmett AH, Nielsen KE, O'Byrne PM. Relationship between quality of life and clinical status in asthma: a factor analysis. The European respiratory journal 2004: 23(2): 287-291.

31. Okelo SO, Wu AW, Krishnan JA, Rand CS, Skinner EA, Diette GB. Emotional quality-of-life and outcomes in adolescents with asthma. J Pediatr 2004: 145(4): 523-529.

32. Raat H, Bueving HJ, de Jongste JC, Grol MH, Juniper EF, van der Wouden JC. Responsiveness, longitudinal- and cross-sectional construct validity of the Pediatric Asthma Quality of Life Questionnaire (PAQLQ) in Dutch children with asthma. Qual Life Res 2005: 14(1): 265-272.

33. Schmier JK, Manjunath R, Halpern MT, Jones ML, Thompson K, Diette GB. The impact of inadequately controlled asthma in urban children on quality of life and productivity. Annals of allergy, asthma \& immunology : official publication of the American College of Allergy, Asthma, \& Immunology 2007: 98(3): 245-251.

34. Wilson SR, Rand CS, Cabana MD, Foggs MB, Halterman JS, Olson L, Vollmer WM, Wright RJ, Taggart V. Asthma outcomes: quality of life. The Journal of allergy and clinical immunology 2012: 129(3 Suppl): S88-123.

35. Tibosch MM, Verhaak CM, Merkus PJ. Psychological characteristics associated with the onset and course of asthma in children and adolescents: a systematic review of longitudinal effects. Patient education and counseling 2011: 82(1): 11-19.

36. Marin TJ, Chen E, Munch JA, Miller GE. Double-exposure to acute stress and chronic family stress is associated with immune changes in children with asthma. Psychosomatic medicine 2009: 71(4): 378-384.

37. Sandberg S, Paton JY, Ahola S, McCann DC, McGuinness D, Hillary CR, Oja H. The role of acute and chronic stress in asthma attacks in children. Lancet 2000: 356(9234): 982-987.

38. Weil CM, Wade SL, Bauman LJ, Lynn H, Mitchell H, Lavigne J. The relationship between psychosocial factors and asthma morbidity in inner-city children with asthma. Pediatrics 1999: 104(6): 1274-1280.

39. Fens N, van der Schee MP, Brinkman P, Sterk PJ. Exhaled breath analysis by electronic nose in airways disease. Established issues and key questions. Clinical and experimental allergy : journal 
of the British Society for Allergy and Clinical Immunology 2013: 43(7): 705-715.

40. van de Kant KD, van der Sande LJ, Jobsis Q, van Schayck OC, Dompeling E. Clinical use of exhaled volatile organic compounds in pulmonary diseases: a systematic review. Respiratory research 2012: 13: 117.

41. Caldeira M, Barros AS, Bilelo MJ, Parada A, Camara JS, Rocha SM. Profiling allergic asthma volatile metabolic patterns using a headspace-solid phase microextraction/gas chromatography based methodology. Journal of chromatography A 2011: 1218(24): 3771-3780.

42. Caldeira M, Perestrelo R, Barros AS, Bilelo MJ, Morete A, Camara JS, Rocha SM. Allergic asthma exhaled breath metabolome: a challenge for comprehensive two-dimensional gas chromatography. Journal of chromatography A 2012: 1254: 87-97.

43. Dallinga JW, Robroeks CM, van Berkel JJ, Moonen EJ, Godschalk RW, Jobsis Q, Dompeling E, Wouters EF, van Schooten FJ. Volatile organic compounds in exhaled breath as a diagnostic tool for asthma in children. Clinical and experimental allergy : journal of the British Society for Allergy and Clinical Immunology 2010: 40(1): 68-76.

44. Dragonieri S, Schot R, Mertens BJ, Le Cessie S, Gauw SA, Spanevello A, Resta O, Willard NP, Vink TJ, Rabe KF, Bel EH, Sterk PJ. An electronic nose in the discrimination of patients with asthma and controls. The Journal of allergy and clinical immunology 2007: 120(4): 856-862.

45. Gahleitner F, Guallar-Hoyas C, Beardsmore CS, Pandya HC, Thomas CP. Metabolomics pilot study to identify volatile organic compound markers of childhood asthma in exhaled breath. Bioanalysis 2013: 5(18): 2239-2247.

46. Ibrahim B, Basanta M, Cadden P, Singh D, Douce D, Woodcock A, Fowler SJ. Non-invasive phenotyping using exhaled volatile organic compounds in asthma. Thorax 2011: 66(9): 804-809.

47. Montuschi P, Santonico M, Mondino C, Pennazza G, Mantini G, Martinelli E, Capuano R, Ciabattoni G, Paolesse R, Di Natale C, Barnes PJ, D'Amico A. Diagnostic performance of an electronic nose, fractional exhaled nitric oxide, and lung function testing in asthma. Chest 2010: 137(4): 790-796.

48. Olopade CO, Zakkar M, Swedler WI, Rubinstein I. Exhaled pentane levels in acute asthma. Chest 1997: 111(4): 862-865.

49. Paredi P, Kharitonov SA, Barnes PJ. Elevation of exhaled ethane concentration in asthma. American journal of respiratory and critical care medicine 2000: 162(4 Pt 1): 1450-1454.

50. Robroeks CM, van Berkel JJ, Jobsis Q, van Schooten FJ, Dallinga JW, Wouters EF, Dompeling E. Exhaled volatile organic compounds predict exacerbations of childhood asthma in a 1-year prospective study. The European respiratory journal 2013: 42(1): 98-106.

51. Meyer N, Dallinga JW, Nuss S, Moonen E, van Berkel J, Akdis C, van Schooten F, Menz G. Defining adult asthma endotypes by clinical features and patterns of volatile organic compounds in exhaled air. Respiratory research 2014: 15(1): 136.

52. Fitzpatrick AM, Gaston BM, Erzurum SC, Teague WG, National Institutes of Health/National Heart L, Blood Institute Severe Asthma Research P. Features of severe asthma in school-age children: Atopy and increased exhaled nitric oxide. The Journal of allergy and clinical immunology 2006: 118(6): 1218-1225.

53. Robroeks CM, van Vliet D, Jobsis Q, Braekers R, Rijkers GT, Wodzig WK, Bast A, Zimmermann LJ, Dompeling E. Prediction of asthma exacerbations in children: results of a one-year prospective study. Clinical and experimental allergy : journal of the British Society for Allergy and Clinical Immunology 2012: 42(5): 792-798.

54. Robroeks CM, Rijkers GT, Jobsis Q, Hendriks HJ, Damoiseaux JG, Zimmermann LJ, van Schayck OP, Dompeling E. Increased cytokines, chemokines and soluble adhesion molecules in exhaled breath condensate of asthmatic children. Clinical and experimental allergy : journal of the British Society for Allergy and Clinical Immunology 2010: 40(1): 77-84.

55. Robroeks CM, Jobsis Q, Damoiseaux JG, Heijmans PH, Rosias PP, Hendriks HJ, Dompeling E. Cytokines in exhaled breath condensate of children with asthma and cystic fibrosis. Annals of allergy, asthma \& immunology : official publication of the American College of Allergy, Asthma, \& Immunology 2006: 96(2): 349-355.

56. Keustermans GC, Hoeks SB, Meerding JM, Prakken BJ, de Jager W. Cytokine assays: an assessment of the preparation and treatment of blood and tissue samples. Methods 2013: 61(1): 10-17.

57. Montuschi P, Paris D, Melck D, Lucidi V, Ciabattoni G, Raia V, Calabrese C, Bush A, Barnes PJ, 
Motta A. NMR spectroscopy metabolomic profiling of exhaled breath condensate in patients with stable and unstable cystic fibrosis. Thorax 2012: 67(3): 222-228.

58. Vijverberg SJ, Koster ES, Koenderman L, Arets HG, van der Ent CK, Postma DS, Koppelman $\mathrm{GH}$, Raaijmakers JA, Maitland-van der Zee AH. Exhaled NO is a poor marker of asthma control in children with a reported use of asthma medication: a pharmacy-based study. Pediatric allergy and immunology : official publication of the European Society of Pediatric Allergy and Immunology 2012: 23(6): 529-536.

59. Yavuz ST, Civelek E, Sahiner UM, Buyuktiryaki AB, Tuncer A, Karabulut E, Sekerel BE. Identifying uncontrolled asthma in children with the childhood asthma control test or exhaled nitric oxide measurement. Annals of allergy, asthma \& immunology : official publication of the American College of Allergy, Asthma, \& Immunology 2012: 109(1): 36-40.

60. Petsky HL, Cates CJ, Lasserson TJ, Li AM, Turner C, Kynaston JA, Chang AB. A systematic review and meta-analysis: tailoring asthma treatment on eosinophilic markers (exhaled nitric oxide or sputum eosinophils). Thorax 2012: 67(3): 199-208.

61. de Jongste JC, Carraro S, Hop WC, Group CS, Baraldi E. Daily telemonitoring of exhaled nitric oxide and symptoms in the treatment of childhood asthma. American journal of respiratory and critical care medicine 2009: 179(2): 93-97.

62. Pijnenburg MW, Bakker EM, Hop WC, de Jongste JC. Titrating steroids on exhaled nitric oxide in children with asthma: a randomized controlled trial. American journal of respiratory and critical care medicine 2005: 172(7): 831-836.

63. Fritsch M, Uxa S, Horak F, Jr., Putschoegl B, Dehlink E, Szepfalusi Z, Frischer T. Exhaled nitric oxide in the management of childhood asthma: a prospective 6-months study. Pediatric pulmonology 2006: 41(9): 855-862.

64. Szefler SJ, Mitchell H, Sorkness CA, Gergen PJ, O'Connor GT, Morgan WJ, Kattan M, Pongracic JA, Teach SJ, Bloomberg GR, Eggleston PA, Gruchalla RS, Kercsmar CM, Liu AH, Wildfire JJ, Curry $M D$, Busse WW. Management of asthma based on exhaled nitric oxide in addition to guidelinebased treatment for inner-city adolescents and young adults: a randomised controlled trial. Lancet 2008: 372(9643): 1065-1072.

65. Peirsman EJ, Carvelli TJ, Hage PY, Hanssens LS, Pattyn L, Raes MM, Sauer KA, Vermeulen $\mathrm{F}$, Desager KN. Exhaled nitric oxide in childhood allergic asthma management: a randomised controlled trial. Pediatric pulmonology 2014: 49(7): 624-631.

66. Petsky HL, Li AM, Au CT, Kynaston JA, Turner C, Chang AB. Management based on exhaled nitric oxide levels adjusted for atopy reduces asthma exacerbations in children: A dual centre randomized controlled trial. Pediatric pulmonology 2014: [Epub ahead of print].

67. Pike K, Selby A, Price S, Warner J, Connett G, Legg J, Lucas JS, Peters S, Buckley H, Magier K, Foote K, Drew K, Morris R, Lancaster N, Roberts G. Exhaled nitric oxide monitoring does not reduce exacerbation frequency or inhaled corticosteroid dose in paediatric asthma: a randomised controlled trial. The clinical respiratory journal 2012.

68. Borland C, Cox Y, Higenbottam T. Measurement of exhaled nitric oxide in man. Thorax 1993: 48(11): 1160-1162.

69. Amann A, de Lacy Costello B, Miekisch W, Schubert J, Buszewski B, Pleil J, Ratcliffe N, Risby T. The human volatilome: volatile organic compounds (VOCs) in exhaled breath, skin emanations, urine, feces and saliva. Journal of breath research 2014: 8(3): 034001.

70. Almstrand AC, Josefson M, Bredberg A, Lausmaa J, Sjovall P, Larsson P, Olin AC. TOF-SIMS analysis of exhaled particles from patients with asthma and healthy controls. The European respiratory journal 2012: 39(1): 59-66.

71. Almstrand AC, Ljungstrom E, Lausmaa J, Bake B, Sjovall P, Olin AC. Airway monitoring by collection and mass spectrometric analysis of exhaled particles. Analytical chemistry 2009: 81(2): 662-668. 



\section{Appendix A}

Summary

Samenvatting

Valorisation

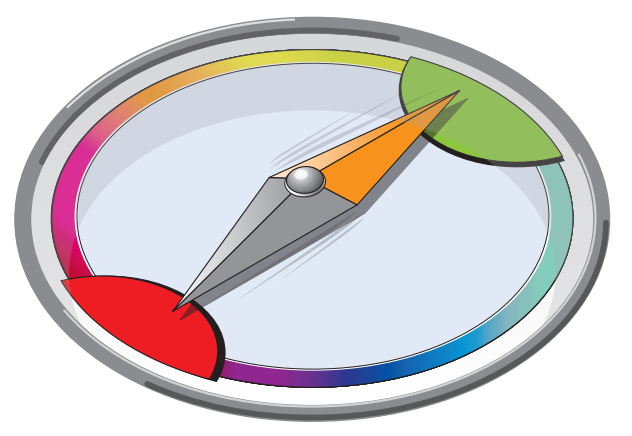




\section{Summary}

In this thesis the potential of different innovative asthma monitoring strategies in children is investigated.

In chapter 1, the objectives of this thesis are introduced. The pathogenesis and aetiology of asthma are shortly described. This is followed by a description of the current asthma monitoring strategy according to (inter)national asthma management guidelines, which comprises medication titration based on respiratory symptoms and lung function. Subsequently the rationale of the objectives of this thesis is given: that despite proper treatment and evidence based guidelines, asthma is not optimally controlled in many children worldwide. Thereafter, the hypotheses and the objectives of this thesis are described. Hypothetically asthma control may be achieved in more children, if monitoring of asthma would improve and treatment could be better titrated. The further description of the hypotheses for each monitoring strategy is included in the summary of the chapters below.

Chapter 2 focusses on home monitoring of asthma control. There are validated questionnaires (for example the Asthma Control Questionnaire (ACQ)) available to assess asthma control in a standardized way. Therefore asthma control can be compared within and between patients. However, a pitfall of these asthma control questionnaires is the risk for recall bias. Therefore, 2 strategies to assess asthma control were investigated, namely prospective home monitoring of symptoms combined with lung function (forced expiratory volume in 1 second $\left(\mathrm{FEV}_{1}\right)$, versus retrospective assessment by means of the $A C Q$ and $F E V_{1}$ during a clinical visit. These 2 strategies were compared and showed a low agreement between the 2 methods. Moreover, $37 \%$ of the children had lower asthma control according to the home monitor compared with the ACQ. In addition, lung function levels were significantly lower in these children compared to children with controlled or partly controlled asthma based on both methods. However only, $47 \%$ of the children were fully adherent to the use of the home monitor. This adherence must improve before the home monitor can be clinically introduced.

In chapter 3, the longitudinal association between asthma control, clinical characteristics and asthma-specific Quality of life (QoL) in children is investigated. Asthma control based on the $A C Q$, other clinical characteristics and asthma-specific QoL, all measured during regular visits every 2 months were compared. Linear mixed models were used to compare these data of the 1 year observational cohort study. Asthma control was significantly associated with asthmaspecific QoL over time. Decreased asthma-specific QoL was significantly associated with increased use of $\beta_{2}$-agonists, occurrence of wheezing episodes in the year before the study, occurrence of an asthma exacerbation in the 2 months prior to clinical visit, and a decline in lung function. Remarkably, there was considerable variation in QoL levels, especially in 
case of uncontrolled and partially controlled disease. Therefore, asthma control and asthmaspecific QoL outcomes are not mutually interchangeable.

Although asthma is an inflammatory disease, asthma management is not based on measures of the underlying airway inflammation, but on symptoms and lung function. If airway inflammation increases, loss of asthma control may follow or even an asthma exacerbation may occur. Markers of airway inflammation may be useful for doctors to assess loss of asthma control or to predict an asthma exacerbation. Therefore, in chapter 4,5 and 6 , the role of exhaled inflammatory markers in monitoring of childhood asthma is investigated.

In chapter 4 the association between asthma control and exhaled inflammation markers (volatile organic compounds (VOCs), fractional exhaled nitric oxide (FeNO) and biomarkers in exhaled breath condensate (EBC)) is described. In general, no association between these inflammation markers and asthma control was found. However, children with persistently controlled or uncontrolled asthma during clinical visits could be discriminated by a set of 15 exhaled VOCs. FeNO and cytokines or chemokines in EBC had no additional value on this subgroup classification.

In chapter 5 and 6 the ability of FeNO and biomarkers in EBC or exhaled VOCs to predict an asthma exacerbation is investigated. Chapter 5 showed that an asthma exacerbation could be predicted 14 days before the clinical manifestation of the exacerbation by a set of 7 exhaled VOCs with a sensitivity of $88 \%$. However, when the time between sampling and exacerbation increased to 21 days, the sensitivity for prediction of an asthma exacerbation decreased to $63 \%$. The identities of the selected VOCs were: 3 aldehydes, 1 hydrocarbon, 1 aromatic substance, and 1 ketone. Chapter 6 showed that FeNO, acidity of EBC or inflammatory markers in EBC (interleukin (IL) 1 $\alpha$, IL-5, IL-6, IL-8, IL-13, IL-17, TNF $\alpha$ ) were not able to predict asthma exacerbations in children. The area under the receiver operating characteristic-curve for prediction of asthma exacerbations by FeNO and inflammatory markers in EBC was only $59 \%$.

Finally, chapter 7 provides a general discussion, in which the main findings of chapter 2 to 6 were discussed and compared to the literature, followed by clinical implications and suggestions for future research. Results in this thesis showed that the investigated monitoring strategies have potential to improve asthma monitoring in children. Prospective electronic home monitoring of symptoms and $\mathrm{FEV}_{1}$ may lead to more accurate assessment of asthma control levels than retrospective assessment by means of an asthma control questionnaire. However, adherence to the home monitor needs to be optimized. Assessments of asthma-specific QoL provide a more complete picture of the health status of children with asthma. Finally, the results suggest that exhaled inflammatory markers reflect another aspect of asthma than asthma control at 
one specific time point; these markers are probably useful in the indication of persistently controlled/uncontrolled disease in children, in the prediction of exacerbations, and therefore help to improve the monitoring of asthma The studies that are presented in this thesis help to determine the direction of future research. 


\section{Samenvatting}

In dit proefschrift, getiteld 'Astma bij kinderen: onderzoek naar verbetering van monitoringsstrategieën' wordt de waarde van verschillende innovatieve strategieën om monitoring van astma bij kinderen te verbeteren onderzocht.

In hoofdstuk 1 worden de doelstellingen van dit proefschrift geïntroduceerd. De pathogenese en etiologie van astma worden kort beschreven. Dit wordt gevolgd door de beschrijving van de huidige astma monitoringstrategie conform de huidige (inter)nationale richtlijnen voor astma behandeling, namelijk het titreren van de medicamenteuze behandeling op basis van astmacontrole (luchtwegklachten, gebruik van luchtwegverwijdende medicatie en longfunctie). Vervolgens wordt de aanleiding voor het onderzoek beschreven, namelijk dat ondanks beschikbare effectieve medicamenten en wetenschappelijk onderbouwde richtlijnen voor astma behandeling, astma bij veel kinderen niet optimaal gecontroleerd is. Daarna worden de hypothesen en de doelstellingen van dit proefschrift beschreven. Hypothetisch kan een goede astmacontrole worden bewerkstelligd bij meer kinderen, indien het monitoren van astma verbetert en vervolgens de behandeling hierop aangepast wordt. Een verdere uitwerking van de hypothese per specifieke monitoringstrategie, wordt in de samenvatting van de hoofdstukken hieronder besproken.

In hoofdstuk 2 wordt het thuis meten van astmacontrole onderzocht. Astmacontrole kan op een gestandaardiseerde wijze worden gemeten met behulp van gevalideerde vragenlijsten (bijvoorbeeld de Asthma Control Questionnaire (ACQ)). Hierdoor kan de gemeten astmacontrole worden vergeleken binnen en tussen patiënten. Een valkuil van deze astmacontrole vragenlijsten, die de astmaklachten retrospectief uitvragen, is het risico voor de herinneringsbias. Daarom is in hoofdstuk 2 het dagelijks prospectief meten van astmacontrole thuis (symptomen en geforceerde expiratoire volume in 1 seconde $\left(F_{E V}\right)$ ) vergeleken met het retrospectief beoordelen van astmacontrole door middel van de ACQ en longfunctie tijdens een ziekenhuisbezoek. Er bleek een slechte overeenstemming te zijn tussen de 2 methoden. Bij 37\% van de kinderen werd een lagere astmacontrole gemeten met behulp van de thuismonitor ten opzichte van de $A C Q$. Bovendien waren longfunctie niveaus significant lager bij deze kinderen ten opzichte van kinderen met gecontroleerde of deels gecontroleerd astma met overeenstemming tussen beide methoden. Slechts $47 \%$ van de kinderen gebruikte de thuismonitor volledig trouw. Om dit instrument klinisch te kunnen toepassen dient de compliantie van het gebruik van de thuismonitor te worden verbeterd.

In hoofdstuk 3 wordt de longitudinale relatie tussen astmacontrole, astma-specifieke klinische kenmerken en astma-specifieke kwaliteit van leven bij kinderen onderzocht. Elke 2 maanden werden de volgende kenmerken gemeten en onderling vergeleken: astmacontrole op basis van 
de $A C Q$, klinische kenmerken en astma-specifieke kwaliteit van leven. Statistische modellen voor herhaalde metingen binnen 1 patiënt werden toegepast om deze gegevens in een 1 jaar observationele cohortstudie te analyseren. Astmacontrole was significant geassocieerd met astma-specifieke kwaliteit van leven. Verminderde astma-specifieke kwaliteit van leven was significant geassocieerd met een verhoogd gebruik van $\beta_{2}$-agonisten, aanwezigheid van piepende ademhaling in het jaar vóór het onderzoek, optreden van een astmaexacerbatie in de 2 maanden voorafgaand aan het ziekenhuisbezoek, en een verminderde longfunctie. Opmerkelijk was de variatie van kwaliteit van leven scores bij eenzelfde mate van astmacontrole, welke vooral bij ongecontroleerd en deels gecontroleerd astma zichtbaar was. Wij concludeerden dat astmacontrole en astma-specifieke kwaliteit van leven onderling niet uitwisselbaar zijn.

Hoewel astma een ontstekingsziekte van de luchtwegen is, wordt de behandeling van astma niet direct gebaseerd op metingen van deze onderliggende luchtwegontsteking, maar op symptomen en longfunctie. Als de luchtwegontsteking toeneemt kan verlies van astmacontrole volgen of kan zelfs een astma-exacerbatie optreden. Mogelijk kunnen artsen met behulp van markers van luchtwegontsteking het verlies van astmacontrole vaststellen of een astmaexacerbatie voorspellen. Daarom wordt in hoofdstuk 4, 5 en 6, de rol van de uitgeademde ontstekingsmarkers bij het monitoren van astma bij kinderen onderzocht.

In hoofdstuk 4 wordt de associatie tussen astmacontrole en uitgeademde ontstekingsmarkers (vluchtige organische stoffen, fractionele uitgeademde stikstofmonoxide (FeNO) en markers in condensaat van uitgeademde lucht ) beschreven. In het algemeen werd er geen associatie tussen deze ontstekingsmarkers en astmacontrole gevonden. Echter subgroepen van kinderen, namelijk kinderen met aanhoudend gecontroleerd of ongecontroleerd astma konden goed worden geclassificeerd met behulp van een set van 15 uitgeademde vluchtige stoffen. Hierbij hadden FeNO en cytokines of chemokines in condensaat van uitgeademde lucht geen toegevoegde waarde.

In hoofdstuk 5 en 6 wordt het vermogen van FeNO en biomarkers in condensaat van uitgeademde lucht of uitgeademde vluchtige stoffen om een astma-exacerbatie te voorspellen onderzocht. In hoofdstuk 5 wordt beschreven dat een astma-exacerbatie 14 dagen vóór klinische aanwezigheid kon worden voorspeld met behulp van een selectie van 7 uitgeademde vluchtige stoffen (sensitiviteit 88\%). Echter indien de tijd tot de volgende exacerbatie toenam tot 21 dagen daalde de sensitiviteit voor het voorspellen van een astma-exacerbatie naar $63 \%$. De geselecteerde uitgeademde vluchtige stoffen behoorden tot de volgende chemische groepen: 3 aldehyden, 1 koolwaterstof verbinding, 1 aromatische stof, en 1 keton. In hoofdstuk 6 wordt weergegeven dat FeNO, zuurgraad van het condensaat of ontstekingsmarkers in het condensaat van uitgeademde lucht (interleukine (IL) 1a, IL-5, IL-6, IL-8, IL-13, IL-17, TNFa) 
niet in staat waren om astma-exacerbaties bij kinderen te voorspellen. De oppervlakte onder de receiver operating characteristic-curve voor de voorspelling van astma-exacerbaties door deze markers was $59 \%$.

Tot slot, wordt in hoofdstuk 7 de overkoepelende discussie gevoerd, waarin de belangrijkste bevindingen van hoofdstuk 2 tot en met 6 worden besproken en vergeleken met de literatuur, gevolgd door klinische implicaties en suggesties voor toekomstig onderzoek. De resultaten in dit proefschrift laten zien dat de onderzochte monitoring strategieën een potentieel hebben om de monitoring van astma bij kinderen te verbeteren. Het prospectief elektronisch thuis monitoren van symptomen en $\mathrm{FEV}_{1}$ kan leiden tot een meer nauwkeurig vaststellen van astmacontrole niveaus ten opzichte van het retrospectief meten met behulp van gevalideerde astmacontrole vragenlijsten. Echter de compliantie van het gebruik van de thuis monitor moet worden geoptimaliseerd. Het bepalen van astma-specifieke kwaliteit van leven geeft een completer beeld van de gezondheidstoestand van een kind met astma dan het meten van astmacontrole alleen. Tenslotte laten de resultaten zien dat uitgeademde ontstekingsmarkers een ander aspect van astma weergeven dan de astmacontrole op één specifiek tijdspunt; deze markers zijn mogelijk in staat om het monitoren van astma bij kinderen te verbeteren. De gepresenteerde studies in dit proefschrift helpen de richting te bepalen voor verder wetenschappelijk onderzoek bij kinderen met astma. 


\section{Valorisation}

The valorisation of acquired knowledge of the different asthma monitoring strategies in children is presented in this chapter.

Society has advantage from the presented research on different levels.

First, some children and parents experienced benefit from the use of the home monitor. Although medication was not even titrated based on home monitor data, individual patients felt supported by the availability of a home monitor, because doctors and nurses were able to identify any increase in symptoms or decrease of lung function. Furthermore, home monitor data were useful to recognize noncompliance to short-acting bronchodilators (an item of the symptom score) in patients. In some children, home monitor data showed that despite the presence of respiratory symptoms, children did not use short-acting bronchodilators. Examples of reasons for not using the short-acting bronchodilators included feelings of shame when using short-acting bronchodilators or because the children did not have medication with them. Thus, in daily practice physicians can use the home monitor data as an aid during consultations to discuss noncompliance, symptom recognition, and asthma management. In addition, home monitoring of symptoms and lung function may lead to more accurate titration of maintenance medication and better asthma control, but the effectiveness of home monitoring e.g. FEV ${ }_{1}$ plus electronic symptom score, needs to be studied in randomized controlled trials.

Second, assessing asthma-specific quality of life (QoL) in children sheds light upon a broader aspect of the impact of asthma on the child, beside focussing on the physical symptoms only. Doctors try to optimize asthma control and therefore focus on respiratory symptoms and lung function. However, in addition to the presence of physical symptoms, patients may also experience a reduction in health related QoL. In the management of chronic diseases, such as asthma, doctors should also pay attention to asthma-specific QoL beside asthma control. The finding that asthma control and asthma-specific QoL are associated but not mutually interchangeable, serves as a reminder for doctors to be aware of asthma-specific QoL during consultation.

Third, future societal value of this thesis is that exhaled VOCs could be used in the monitoring of children with asthma (and perhaps other diseases), with the goal to improve asthma control and asthma-specific Qo, and to prevent exacerbations. However, the effectiveness of exhaled VOCs as a monitoring tool in asthma management should be confirmed in additional studies, including a cost-effectiveness study of this method.

Different companies may profit from the results presented in this thesis. Assessing inflammatory markers in exhaled breath alone or in combination with respiratory symptoms and lung function 
is innovative. Therefore, this may be an interesting opportunity for companies to invest in. Possible products to develop could be: a point-of-care device for exhaled VOC assessment during clinical visits, or even an instrument which is able to record symptoms and assess lung function plus exhaled VOCs on a regular basis at home. The collaboration between clinical, chemical and statistical researchers (knowledge about disease-specific VOCs) and companies (technical ability to produce small device and design) is required to develop such instruments.

Furthermore, in this thesis specific methods of collection of exhaled breath are used. Collection of exhaled breath and exhaled breath condensate (EBC) in children is a feasible process, which is also supported by previous studies. ${ }^{1-3}$ Study findings in this thesis concerning exhaled VOCs showed that an optimal sampling frequency would be at least every 2 weeks, in order to be able to predict asthma exacerbations in children.

Assessment of markers in EBC and of VOCs in exhaled breath are innovative methods to monitor asthma. Currently, asthma in children is managed based on asthma control. Asthma exacerbations are determined based on the severity of respiratory complaints and need for care. A valorisation of the findings in this thesis is that exhaled VOCs may help in the prediction of asthma exacerbations and the identification of children with persistently controlled and uncontrolled asthma. Therefore, assessments of exhaled VOCs probably are helpful for the monitoring of children with asthma, and may provide the opportunity to more accurate titrate asthma medication. The data is this thesis support the concept that airway inflammation is increased before respiratory symptoms are present and lung function deterioration occurs.

The results regarding the inflammatory monitoring strategies emphasize the need for new methods to analyse markers in EBC. Results showed that it is difficult to measure inflammatory markers in EBC with current analytical methods. Therefore, the next step is to test which markers can be detected in EBC by using different innovative analytic methods. Additionally, the hypothesis that the EBC matrix has negative effects on the stability of cytokines/ chemokines during storage of EBC could be tested.

Future research plans should include the testing of smaller instruments that can measure exhaled VOCs real-time in children. This can be performed in a pilot-study to evaluate the feasibility of the measurements. Afterwards, a cross-sectional study can be performed to investigate the predictive properties of a set of VOCs in a larger cohort of asthmatic children. If the results are promising, the instruments can be tested in an intervention study in a large sample of asthmatic children. 


\section{References}

1. Robroeks CM, Rijkers GT, Jobsis Q, Hendriks HJ, Damoiseaux JG, Zimmermann LJ, van Schayck OP, Dompeling E. Increased cytokines, chemokines and soluble adhesion molecules in exhaled breath condensate of asthmatic children. Clinical and experimental allergy : journal of the British Society for Allergy and Clinical Immunology 2010: 40(1): 77-84.

2. Rosias PP, Dompeling E, Dentener MA, Pennings HJ, Hendriks HJ, van lersel MP, Jobsis Q. Childhood asthma: exhaled markers of airway inflammation, asthma control score, and lung function tests. Pediatric pulmonology 2004: 38(2): 107-114.

3. Klaassen EM, van de Kant KD, Jobsis $Q$, van Schayck OC, Smolinska A, Dallinga JW, van Schooten FJ, den Hartog GJ, de Jongste JC, Rijkers GT, Dompeling E. Exhaled biomarkers and gene expression at preschool age improve asthma prediction at 6 years of age. American journal of respiratory and critical care medicine 2015: 191(2): 201-207. 



\section{Appendix B}

Curriculum Vitae

List of publications

Dankwoord

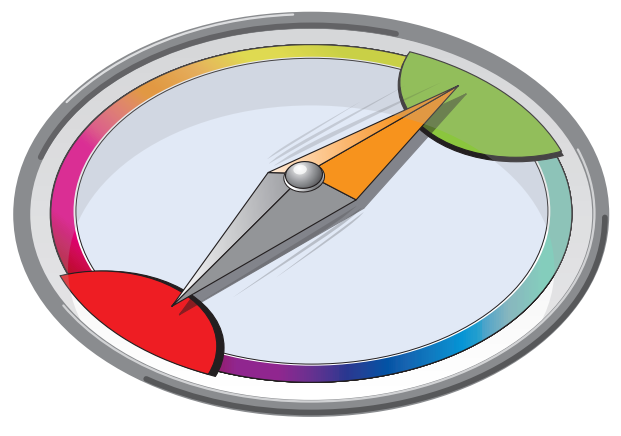




\section{Curriculum Vitae}

Dillys van Vliet was born in Paramaribo, Suriname on May $27^{\text {th }}$ 1982. After finishing her secondary school in 2000, she obtained her propaedeutics in Medische Beeldvormende en Radiotherapeutische Technieken at Fontys Hogeschool Eindhoven in 2001. That same year, she started with the bachelor Health Sciences at the Faculty of Health, Medicine and Life Sciences of the Maastricht University Medical Centre (MUMC+). Thereafter, in 2002 she started with the Master in Human Movement Sciences and in 2003 with the Medical School at the same faculty.

Dillys performed her final scientifical internship for both Masters at the Paediatric Department of the MUMC+ under supervision of dr. C. Robroeks-Bootsma, dr. Q. Jöbsis and prof. dr. E. Dompeling. In 2006 she finished her Master Human Movement Sciences and in 2009 she graduated for Medical School.

In 2009 and 2010 Dillys worked as a resident at the Paediatric Department of the Maxima Medical Centre in Veldhoven. Subsequently, in October 2010 she started her PhD research at the Paediatric Department of the MUMC+ and the School of Public Health and Primary Care (CAPHRI) under supervision of prof. dr. E. Dompeling, prof. dr. J. Muris and dr. Q. Jöbsis. This research has resulted in several WI1 publications. 


\section{List of publications}

van Vliet D, Alonso A, Rijkers GT, Heynens JW, Rosias PPR, Muris JWM, Jöbsis Q, Dompeling E. Prediction of asthma exacerbations in children by innovative exhaled inflammatory markers: results of a longitudinal study. PloS One 2015: 10(3): e0119434.

van Vliet D, van Horck MWP, van de Kant KDG, Vaassen SEM, Gulikers S, Winkens B, Rosias PPR, Heynens JW, Muris JWM, Essers BAB, Jöbsis Q, Dompeling E. Electronic monitoring of symptoms and lung function to assess asthma control in children. Ann Allergy Asthma Immunol 2014;113: 257-262 e251.

Robroeks CMHHT, van Vliet D, Jobsis Q, Braekers R, Rijkers GT, Wodzig WKWH, Bast A, Zimmermann LJI, Dompeling E. Prediction of asthma exacerbations in children: results of a one-year prospective study. Clin Exp Allergy 2012; 42: 792-798.

Robroeks CMHHT, van Vliet D, Jöbsis Q, Braekers R, Rijkers GT, Wodzig WKWH, Bast A, den Hartog GJM, Zimmermann LJI, Dompeling E. Prediction of asthma exacerbations in children: results of a one-year prospective study.Clin Exp Allergy 2011;41:299-301.

Robroeks CMHHT, van Vliet D, Dompeling E, Hendriks JJE, Jöbsis Q. Feasibility of exhaled nitric oxide measurements at various flow rates in children with asthma. Pediatric Allergy and Immunology 2010;21:222-28.

Robroeks CMHHT, van de Kant KDG, van Vliet D, Kester AD, Hendriks JJE, Damoiseaux JGMC, Wodzig WKWH, Rijkers GT, Dompeling E, Jöbsis Q. Comparison of the antiinflammatory effects of extra-fine hydrofluoroalkane-beclomethasone vs fluticasone dry powder inhaler on exhaled inflammatory markers in childhood asthma. Annals of Allergy, Asthma and Immunology 2008;100(6):601-7.

Robroeks CMHHT, Rosias PPR, van Vliet D, Jöbsis Q, Yntema JL, Brackel HJL, Damoiseaux JGMC, den Hartog GJM, Wodzig WKWH, Dompeling E. Biomarkers in exhaled breath condensate indicate presence and severity of cystic fibrosis in children. Pediatric Allergy and Immunology 2008;19(7):652-9. 


\section{Dankwoord}

Gedurende mijn promotie onderzoek hebben meerdere mensen direct of indirect een steentje bijgedragen aan het eindresultaat: mijn proefschrift en de ervaring die ik rijker ben geworden. Ik ben dankbaar voor de kracht die ik heb ontvangen om dit promotietraject succesvol af te ronden en voor de waardevolle mensen die ik op mijn pad ben tegengekomen. In dit hoofdstuk wil ik al deze mensen bedanken voor hun hulp, en enkele personen in het bijzonder benoemen.

Alle deelnemers van de RASTER-studie en hun ouders, bedankt voor jullie deelname aan de studie. Jullie inzet heeft dit onderzoek mogelijk gemaakt. Van grote waarde waren daarbij jullie openheid, interesse in het onderzoek en intentie om de behandeling van astma bij kinderen te verbeteren.

Veel dank gaat uit naar mijn promotieteam: prof. dr. E. Dompeling, dr. Q. Jöbsis en prof. dr. J. Muris. Beste Edward, Rijn en Jean, 'het is de tegenwind die de vlieger doet stijgen'. Jullie inhoudelijke en tekstuele commentaar op de stukken was essentieel voor de kwaliteit van dit proefschrift, ik heb er in veel opzichten van geleerd. De promotie overleggen waren soms pittig, gelukkig was er ook regelmatig ruimte voor humor. Bedankt dat jullie mij de kans hebben gegeven om te promoveren. Edward, als professor met een volle agenda had jij altijd een gaatje voor een korte vraag, dit heb ik als heel fijn ervaren. Jouw positieve blik op ons onderzoek werkte motiverend. Rijn, bedankt voor jouw openheid, kritische opmerkingen en je frisse invalshoeken. Jean, jij hebt een waardevolle ondersteuning geboden in een belangrijke fase van het onderzoek. Prettig was jouw trouwe feedback met oog voor detail.

Prof. dr. G. Wesseling, prof. dr. P. Bindels, dr. P. Merkus, prof. dr. L. Zimmermann en prof. dr. C. van Schayck, bedankt voor het beoordelen van dit proefschrift op zijn wetenschappelijke inhoud. Geertjan, bedankt voor jouw voorzitterschap in de beoordelingscommissie.

Philippe Rosias en Charlotte Robroeks-Bootsma, jullie promotietraject vormde de basis voor mijn promotie onderzoek. Philippe, ik heb veel geleerd van jouw feedback op mijn manuscripten. Charlotte, ik heb jouw ondersteunende woorden en interesse tijdens mijn promotie zeer gewaardeerd.

Philippe Rosias en Jan Heynens, bedankt voor het bieden van de gelegenheid om de RASTER-studie deels in Sittard uit te voeren. Jan, belangrijk was jouw feedback over de praktische uitvoering van het onderzoek.

Tiny Dauven, Irene van der Strerren-Breugelmans, Rianne Römers en Sylvia Esten, jullie 
inzet vormde een van de voorwaarden om goede zorg te bieden voor de deelnemers en om dit onderzoek op een consistente wijze uit te voeren. Ik vond het prettig om met jullie samen te werken. Tiny, bedankt voor jouw kritische feedback op het onderzoek. Sylvia, jouw positieve houding en vermogen tot doorpakken vormden voor mij een belangrijke ondersteuning.

Secretaresses op het secretariaat Kindergeneeskunde, bedankt voor jullie secretariële ondersteuning. Peggy van den Heuvel en Petra Delahaije, bedankt voor jullie hulp bij het plannen van overleggen met de drie drukke heren tegelijk. Tamara Cauberg, Erie van den Heuvel, Sonja Rütter en Carl de Bont, bedankt voor het beantwoorden van vragen met betrekking tot financiën. Medewerkers van de poli Kindergeneeskunde in Sittard en Maastricht en van de longfunctie afdeling in Maastricht, bedankt voor jullie interesse en praktische hulp waar nodig tijdens het onderzoek.

Meerdere WESP-studenten hebben meegeholpen met praktische zaken binnen het onderzoek. Myrthe Kersemaekers, Myrthe Berkhof, Sanne Vaassen, Sjoerd Gulikers en Elles Broen, bedankt voor jullie inzet. Sjoerd en Sanne, fijn dat jullie hebben geholpen met het cleanen van de astmamonitor data.

Brigitte Essers, bedankt voor je hulp tijdens de verschillende fases van het onderzoek en jouw inbreng als co-auteur. Ik heb je stimulerende en ondersteunende woorden zeer gewaardeerd.

Gerard van Breukelen, Bjorn Winkens en Ariel Alonso, als statistici waren jullie onmisbaar tijdens mijn promotietraject. Dank voor de inzet van jullie statistisch brein. Thank you for the mini-colleges concerning statistical analysis.

Medewerkers van CTCM: Marijke, Florence, Joek, Lilian, Arno, Tine, Maarten, Mathieu, bedankt voor het bouwen van het datamanagement systeem, de elektronische vragenlijsten, het planningssysteem voor de studie en het monitoren van de studie.

Jan Dallinga, Frederik-Jan van Schooten, Edwin Moonen en Agnieszka Smolinska, bedankt voor jullie expertise met betrekking tot het bepalen van de vluchtige stoffen in de uitgeademde lucht en jullie inbreng als co-auteurs. Agnieszka, thank you for performing the statistical analysis of the huge VOC-database.

Medewerkers van Maastricht Instruments/IDEE, in het bijzonder Peter Gerits, Marc Schoenmakers, Bart Beulen en Pascal Huysmans, bedankt voor jullie hulp bij de technische problemen van de ademcondensors.

Ger Rijkers, bedankt voor jouw advies met betrekking tot het analyseren van het ademcondensaat. Ben de Jong, bedankt voor het ontcijferen van alle codes op de cupjes en 
de analyse van de condensaat-monsters. Bob Meek, bedankt voor je waardevolle inbreng met betrekking tot de analyse van markers in ademcondensaat.

Tim Wolfs, Nico Kloosterboer en Lilian Kessels-van Wijlick, bedankt voor jullie interesse en hulp bij het testen van alternatieve methoden om markers in het ademcondensaat te meten. Tim, bedankt voor het meedenken over de analyse van ademcondensaat.

Het meten van de longfunctie in het ziekenhuis en thuis was mede mogelijk dankzij hulp van meerdere mensen: Stephan Vervuren, Chris van der Grinten, Alwin Brouwer, Mariëlle Pijnenburg, Manon Walterfang, Filip Knez, Skip Veugen, Maurice Ouwerling, Michael Taylor, Moritz Gmelin. Stephan, wat fijn dat ik je altijd kon bellen voor technische vragen. Manon, bedankt voor jouw vakkundige hulp.

Arjenne Louter, jij hebt mij meer inzicht gegeven in de systematiek achter het schrijfproces. Lesley Menzies, thank you for your efforts to correct my papers.

George Nietsch, wat was ik blij met jouw expertise en bereidwillige inzet bij de vormgeving van de logo's voor de RASTER en PREVEC-studie en die van de omslag van dit boekje.

Wil Botden, bedankt voor jouw effectieve manier van reflecteren en wijze adviezen. Hannerieke van der Boom, fijn dat jij zo laagdrempelig bereikbaar bent voor promovendi, bedankt voor je advies.

Lieve collega's Kim, Ester, Sasha, Inge, Bob, Maartje, Marlou, Marieke, Jesse, Britt, Elke, Ana, Yvon, Michelle, Sanne en Michiel, wat is het fijn om jullie als geïnteresseerde en warme collega's om me heen te hebben. Wat heb ik genoten van de humor die we samen deelden op het werk. Kim, ik ben je nog altijd dankbaar dat je mij attent maakte op de stageplek bij de Kinderlongziekten. Bedankt voor je eerlijke adviezen, feedback op stukken, je ondersteunende woorden en voor onze vriendschap. Ester, prettig waren je bemoedigende woorden en wijze raad. Sasha, bedankt voor je openheid en jouw mooie Engelse zinnen. Ana, muito obrigada por conceber o titulo da minha tese, acertaste em cheio! Marieke, dank voor het waarnemen van de RASTER-studie tijdens mijn zwangerschapsverlof. Wij hebben met en van elkaar mogen leren tijdens de turbulente fase van het onderzoek. Fijn dat jij nu aan je eigen boekje mag werken, ik wens je veel succes. Elke, bedankt voor je interesse, zorgzaamheid en enthousiasme. Arno, ik heb je wijze raad en warme complimenten gewaardeerd.

Maartje, lieve ex-roomie, bij jou denk ik aan samen met de koptelefoon op werken, burpees doen als het hoofd niet meer helder was, samen koffie drinken, squashen en Barcelona ontdekken. Fijn dat ik je mocht bijstaan als paranimf tijdens jouw promotie en dat jij dat nu bij mij doet. 
Lieve vrienden, ik heb jullie leren kennen tijdens onze studie in Maastricht, bij Navigators, bij de Kindergeneeskunde in het MMC of gewoon in de trein. Deze ontmoetingen met jullie en een aantal van jullie partners zijn uitgegroeid tot waardevolle vriendschappen. Bedankt voor jullie interesse in mijn onderzoek-avonturen, de ontspannende dates en jullie relativerende woorden. Ik waardeer onze warme vriendschap en jullie vertrouwen in mij.

Tante Mien, Robbert, Sindy, Audry, Charle, Verdy, Eline plus partners en kinderen, fijn om jullie als lieve familie te hebben zowel in Nederland als in Suriname.

Mijn schoonouders Jannie en John, ik vind jullie lief en waardeer jullie warmte, interesse, nuchterheid en ondersteuning. Bedankt ook voor jullie zorg voor Irene en Valerie waar nodig. Rob, Miranda en de rest van mijn schoonfamilie, dank voor jullie interesse en ontspannende momenten.

Papa, mama, Vivian en Andrew, wat ben ik blij dat ik onderdeel vorm van ons gezin. Papa en mama, de voorwaarde om mezelf te ontwikkelen en een gelukkig leven op te bouwen, hebben jullie geschapen. Ik ben gezegend met jullie onvoorwaardelijke liefde en dit warme nest. Papa, bedankt voor jouw wijze raad bij het nemen van de drempels tijdens dit promotietraject. Mama, bedankt voor je luisterend oor, je interesse en je aanmoediging. Vivian, lieve grote zus, maatje, coach, en nu ook paranimf, ik ben blij met je openheid, warmte, ondersteuning en je liefde. Andrew, lief broertje, ik bewonder jouw ontspannen manier van omgaan met het leven; het is prettig om jou als positief mens dichtbij ons te hebben. Marcel, oprechte en zorgzame schoonbroer, wat fijn dat je bij ons hoort en samen met Viv, Julia en Lennard een warm gezin vormt.

Peter, Irene en Valerie, elke avond tel ik jullie als één van mijn grote zegeningen. Jullie aanwezigheid is van onbeschrijfbare waarde voor mij. Peet, wat is het fijn om jou als lieve, oprechte, krachtige en nuchtere man naast mij te hebben. Bedankt voor je liefde, geduld, humor, luisterend oor, stimulerende woorden, de slimme Excel-formules, wijze raad en je geloof in mij. Dankbaar ben ik dat wij samen Irene en Valerie mogen helpen opgroeien. Irene en Valerie, jullie wonen in mama's hart voor altijd. Ik vind jullie prachtige mensen. Jullie laten mij zien hoe makkelijk het kan zijn om te leven in het hier en nu. 